\title{
Grassroots radio and the episteme of development: \\ The NGO-ization of community radio in Nepal
}

\author{
by \\ Heather Gilberds, B.A.
}

A thesis submitted to the Faculty of Graduate Studies and Research

In partial fulfillment of the requirements for the degree of

Master of Arts

School of Journalism and Communication
Carleton University
Ottawa, Ontario
June, 2009

(C) 2009. Heather Gilberds 


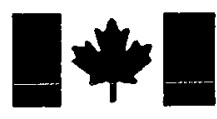

\author{
Library and Archives \\ Canada \\ Published Heritage \\ Branch \\ 395 Wellington Street \\ Ottawa ON K1A ON4 \\ Canada
}

Bibliothèque et

Archives Canada

Direction du

Patrimoine de l'édition

395 , rue Wellington

Ottawa ON K1A ON4

Canada
Your file Votre reférence
ISBN: 978-0-494-60303-1
Our file Notre reference
ISBN: $978-0-494-60303-1$
NOTICE:

The author has granted a nonexclusive license allowing Library and Archives Canada to reproduce, publish, archive, preserve, conserve, communicate to the public by telecommunication or on the Internet, loan, distribute and sell theses worldwide, for commercial or noncommercial purposes, in microform, paper, electronic and/or any other formats.

The author retains copyright ownership and moral rights in this thesis. Neither the thesis nor substantial extracts from it may be printed or otherwise reproduced without the author's permission.
AVIS:

L'auteur a accordé une licence non exclusive permettant à la Bibliothèque et Archives Canada de reproduire, publier, archiver, sauvegarder, conserver, transmettre au public par télécommunication ou par l'Internet, prêter, distribuer et vendre des thèses partout dans le monde, à des fins commerciales ou autres, sur support microforme, papier, électronique et/ou autres formats.

L'auteur conserve la propriété du droit d'auteur et des droits moraux qui protège cette thèse. $\mathrm{Ni}$ la thèse ni des extraits substantiels de celle-ci ne doivent être imprimés ou autrement reproduits sans son autorisation.
In compliance with the Canadian Privacy Act some supporting forms may have been removed from this thesis.

While these forms may be included in the document page count, their removal does not represent any loss of content from the thesis.
Conformément à la loi canadienne sur la protection de la vie privée, quelques formulaires secondaires ont été enlevés de cette thèse.

Bien que ces formulaires aient inclus dans la pagination, il n'y aura aucun contenu manquant. 


\begin{abstract}
Nepal's community radio sector has flourished since it liberalized the airwaves for the first time in 1997. Drawing on an established tradition in other areas of the developing world, Nepal embraced community radio for its potential to overcome propagandistic and exclusive national media systems, to bring news and information to remote areas, and to educate people about human rights, equality, health, family planning and sustainable agricultural practices. This thesis has two major objectives: first, to explore how marginalized social groups use radio as a tool of empowerment. It focuses upon the case of Radio Jagaran, a community-based radio station in Butwal, Nepal that uses participatory media to advocate for social justice on behalf of those who are otherwise excluded and discriminated against. Second, it problematizes the ways in which the funding requirements established by the international NGO donor community appear to be re-focusing the programming agendas of grassroots media organizations such as Radio Jagaran. It attempts to highlight the potential implications of donor-led community media projects by drawing attention to the ways 'truths' and 'realities' of poverty, human rights violations and related issues are constructed by CR stations through negotiating what they perceive to be INGO priorities and objectives.
\end{abstract}




\section{Acknowledgements}

I would first like to acknowledge the people with whom I shared my experiences in Nepal. I am enduringly grateful to the staff and management of Radio Jagaran and Jagaran Media Center. Although I was only with them for a short time, they welcomed me as a member of their family. Special thanks to Radio Jagaran's Shivaji Gayak for being a sensitive and accommodating station manager and Deepa Bardewa for helping with translation, for taking me to new areas of Nepal, and for being a wonderful friend. I also extend thanks to JMC's Uma Paudel and Prakash Mohara for their hard work and dedication to this project. I am grateful to the Advocacy Project for giving me the opportunity to go to Nepal and work with Radio Jagaran, with particular thanks to the Nepal coordinator, Nicole Farkouh, for her tireless efforts to support me while I was there and for chasing down documents for me once I returned home. Special thanks to one of the other AP interns, Libby Abbott, for the support and friendship she gave to me in Nepal and the amazing times we shared together there. Also, sincere appreciation goes to Mario Bruzzone for the endless and always stimulating conversations about Nepal and development, Foucault and governmentality.

At Carleton, I am deeply indebted to my thesis supervisor, Professor Joshua Greenberg, for encouraging me to go to Nepal, for helping to formulate a thesis out of a whirlwind of an experience, for challenging me to extend my thoughts in new directions and to recognize and overcome self-imposed boundaries, and for catalyzing a desire to continue along an academic path. You are much more a mentor than a supervisor and your dedication and sincerity continuously exceeds my expectations. I would also like to thank my other committee members, Professor Allan Thompson for providing a practitioners' point-of-view and for helping me to recognize that theory needs to be grounded in lived experience, and Associate Dean Ted Jackson for his provocative questions about this project and his insights about development during my defense.

I am grateful for the company of my colleagues at Carleton, especially the Resource Centre crowd, for sharing lunches and stimulating conversations while we wiled away those long days. A big shout-out goes to Lauren Cheal for her friendship, encouragement and Microsoft Office wizardry. Your voice resonates in every page of this project.

Last, but certainly not least, I would like to thank my family for the emotional and financial support they graciously and ceaselessly offer to support my academic ambitions. I am indebted to my parents Gail and Jim in ways I will never be able to repay, so I dedicate this project and all future academic successes to you. 


\section{Table of Contents}

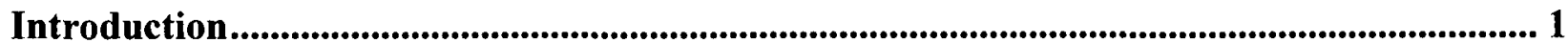

Chapter I - Community, Democracy and Rhizomes:

Perspectives on Community Radio Research.......................................................................14

Chapter II - The Episteme of Development:

Community Radio as Governmentality

Chapter III - Realism or Idealism?

Community Engaged Research and Grassroots Radio

Chapter IV - Grassroots Media as Development Encounter:

A Case Study of Dalit Community Radio in Nepal.

Conclusion

References.

List of Appendices

Appendix 1 -Map of FM Radio in Nepal............................................................ 130

Appendix 2.1 - Radio Jagaran Strategic Plan........................................................... 131

Appendix 2.2 - Radio Jagaran Progress Report ............................................................. 139

Appendix 3 - Typology of Community Radio in Nepal....................................................... 146 


\section{Introduction}

In Nepal, one of the world's poorest and least-developed nations, participatory community radio projects have flourished, growing from only 1 station in 1996 to 165 stations in 2008. Described by UNESCO (2002) as "one of the country's bright lights" community radio in Nepal is lauded for its ability to empower disadvantaged groups and enhance development goals by giving "a voice to those whose voices are silenced" (AMARC, 2007). Programs dealing with poverty, injustice, human rights abuses, inequity and ethno-cultural discrimination are intended to provide hope and optimism for the possibility of enhancing democratization. Given my extensive and ongoing involvement in citizens' media and community radio and my interest in the area of media development, the nascent community radio sector in Nepal provides a rich arena to explore issues relating to the use of participatory media as a tool for development in impoverished and transitional regions.

This thesis initially set out to explore how marginalized social groups use radio as a tool of empowerment. During the 14 weeks spent in the field, I worked closely with Jagaran Media Centre (JMC), a grassroots media organization in Kathmandu, and Radio Jagaran, JMC's community-based radio station located in Butwal, Nepal. Radio Jagaran was established in 2007 and its activities are focused upon JMC's mandate to use participatory media to draw attention to practices of social and political exclusion and discrimination and to advocate for change. Yet, during the course of my research in Nepal, new questions inevitably arose. Development programs to improve the state of human rights in Nepal are largely funded by international nongovernmental organizations (INGOs) and international development agencies (IDAs) such as ActionAid, United Nations Development Program (UNDP), United Nations Educational, Scientific and Cultural Organization (UNESCO), Danish International Development Agency 
(DANIDA), Swiss Development Corporation (SDC), The Finnish Embassy and Cordaid, among others. In conducting the research, I became intrigued by the ways in which the funding requirements established by the international donor community appear to be re-focusing the programming agendas of grassroots media organizations. A fundamental set of questions thus emerged: have the funding models developed by the INGO sector, which underwrites much of this media programming, shifted the episteme (Foucault, 1970) of media development initiatives in Nepal? To what extent, if at all, are grassroots media practices influenced by broader funding contexts? Is there a close or loose 'fit' between the donor community's definitions of successful community radio programming and the definitions of community activists? To what extent do community radio activists and practitioners in Nepal accept indicators of impact that are defined by donor agencies and inscribed in funding models? Are these indicators adopted uncritically, are they negotiated, are they resisted, and/or have other methods for evaluating impact also been developed?

These are important questions to ask given that community radio in Nepal is explicitly a development intervention. As such, the aims of radio projects often rely upon the international (and arguably western) indices of development and underdevelopment that justify interventions in economically impoverished and transitional regions of the global south. Currently, international aid money makes out a high percentage of the country's GNP, and the country's foreign relations are largely linked to development (Alsvik, 2002). Consequently donors still mainly drive the economic agenda of the country, as manifested by the involvement of international as well as national NGOs involved in various development initiatives (Dixit, 1997). In order to contextualize Nepal's community radio sector in terms of its place within the national project of development, it is necessary to highlight the historical emergence of international aid 
presence in Nepal and the place it has come to occupy in relation to traditional state governance structures.

\section{The Historical Context of Development Aid in Nepal}

Since the fall of the Ranas in 1951, when Nepal was opened to foreigners for the first time in over 50 years, its relations to foreign countries have been based primarily upon a multitude of projects related to development (Alsvik, 2002). Nepal not only remained an independent state on the fringe of the British Empire throughout the colonial era in South Asia, but also attempted to barricade itself from direct British influence. The country was ruled from 1846 to 1951 by a succession of prime ministers of the elite Rana family (Pigg, 1992). The 195051 revolution overthrowing the Ranas owed much to India's successful campaign for independence, and the political forces bringing about the change of power in Nepal were energized not only by visions of democracy but also by a desire to modernize and to develop a society that for so long had been systematically impoverished under the Rana oligarchy (ibid.) After 1951 the government's attitude towards international intervention changed fast; where the Ranas had severely restricted foreign presence in Nepal, the new government invited international aid; where the Ranas had discouraged the construction of schools and hospitals, the new regime encouraged these projects. According to Dixit (1997), "by the end of the first Five Year Plan (1956-61) Nepal had metamorphosed from "forbidden kingdom" to "developing country"' (p.173).

Reversing the isolationist policies of the Ranas, the new government enlisted the help of western, industrialized countries which, in the post-war era, had begun to erect an international apparatus of foreign aid (Alsvik, 2002). In the case of Nepal, Pigg (1992) argues that 
"development - rather than the residues and scars of imperialism - is the overt link between it and the West" (p.497). This history has to be seen in connection with trends in the international society after World War II when the focus on strategies for development started to take form (Alsvik, 2002). Escobar (1995) calls this the "invention of development" where particular institutions were created to produce ideas on development and forms of development intervention. In a similar vein, Singh (1999) suggests, "it would be appropriate to refer to 'aid' as 'involvement' of the more developed countries in the economic, political, military and social sectors of developing countries, either directly or through international agencies" (p.310).

Since the 1950s, the amount of foreign aid in Nepal has more than tripled in each decade, and aid has increasingly penetrated a wide range of economic and social sectors of the country (Misra \& Sharma 1983). Foreign aid has become an integral part of national economic and political life. The main focus of the various development plans has changed through the years, depending on the agenda of the international aid society and succeeding governments in Nepal. The following quote from Dixit exemplifies the role the international community has played, and continues to play, in driving development in Nepal:

Over the decades, one development slogan pursued another, and Nepalis experienced it all as passive participants. The fads were all prepared elsewhere and were handed one every five years or so- from industrialization to sustainable development, integrated hill development to structural adjustment, import-substituted to export-led, basic needs to growth-oriented, trickle down to people first, privatization to poverty alleviation (the slogan currently doing the rounds). When the United Nations and the bilateral aid agencies discovered 'ngos" (non-governmental organizations) as the carriers of donor dollars in the late 1980s, Nepalis immediately conjured them out of the thin air to access the money which began flowing from that particular tap" (Dixit 1997, p. 174).

The Nepali government's strategies for development are in accordance with the dominating tendencies in the international aid community and are concentrated around issues 
such as community development, decentralization and good governance (Alsvik, 2002). Mishra and Sharma (1983) describe foreign aid as "a trickle turning into a torrent" (as cited in Alsvik, 2002). They suggest that in Nepal the vast amounts of foreign aid have succeeded only in supporting the upper classes and reinforcing the traditional power structure. With regard to the ideological implications of development interventions, they argue that, "[a] belief in the possibility and desirability of rather rapidly induced social change, an overwhelming faith in the western cultural-technological complex and a growing sense of national frailty may be identified as the major foreign-aid crystallized ideological dimensions"(ibid.).

\section{Community Radio and Development in Nepal}

As will be discussed in Chapter I, community radio entered mainstream development discourse in the late 1970 s, primarily under the directive of UNESCO. It emerged in relation to the "radio libres" and alternative radio movements that swept North America and Europe in the 1960 s, linking community radio to the will to redistribute power and to claim for groups that were socially or politically marginalized or oppressed (Lewis \& Booth, 1994). The ideology of opposition embedded in community or alternative radio activities in North America, Europe and Australia was well-suited to the post-colonial context within which the concept of "development" took on its contemporary manifestation: "on a global level, the less well-off countries of the world are in the same position vis-à-vis rich countries as are the marginalized and oppressed communities within Western societies to the dominant sections of society" (ibid, p.163). Community radio in South Asia developed much later than in regions of Latin America and Africa where, in various articulations (Farm Radio, Bush Radio, Tin-Miners Radio, indigenous radio, and so on) it has acted as a tool for education, development, resistance and 
empowerment since the early 1970s (Lewis \& Booth, 1994, Girard, 1992, Huesca, 1995, Downing, 2001, Rodriguez, 2001, O’Connor, 2006).

Radio has been an important medium of communication in Nepal for more than a century. However, it was traditionally controlled by the ruling and urban elites, and primarily served as a propaganda arm of the state. Radio broadcasting first saw the initiative of liberalization in Nepal's 1990 constitution. During this period, issues like right to information and freedom of expression were mentioned for the first time (Pringle \& Shuba, 2007), however, the same leaders who helped to liberalize the airwaves quickly tried to ban news programs broadcast by FM stations (Banjade, 2007). In their history of community broadcasting in Nepal, Pringle and Shuba (2007) outline how the National Media Policy of 1992 and the National Broadcasting Act of 1993 paved the way for the development of independent radio. Inspired by this period of relative freedom of the airwaves, the Nepal Forum of Environmental Journalists (NEFEJ) applied for a broadcast permit in October 1992. However, promises of liberalization proved to be little more than lofty declarations as NEFEJ and its partners struggled with successive governments over permission to broadcast. It wasn't until March 1996 that the station that would become Radio Sagarmatha aired its first test signals on FM $102.4 \mathrm{MHz}$ without a license (ibid.). When NEFEJ finally received a broadcasting license in May 1997, Radio Sagarmatha became the first fully independent radio station in the country and Nepal became the first country in South Asia to grant a license for independent radio broadcasting (Banjade, 2007).

Radio Sagarmatha marked an important movement in media democratization in Nepal: "Radio Sagarmatha broke new ground, gradually shedding the restrictions that initially accompanied its license, and the movement for 'community radio' gained momentum outside the valley. In the process, Radio Sagarmatha set the standard for independent, public-interest radio in 
the country" (Pringle \& Shuba, 2007, p.12). More FM licenses were granted and in 2002 the Association of Community Radio Broadcasters (ACORAB) was established as a representative body for community radio in Nepal (ibid.). By 2005 there were 50 FM stations on the air with more than one third that were non-profit and non-commercial (the basic criteria to be considered "community radio" stations). After the success of the People's Movement of 2006 FM licenses were issued en masse, and in August 2007, ACORAB listed its membership at 90 radio stations (ibid.). ${ }^{1}$ There are more than 100 community-based radio stations operating in Nepal today. Initially, community-based broadcasting in Nepal was premised upon ideals similar to those embedded in alternative or oppositional media movements in North America and Europe (Downing, 2001, Lewis \& Booth, 1994) in that it was primarily viewed as a force to counter the partisan journalism representative of a tightly controlled state broadcasting system (Pringle \& Shuba, 2007, Banjade, 2007). Early developments in independent FM radio in Nepal relied on a conception of community media in terms of its oppositional relationship to mainstream media structures and a station's value was assessed in terms of its ability to contest, supplement and resist mainstream media (Carpentier et al., 2007). In Nepal, community-based stations were initially clustered in urban centers such as Kathmandu, where they served to enhance democratic processes by acting as watchdogs of state-sponsored media institutions that were historically criticized for propagandistic reporting and censorship (Mainali, personal communication, July $\left.18^{\text {th }}, 2008\right)$. It wasn't until later in the history of community radio in Nepal that it became linked to issues such as human rights, empowerment, participation and community-capacity building that form the core tenets of development discourse. The features of participatory radio that promote it as a tool to facilitate development goals are increasingly gaining currency as media

\footnotetext{
${ }^{1}$ See appendix 1 for a detailed map of FM stations operating in Nepal
} 
development projects move away from urban centers and into villages where more than $80 \%$ of Nepalis live (AMARC, 2004-2005, p.5), where access to communication resources is extremely limited, and where discrimination, illiteracy and poverty are endemic to social life.

Within the realm of communication studies that focuses on independent, grassroots media activities, community radio is celebrated as a tool that can contest the homogenizing forces of globalization (Jankowski \& Prehn, 2002), resist dominant forms of representation (Rodriguez, 1995, Downing, 2001), counter big corporate media institutions (Huesca, 1995, Howley, 2005), enhance participatory civic engagement, give a voice to those rendered voiceless (AMARC, 2007, UNESCO, 2002, Banjade, 2007) and empower the marginalized, underrepresented, and oppressed (Aw, 1992, Horchheimer, 1999, Girard, 1992, Jallov, 2002). Although these may seem like grand claims, there is a virtual consensus that there is something good, important, and necessary about community media. These assumptions about the value of local, participatory media are at the heart of the activities of the Jagaran Media Center (JMC). This project specifically focuses on JMC's community radio initiative, Radio Jagaran, and attempts to articulate the ways that assumptions underlying the conception of community media's ability to catalyze social change, as well as the definitions of human rights and equality inscribed by international development organizations, form the basis for research on community radio and underpin the implementation and evaluation of community radio initiatives.

\section{Thesis Overview}

In the first chapter, I provide a review of the literature that deals with participatory media in an attempt to examine how community radio is defined and the implications of these definitions in practice. In reviewing the literature on community media generally and community 
radio as a tool of development more specifically, I tease out the conceptual difficulties and strengths of particular models by highlighting the theoretical underpinnings that form the basis for inquiry and interpretation of community radio projects.

Definitions of what actually counts as "community media" are diverse - at times contradictory, and often hotly contested. Assumptions inherent in each definition of community media have implications for research; they underpin the theoretical perspectives that shape and frame research questions, the methodological tools employed in undertaking research projects, as well as the evaluation of perceived successes or failures. In wider discussions on poverty reduction and international development, there is a focus on the need for governance that is more accountable and "strategies that are people-centered, community-driven and empowermentoriented" (Voices for change, 2005). It is within this context that the potential for community radio entered mainstream development initiatives. UNESCO's Community Radio Handbook (2001) explicates the features of participatory radio that enable it to be a valuable resource for achieving development goals in terms of its relevance to local problems and concerns and its ability to help communities develop socially, culturally and economically. Similarly, Kate Coyer (2007) makes the case that radio is unique - it holds the potential to facilitate the democratization of communication because it is "cheap, is easy to learn, is a predominantly live medium requiring minimal production facilities compared with television, is an aural medium that alleviates issues of literacy, and has a seemingly timeless quality of immediacy and intimacy that resonates with audiences" (p.2).

This chapter discusses the mandates of community radio in relation to global media operations and centralized, urban-based national media, which are remote from the realities of rural people and often entrench existing hierarchies and systems of power. It demonstrates that 
the literature on community radio makes a compelling case for radio as a useful tool for development in comparison with other media on a practical level (i.e. in terms of issues related to literacy, affordability, accessibility, electrification). However, on a theoretical level, there is a tension between the overly deterministic perspective of some medium theorists (especially those that emphasize the innate 'transformative' nature of media) and other scholars who claim that media can only be as democratic as the structures from which they spring (e.g. Horchheimer, 1999).

In chapter two, I draw on theories of "governmentality" (Foucault 1970; Gordon \& Foucault, 1980; Burchell, Miller, Gordon \& Foucault, 1991; Rose, 1999; Rose, O’Malley and Valverde, 2006) in an attempt to confront epistemological issues relating to the influence of donor-led participatory media initiatives on Nepal's independent media community. Specifically, I will examine the community radio sector in Nepal both in terms of the extent to which INGO and IDA expectations with regards to funding are influencing decisions relating to media programming and the frameworks that are adopted to evaluate impact. I argue that the combination of funding programs and evaluation metrics have a profound impact on how community radio organizations visualize their own operations and the issues they report.

Studies that theorize grassroots media conceptualize participatory media as both a response to and an attempt to change existing conditions (Atton, 2002; Downing, 2001; Howley, 1999, 2001; Jankowski \& Prehn, 2002; Rodriguez, 2001). However, I argue that what is missing in a great deal of this formative literature is a consideration of broader contexts of practice. Drawing theoretical insight from Foucault's work on epistemes, the project explores the ways in which the power-knowledge dynamics inherent to practices of international development organizations are transforming the social development agendas of grassroots media 
organizations. These theoretical shifts offer a language for discussing issues related to the development of communications structures in relation to the discourses of democracy and human rights inscribed by international development organizations. I explore whether such discursive structures, perpetuated by the emergence of a global civil society, have refigured the contours of the mediascape in Nepal through the proliferation of grassroots media organizations committed to upholding internationally mandated principles of democracy, rights and equality. A research formulation oriented according to a theory of governmentality in the field of development communications attempts to confront issues relating to the influence of donor-led participatory media initiatives and to highlight the epistemological tensions that are always present in these programs (e.g. Hearn \& Foth, 2005).

In chapter three I present the methodological approach that informed the different elements of the thesis, and make a case for community engaged scholarship. The critiques of traditional ethnographic methods that underpin the move towards participatory research models are particularly relevant to studies of grassroots social movements. By inviting input from research participants into the generation of the research questions, the design of data collection methods and the analysis of results, community engaged research projects stem from a critique of traditional research methods that are potentially exploitative and damaging to the community where the research takes place. Moreover, in terms of the theoretical analytic of governmentality, the issues, concerns and overarching problematic articulated by journalists and decision makers within JMC and Radio Jagaran form a discourse that reflects the "ideologically charged and discursively bound rhetorical acts constitutive of a hegemonic struggle for representation and meaning" (DeChaine, 2005, p15).

The nature of grassroots media and community-based social movements articulate a need 
for research designs that take into account the patterns of social relations and the relationships between messages, senders and receivers. In using voice as a metaphor for the field (Putnam, 2001), community engaged research designs open up the possibility for an exploration of oppositional discourse, i.e., "the practice of valuing and embracing differences simultaneously, without casting them as rigid polarities (which) seek to uncover contrasting positions and to inspect the integrity of knowledge claims" (Putnam, 2001, p.43). In this way, an engaged research model was useful to employ for the field component of this project given my focus on the epistemological implications of community radio initiatives and the underlying powerknowledge relationship that emerges in community media development programs. The chapter also addresses the criticisms that emerge from a normative stance on communications scholarship (i.e. participatory research lacks objectivity and does not serve to advance theory). In highlighting the criticisms and tensions that surround engaged scholarship, chapter three will locate this research project within these contestations and examine the ways they speak to difficulties encountered during the course of fieldwork.

The presentation of the case study is the focus of chapter four. The interviews, informal observations, and daily interactions with journalists, radio activists, station managers and representatives from independent media advocacy groups emerged out of a mutual commitment to collaboration and knowledge co-generations. In addition to analyzing these interviews and observations, I also explore the hermeneutics of donor-led community media projects by examining the development mandates propounded by funding agencies and advocacy organizations in Nepal's community radio sector. Through a detailed analysis of data collected in the field, the case study presents findings that problematize static conceptions of power often relied on in development criticism while demonstrating how grassroots radio development 
projects nonetheless act as governmental techniques of normalization and consensus.

The final concluding chapter is reflexive in tone and intent and serves to tell the narrative of this thesis by providing a summary of its genesis, evolution and outcome. Reflexivity is an important part of this project, especially given its focus on voice. The final chapter attempts to locate the voice of the researcher in the research project and, in doing so, "bring the teller of the tale back into the narrative, embodied, desiring, invested in a variety of often contradictory privileges and struggles" (Nairn et al., 2005, p.222). Rather than try to gloss over contradictions and tensions, such moments of reflexivity embrace the messiness and uneasiness that is often at the heart of graduate student research. 


\section{Chapter I - Community, Democracy and Rhizomes - Perspectives on Community Radio Research}

\section{Defining Community Media}

Participatory media is an analytical term with a lot of close cousins: "community media" (Howley, 1999; Lewis, 1994, Dagron, 2007), "alternative media" (Atton, 2002), "citizens' media" (Rodriguez, 2002), "radical media" (Downing, 2001, Carroll and Hackett, 2006), and “community communication" (Berrigan, 1979, Jankowski \& Prehn, 2002). Many of the foundational texts written about community media identify the key components shared by citizens' media, alternative media, and community radio according to the following features: produced by its potential audience (Harcup, 2001) and as such self-managed and nonhierarchical (Downing, 2001), involved in reclaiming citizen ownership of the sites of media production to confront localized and historical marginalization and oppression (Rodriguez, 2001), incorporating voices normally excluded from the mainstream media (Atton, 2002), and focused on people-centered development (Horchheimer, 2002) and the engagement of community members in program planning (Lewis, 2002).

The normative assumptions that cut across all of these different terms are similar and can be traced to the UNESCO debates of the 1970s. In his foundational text, Community Communications (UNESCO, 1979), Berrigan defines community media as:

Adaptations of media for use by the community, for whatever purposes the community decides...media to which members of the community have access, for information, education, entertainment, when they want access...media in which the community participates, as planners, producers, performers....the means of expression of the community, rather than for the community (p.7).

Berrigan's focus on community with regard to questions of access and participation has formed 
the core tenet of much of the literature on community radio since the 1970 s. However, recently, community media scholars have begun to question this formulation, criticizing such studies for producing largely uncritical accounts that do not take into account the ways people define themselves as part of a social, geographical or cultural group, or the ways that people actually use media. Rodriguez (2001) describes community media as "citizen's media" and argues that:

The difficulty in defining community media lies in the fact that citizens' media are widely heterogeneous and eclectic...labels applied to citizens' media are equally eclectic. However, despite geographic, economic, and cultural differences, citizens' media all express the will and agency of a human community confronting historical marginalization and isolating forces (p.63).

Another important definition of community media is provided in Howley's book Community Media: People, Places, and Communication Technologies (2005):

Grassroots or locally oriented media access initiatives (are) predicated on a profound sense of dissatisfaction with mainstream media form and content, dedicated to the principles of free expression and participatory democracy, and committed to enhancing community relations and promoting community solidarity (p.2).

These formulations express a desire to move the field away from interpretations of community media that focus on the empowerment of community members towards conceptualizations that do not frame "communities" as static, homogenous entities where everyone has a voice, everyone wants a voice, and everyone has equal opportunity to express his or her voice (Horchheimer, 1999).

In general terms, the literature on community media can be grouped according to three predominant themes: the role of community media in community building, the relationship between communications structures and democracy, and community media as catalyzing forces that functions at the crossroads where people from different groups and social movements meet to articulate a common struggle for equality (Carpentier et al., 2007). 


\section{Community Media as Tools for Capacity Building}

Literature that locates a definition of participatory media in terms of the role it plays in community capacity building emphasize its ability to mobilize, validate and empower a community - whether geographically defined or defined according to a common history or shared background. The World Association of Community Radio Broadcasters (AMARC) ${ }^{2}$ places a strong emphasis on community in their definition of community radio: "a community radio station is a non-profit station, currently broadcasting, which offers a service to the community in which it is located or to which it broadcasts while promoting the participation of this community in the radio" (as cited in Carpentier et al., 2007, p. 220). Similarly, Zane Ibrahim of Bush Radio asserts, "community radio is of course more than just radio. It is a means of social organizing and social engagement...Community radio is 90 percent community and 10 percent radio" (as cited in Coyer, 2007, p.3) According to these formulations, which draw on Berrigan's (1979) notion of community communication, the aim of community media hinges on the concept of dialogue (2-way flow of ideas) and is often translated as enabling and facilitating access and participation among members of a particular community. Participation is seen as applying at the levels of production, decision-making and planning. Many projects in developing countries, partfunded by UNESCO and other international agencies, are premised upon trying to put these ideas into practice.

Hollander et al. (2002) trace the emergence of the term "community communication" to the development of community-based electronic media in the 1970s. The term illustrated "the inability of the concepts "mass" media and "mass" communication to contain this new phenomenon" (p.22). In studies describing small-scale media or community media, the

\footnotetext{
2 The acronym AMARC is based on the French name of the organization - Association Mondiale des Radiodiffuseurs Communautaires
} 
expression community communication was introduced to stress community as the essential context for participatory media. The articulations of local media drew upon an antagonism that grew in North America and Western Europe during the social and political movements of the 1960s. During this period, the image of mass media as pillars of democracy was questioned and led to movements espousing greater participation and codetermination in the expression and formation of opinions by those concerned. The development of a notion of "participatory democracy" manifested in the emergence of alternative forms of media, underground press, and independent cinema (Hollander et al., 2002). The notion of community communication in relation to radio also emerged at this time. Lewis (1994) proposes that one of the first influential uses of the term "community radio" was by the Canadian Radio and Television Commission in its cable and radio policy of the early 1970s which was "concerned to support Canadian culture and identity against programming and editorial techniques from south of the border" (p. 52).

There is a strong resonance of these early definitions of community communication in grassroots radio literature. Typically, case studies formulated around ideals of communitarian politics laud community radio for its ability to foment a shared articulation of oppression and empower groups that are disadvantaged, misrepresented or oppressed. Girard's edited volume, $A$ passion for radio (1992), presents case studies written by community radio practitioners working in various regions around the globe. Girard defines community radio in terms of its ability to:

fulfill an essential role for the outcasts of commercial and large-scale State media; women, indigenous peoples, ethnic and linguistic minorities, youth, political left, peasants, national liberation movements and others are discovering the potential of radio as a means of political and cultural intervention and development (p.3).

The implicit assumption is that people who are involved in community communication are members of the same community and as such have the same concerns and are interested in the 
same topics. In this conceptualization, participatory media opens up channels of communication thereby strengthening individual and collective identities, voicing this identity to the outside world, and thus enabling social change and development (Lewis, 1994). However, a great deal of the literature that is built upon ideals of community remains theoretically underdeveloped in its articulation of communities as homogenous, integrally good forces that are built on consensus and cooperation. In praxis, there remains great contestation over what actually counts as community media and the role it does or should play within a community.

Part of the difficulty in isolating an adequate definition of community media comes from a lack of awareness on the part of media scholars to the theoretical underpinnings that inform the very notion of community itself. The question of what exactly community is has occupied sociologists for more than a century (Jankowski, 2002). Community is traditionally identified in terms of geography - a neighborhood, village, town, city, or even a nation constitutes a community. This geographic determinant is widely discredited as a marker of community and is contrasted with "communities of interest" in which members share some cultural, social, and political views that are independent of geographical proximity (ibid.). However, in studies describing small-scale, locally based participatory media, there is a strong persistence of place to a sense of individual and collective identity. The central question is whether the media merely reflects the social conditions tied to a particular place or whether, to use Hall's (1986) terminology, media articulate a sense of place.

White (1999) describes community as:

a collection of people linked together by communication within a physical environment that can be altered by their collective action (which), when overlaid with the structures of nation, state, and region, becomes a defined area within which political and social structures become the boundaries for development (p.29). 
Notions of "community" as outlined by White (1999) and Jankowski (2002) resonate in literature that discusses the use of community radio as a tool for development in impoverished or developing regions. Many empirical and theoretical studies of community radio in development contexts focus on the geographic locale where participatory media is produced (e.g. Huesca 1995, Ansu-Kyeremeh, 2007, Maslog, 1997, Dagron, 2007, Girard, 1992, O'Connor, 2006). There are a number of key debates situated within the notion of community as inextricably linked to place that are important to examine in relation to community media: the effect of globalization on conceptions of community, the corresponding assertion of locality in research on community radio, and the role of mass communications in creating a sense of communion among members of a geographic community.

For some thinkers, globalization is heralded as a force that will lead to the erasure of national borders and equitable participation in a worldwide community released from the shackles of essentialism imposed by nationalist belief systems - a new age of access, growth, and vitality (i.e. McLuhan, 1964). For others, globalization is a force that will lead to cultural homogenization and political domination - a withering away of community (i.e. Schiller, 1979, Martin-Barbero, 2002). If global media systems express the diminishing centrality of place to community, then community communication serves to reassert it. Within each perspective, the connections between the centrality of place to feelings of communion are assumed. The tension between globalization and community is central to many studies that focus on the imbalance of global media systems in terms of a cultural imperialism framework. Community broadcasting is often conceived of according to the "contradictory movement of globalization and the fragmentation of culture (that) simultaneously involves (sic) the revitalization and worldwide extension of the local" (Martin-Barbero, 2002, p.236). Community broadcasting is thus a means 
for people to connect and communicate with each other on a local level in an increasingly global media environment.

The assumptions about the ability of media to reassert community in the face of the degenerative effects of transnational flows of communication are depicted in Ansu-Kyeremeh's (2007) study of community radio in Ghana. According to her, community radio serves as a force to contest "pervasive foreign influence on what is used to broadcast (means), how broadcasting occurs (process), and what is broadcast (content)" (p. 101). Similarly, O'Connor (2006) describes the creation of a tin miners' radio station in La Volz de Minero in Bolivia in terms of how it was able to contest news and information broadcast by the national station from the capital of La Paz, which did little to voice the concerns and perspectives of villagers.

The underpinning of locality as the root of community in discussions of community radio is also evident in Maslog's (1997) account of community media in the Philippines. Lauding its provision of access and opportunity, Maslog cites the following characteristics of participatory communication endeavours: owned and controlled by people in the community, has limited coverage or reach, utilizes appropriate indigenous materials, reflects community needs and interests, and develops programs and content that reflect community interests. This body of literature exemplifies discourses premised upon ideals of community-based social regeneration wherein the community as a compact, coherent and pure entity is promoted. As Alfonso (2007) argues, "anything from the community had an aura of purity and rightfulness" (ibid.)

The persistent focus of place to notions of community is valuable to empirical studies of community media in a number of ways, but causes many to become theoretically stunted and trapped in an interpretation of alternative media within a politics of resistance rooted in grand narratives of emancipation. Furthermore, it posits an externally coherent, unified, static place 
within which people form their respective identities. In this regard, community media are evaluated on their ability to bind together people who share a common environment, history and ethnicity. According to this criteria, locally based participatory media are herculean in their ideals, but often fail as forces to assert and preserve local identity and to contest the encroachment of big, corporate media. In reality, participation in local affairs is sporadic and inconsistent at best. Also, people vary in the degree of their attachment and integration into a place; merely living in the same proximal space as others does not necessarily infuse a sense of communion (Shepherd, 2001). As such, the question of which community is actually being represented and by whom often remains unclear.

However, it is equally as problematic to do away with a notion of community tied to place altogether. In perceptions of community, there is something intrinsic about a shared locale, a rootedness in a common place, however real or imagined this commonality may be. Lewis and Booth (1994) stress this fact in their historical depiction of radio wherein they emphasize the need to examine community radio projects in developing regions in terms of the unique histories of colonialism, post-colonialism and European and North American flows of capital that set the parameters for a reassertion of locality. Similarly in his explication of issues in organizing democratic radio, Horchheimer (2002) argues, "the media can only be as free, democratic and pluralistic as the society within which they exist" (p.495). As such, participatory radio projects must be implemented and evaluated according to their linkage to the positions and structures of power that reside in a particular place at a particular time. It is fruitful to follow suit with Howley (2005) in proposing a model of community media that foregrounds the symbolic construction of community without dismissing the importance of place or rejecting the materiality of 
communication and community. ${ }^{3}$

\section{Community Media as Tools to Enhance Democracy}

A second approach that is commonly utilized in literature on community radio links participatory media to civil society and places it in a third space between state and commercial media. According to this model, community media are inextricably linked to questions about democracy. Studies that address the role communications media play in enhancing democracy shift the focus away from an interpretation of community media in terms of its 'empowerment capacity' for individuals and groups toward an inquiry based on examining its role in strengthening the public sphere. Community radio literature that is formulated according to assumptions about its ability to change media messages, practices, institutions and contexts in a direction that enhances democratic values and subjectivity usually takes one of two forms: studies that define participatory media as an alternative to mainstream media (Atton, 2001, Barlow, 1988, Lewis, 2002) and studies that define it as a part of civil society (White, 1999, Horchheimer, 1999, David, 2007, Jallov, 2006, Kivikuru, 2006, O’Connor, 2006). Most of the literature describing community radio projects in North American or western European contexts, wherein community-based radio emerged in contrast to commercial and public broadcasting models (Lewis and Booth, 1994), take the first form, whereas descriptions of community radio in developing regions, premised upon the notion that all people have the right to become active

\footnotetext{
${ }^{3}$ This position draws on two concepts often drawn upon in studies of media democratizations. The first is Hall's (1986) notion of "articulation", which he describes as "the form of the connection that can make a unity of two different elements under certain conditions. It is a linkage which is not necessary, absolute and essential for all time" (p.53). In this way, the "unity" of a discourse is a contingent manifestation of different, distinct elements which can be re-articulated in different ways (ibid.). Similarly, in his work on nationalism, Andersen (1983) posits that communities are invented through narratives which, in their accumulation form "the imagined creation of communities where they do not exist" (p.14).
} 
partners in the development process (White, 1999), typically take the second.

A great deal of literature that describes the role of participatory media in facilitating development objectives in impoverished, post-conflict, or transitional societies is formulated according to assumptions about its potential to enhance civil society, thereby establishing greater plurality and representation at the grassroots level and ultimately leading to social transformation. White (1999) describes development communication as a 2-way, interaction "which, through dialogue, transforms grassroots people" (p. 36). In a similar vein, Horchheimer (1999) explains that when a community aspires to establish its own radio station, "it is an intermediate step in the long path toward greater power and control at the grassroots" (p.255). Coyer (2007) argues similarly when she states that

community radio programming offers crucial spaces for empowerment of gender, youth, elders...helps bridge ethnic and linguistic divides...provides a site for healing in post conflict zones... (creates) a space for lifesaving health, agricultural and other education...(provides) the affirmation and celebration of local culture (p. 6).

In her case study of Radio Candip in Zaire, Aw (1992) describes community radio as a valuable resource for grassroots organizations that are demanding change given its flexibility to cross physical, social and political spaces with fewer restrictions than other media. The characteristics of community radio, including its ability to reach many people inexpensively and its accessibility by people of varying degrees of education and literacy, enable it to contest "government imposed censorship, threats and assassinations of journalists, and the media's own hostility toward change (that) can all work to exclude certain perspectives from the public forum" (p. 50).

In a similar vein, Kivikuru (2006) presents a case study comparing Democracy Radio in South Africa and People's Parliament in Namibia to assess the normative claim that community 
radio works in service of democracy. She discusses community radio stations in South Africa and Namibia in terms of the way they have "a unique possibility, due to their geographic closeness to local government bodies, to check, to criticize and to analyze the activities of local governments and to encourage citizens to participate" (p.7) and the potential they hold to strengthen African citizenry. However, she claims that laudatory accounts of the way community radio can contribute to the development of informed active citizens and a robust public sphere are removed from the reality of the mediascape in many regions of Africa in which the role of the media remains blurred. In actuality, processes that are premised upon 'instigating citizens' interest in collective affairs pose great challenges in countries where media messages are scarce or unevenly distributed, perhaps also found irrelevant by a considerable part of the population or, where the public sphere in general does not create great motivation for action" (ibid.,p. 9).

Many community media projects are developed according to assumptions about their ability to promote good governance, increase transparency, and act as a fourth estate in countries where the media has traditionally been an extension of authoritarian regimes. For instance, in the context of Mozambique, Jallov (2006) discusses the ways UNESCO and the United Nations Development Program (UNDP) implemented projects with the explicit aims of helping a democratic media structure develop and mature: "the project aimed to help strengthen the professional media such as public radio, increase the diversity and quality of print media, train journalists, facilitate the role of women in the media and strengthen the quality of coverage of HIV/AIDS" (p.3). The project mandated to strengthen civil society voices through the development and strengthening of community radio (ibid.)

These descriptions of community radio foreground the relationship between community media, the state and the market and support a case for community media as a key part of civil 
society, where it is considered the "third voice" between state and private commercial media (Carpentier et al., 2007). Such descriptions are formulated according to notions of access and participation wherein it is implicitly assumed that greater access leads to greater participation, and that greater participation leads to a greater plurality of voices and representation in the public sphere. Although these studies differ in the degree to which their respective theoretical grounding is elaborated and investigated, they all take as their starting point the role that community media can play in the democratic process (Jankowski, 2002). Horchheimer (2002) outlines a number of difficulties inherent to a democratic approach to organizing community radio. One issue that often poses ethical and practical difficulties for community radio organizers has to do with the fact that "media can be no more democratic than the societies within which they exist...just saying to people now you are free to say what you like is not the same as them believing that such freedom is theirs or that they have something worth saying" (p.321). Questions that are central to accounts of community radio formulated upon democratic ideals include: Who are the leading voices? Who do they represent? What are the competing interests in a community? How are these voices integrated? How is participation enlisted? How is success measured in projects that are founded upon highly ambivalent liberal notions, such as "participation" and "empowerment"?

Scholarship that articulates community radio in terms of building independent, democratic and participatory media focuses on its potential to give a voice to marginalized groups of people through communication channels that are independent of state or commercial control. Empirical studies that conceive of community radio initiatives in terms of their relationship to dominant institutions focus on the ways they attempt to influence the content and practices of mainstream media and to advocate for government reform of media regulation (ibid.). For instance, in his 
discussion of community radio in Bolivia, O'Connor (2006) describes the way that the most popular tin miners' station - La Voz del Minero - carved out a site of resistance to the national broadcaster - Radio Fides - one of the most influential radio stations in Bolivia, which is owned by the Jesuit Order. La Voz del Minero broadcasts the national morning news show produced by Radio Fides from the capital city, La Paz. This news broadcast is repeatedly interrupted by advertisements. La Voz del Minero, instead of simply blocking out the advertisements with music, substituted its own commentary during the Radio Fides newscasts: "they improvised a commentary on what was heard - "well, no we don't agree with the analysis just presented by Radio Fides". Against the framing voice of the newscast from the capital, a different political voice said firmly: "we see it differently"' (p. 29). O'Connor's case study exemplifies interpretations of democratic media initiatives in terms of the ways they work to contest main forms of institutional power (Carroll \& Hackett, 2006).

\section{Community Media as Catalyzing Forces}

A third theme that can be used to group literature on community radio suggests an implicit rejection of notions of community media as tools to empower communities or as entities fundamentally linked to deepening democracy. Carpentier et al. (2007) define an approach to community media that works to unravel traditional and static definitions of community and democracy that are trapped in oppositional politics by invoking Deleuze and Guattari's (1987) epistemological model of the rhizome: "As rhizomes, community media tend to cut across borders and build linkages between pre-existing gaps...in this sense, community media do not operate outside the market and/or the state although its identity is often defined in an antagonistic relationship toward the market and state" (p. 230). This approach builds onto the importance of 
both community-building and democratization in accounts of participatory media, but rather than conceiving of media in terms of how they articulate communities or their role as part of the public sphere, this approach stresses the role media play as catalyzing forces. This construction of community media draws on theories of radical democracy and emphasizes the crossroads where people from different types of movements and struggles meet to collaborate. In this fashion, they function not only as instruments giving a voice to people who are mobilized according to a specific issue, but they also serve as catalysts, grouping people who are active in different types of struggles for equality (ibid.)

Atton (2001) and Downing (2002) use a similar theoretical grounding in their descriptions of alternative and radical media respectively. Atton argues that

Any model must consider not simply the differences in content and medium/carrier (and its dissemination and delivery) but how communication as a social (rather than simply an informational) process is constructed...A model of alternative and radical media must account not only for active audiences...but also for mobilized audiences. (p.25)

Atton's framework, as with Downing's (2001), expresses the ways alternative media is inextricably linked to the social movement that produces it and, as such, must be studied in terms of the relationship between the actors who produce and disseminate the content to the audiences who consume it. They also suggest that studies must attend to how this relationship is situated within a larger social context that interpellates the very nature of the producing and consuming within the mobilizing capacity of a particular "alternative public sphere". Atton's typology of alternative media articulates a horizontal model that explores the ways social relations stand to be transformed through alternative, community-based communications processes at the same time as the media themselves stand to be transformed by their relationship to the communities and movements they seek to address. 
Rodriguez (2001) employs a similar model in her interpretation of Laclau and Mouffe's (1985) notion of radical democracy. Both theories—rhizome and radical democracy—work to unravel traditional and static definitions of community media and its relationship to power. Horchheimer (2002) illustrates this dynamic model of power in his discussion of community radio wherein he describes the development of a community station as "the extension of efforts to draw upon people's felt and articulated needs to communicate amongst themselves and with others to establish their own sense of personal and community power" (p. 320). According to these conceptions, power is not a fixed entity that cements people in one social identity or power relation. Power relationships are continually reconstituted and reconfigured in everyday existence wherein "each of our everyday identities moves into power relationships with others' multiple identities" (Rodriguez, 2001, p. 17).

Laclau and Mouffe's (1985) theory of radical democracy and Carpentier et al.'s (2007) interpretation of Deleuze and Guattari's model of the rhizome, are useful for studies of community media. According to Laclau and Mouffe, political subjects are located in differentiated power positions, but these positions are not fixed; they may be shaped by history but they are never deterministic; rather, they are "potentially riven with a series of other relational differences" (Mouffe as cited in Rodriguez, 2001, p. 26). According to this perspective, community does not eradicate differences and cohere distinct individuals into a singular movement based on consensus; communities are made up of differing individuals, in different positions, with different interests, facing different life circumstances. Laclau and Mouffe (1985) argue that radical democracy is dependent on difference, dissent, and antagonism. Moreover, an individual's relation to power is not fixed; in some circumstances an individual may possess greater power than in another context, based on a different matrix of contingencies. 
According to a theoretical model of community that invokes Laclau and Mouffe's (1985) notion of radical democracy, participation in community media can be perceived in terms of the way it transforms the realm of symbolic production and empowers the communities involved. Within this framework, the most important thing about participatory media is not how the mainstream media structure is altered or how oppression is overturned, but how participation ruptures pre-established power structures and opens spaces for reshaping social and individual identities and reforming cultural definitions (Rodriguez, 2001). Since most social groups that participate in community media production are situated in marginalized relations to hegemonic social structures, they are important sites where symbolic resistance to such structures occurs. A theory of radical democracy offers an important shift in thinking about community radio. Thinkers such as Howley (2005), Horchheimer (1999, 2001) and Rodriguez (2001) mandate to break away from the traditional and static definitions of democracy, participation and communicative action. In doing so they aim to capture the richness of the lived experiences of people articulating their shared experience of oppression while asserting that "each social subject will experience being indigenous in a different way according to other social dimensions" (Rodriguez, 2001,p.19). Downing (2001) offers a similar frame in an analysis that outlines four guiding principles for media democracy: the need to recognize oppression and marginalization as heterogeneous, the need to establish links between fragmented movements, the need to envision the struggle against oppression in terms of movements rather than institutions, and the need to think of liberation as an everyday process. From a radical democracy perspective, each of these thinkers on community media expresses that participation in these media endeavours enables historically situated social subjects to negotiate and re-negotiate the circulation of dominant representations and social codes. This perspective recognizes the variation of people, interests, 
and histories within any given locality, as well as their commonality and interrelatedness.

The core body of literature that charts the emergence and development of participatory media/alternative/community radio projects is rooted in oppositional theory and practice. Empirical studies highlight a kind of radio that aims to redistribute power: to claim for groups that are socially or politically marginalized or oppressed the right to a fairer share of resources. This review of the formative literature in community radio studies serves to tease out the key debates and draw attention to the central assumptions that underlie the interpretation and evaluation of community radio projects. Most studies rely on a theoretical basis that locates participatory media as both a resource claimed and an essential tool in the struggle against domination (Lewis \& Booth, 1994). The tensions and conflicts that divide the field center around theoretical debates related to media determinism, power and resistance. The next chapter attempts to answer the call issued by Atton (2005), when he argues that in alternative media studies "attempts to theorize and develop conceptual frameworks are sparse" (p.7), Hollander (2002), who says "community communication remains a field where the same questions are asked over and over" (p.35), and Lewis (2002) who asks how "a theoretical vacuum in the field of community radio came about" (p.47). The following theory section outlines an analytical framework based upon Foucault's (1991a) notion of governmentality in an attempt to redress theoretical deficits in research on community radio development. 


\section{Chapter II - The Episteme of Development: Community Radio as Governmentality}

In the previous section, I aimed to illustrate how assumptions about the capacity of community media to catalyze social change, as well as the definitions of human rights and equality inscribed by international development organizations, form the basis for research on community radio and underpin the implementation and evaluation of community radio initiatives. This section goes a step further to examine accounts of power in the formative body of literature that takes a critical look at international development initiatives. This is an approach that is largely absent in accounts of participatory media development, which typically laud the ability of grassroots radio to facilitate democratization and empowerment among marginalized social groups.

In different fields of knowledge, there has been a growing interest in "governmentality" a problematic that became a significant theme in the later work of Michel Foucault (Merlingen, 2004). Foucault used the term "governmentality" to refer to what he saw as a distinctive, modern form of power which seeks to regulate the conditions under which people live their lives. Often called "governing through freedom" (Watts, 2003, Merlingen, 2004, Li, 2007), govermentality is typically conceptualized as a form of "positive power that wins legitimacy and empowers action" (Watts, 2003, p.12). Within this perspective, people constitute their aspirations and interests in terms of the norms through which they are governed as free social agents (Lewis \& Mosse, 2005).

Development practices can, in this framework, productively be construed as forms of what Foucault called "governmentality". To understand development is to grasp how "the possible field of action of others" (Foucault, 1982, p.221) is structured through a variety of technics and micropolitics of power - from the map, to the national statistics, to forms of 
surveillance - to accomplish, or attempt to accomplish, stable rule through certain sorts of governable subjects and governable objects (Watts, 2002; Li, 1999). Like the Gramscian notion of hegemony - an idea that had a profound impact on critical political analysis during the 1980s - governmentality has become a core concept within a wide range of studies of power, order, subjectivity and resistance. Studies that employ Foucault's notion of governmentality focus on the political rationalities and techniques of the organization and exercise of power. This section extends the Foucauldian analytic of governmentality in order to develop a critical framework for the study of international non-governmental development organizations and agencies (INGOs and IDAs) and the role they play in the establishment of grassroots radio projects in Nepal. Such a framework enables a new interpretive purchase upon donor-led participatory media development by offering a different theoretical stance on the power exercised by INGOs and IDAs. According to a Foucauldian epistemic perspective, development interventions may-and commonly do-fail in their own terms, while succeeding in their political effects (Lewis \& Mosse, 2005).

\section{Nepal as "Developing Country"}

Nepal defines itself as an undeveloped country in relation to the rest of the world. In terms of the discursive structures that posit some countries as developed and others as developing, this is not at all off the mark - it is considered to be the second poorest nation in the world where more than $80 \%$ of the population comprises the rural poor (AMARC, 2004-2005). In Kathmandu, United Nations SUVs weave throughout the chaotic processions of traffic. It is a country that, underneath the mythos of a Shangri-la that invokes a sense of serene mysticism and images of shy, soft-spoken Sherpa living in pastoral villages nestled amidst the peaks of the 
Himalayas, is deeply scarred by political corruption, a rigid Hindu-based social structure, poverty and conflict. Development workers who work for various international nongovernmental organizations often state that "everyone in Nepal belongs to a disadvantaged group." In her book The Tutor of History, Manjushree Thapa (2001) describes the political climate in Nepal as, "an undeclared war against the unfortunate" (p.362). Although democracy has failed miserably in the past and has done little to improve the conditions of those who are most disenfranchised, Nepal is currently in a state of political transformation and is attempting democratic reform. The country is in the process of drafting a new constitution to embody these transformations. As a result, groups that were historically marginalized and silenced are struggling, at times violently, for social inclusion and representation.

Arturo Escobar (1995) charts the emergence of a notion of the "third world" to the postcolonial redefinition of global relationships, which organized certain complexes of social relations in a condition labeled "underdevelopment". Nepal forged its contemporary political identity during this post-war, post-colonial period (Pigg, 1989). To the developed countries of the world, Nepal is underdeveloped economically-it lacks the infrastructure necessary for modernization - and underdeveloped ideologically - many people have not yet reached the common, international understanding that the "equal and inalienable rights of all members of the human family is the foundation of freedom, justice and peace in the world" (UDHR, preamble). Many Nepalis see their nation in similar terms; they describe village life with its absence of electricity or running water, its disease and malnutrition, and its enduring traditions of caste hierarchy and gender inequality as "backward" (Pigg, 1992, Stone, 1989). At the heart of Nepal's national imaginary is a conception of "progress" embedded in visions of social transformation realized through development interventions that aim to facilitate agricultural productivity, 
improve health conditions, enhance literacy, and educate people to understand their "rights". It is within this context, this shifting and tension-ridden site of political transition marked by visions of emancipation rooted in westernized notions of modernization and empowerment, that community radio in Nepal has flourished.

\section{Community Radio as "Development Intervention" in Nepal}

Community radio development projects in Nepal fall under the umbrella of "international development", and carry the explicit aim of promoting freedom of information, inclusion and participation for groups historically marginalized along lines of history, ethnicity, gender or caste. Programs designed to improve the state of human rights and to work towards poverty alleviation and discrimination are often supported and implemented by international nongovernmental development organizations and international development agencies such as ActionAid, United Nations Development Program (UNDP), MS Nepal (Denmark), United Nations Educational, Scientific and Cultural Organization (UNESCO), Danish International Development Agency (DANIDA), CARE, Equal Access (U.S.), and Cordaid, among others, that act as "trustees". The position of "trustee" that development organizations enact is one "defined by the claim to know how others should live, to know what is best for them, to know what they

need" (Li, 1999, p.4). In contemporary development schemes this manifests as projects that work to empower poor communities to help themselves. Within the rhetoric of empowerment, the objective of trusteeship is not to dominate others; rather, it is to enhance their capacity for selfimprovement and action.

This chapter interrogates critiques of power in accounts of international development operations by employing a "governmentality" (Foucault 1970; Gordon \& Foucault, 1980; 
Burchell et al., 1991; Rose, 1999; Rose, O’Malley and Valverde, 2006) perspective to confront some of the core epistemological issues relating to the influence of donor-led participatory media initiatives on Nepal's independent media community. Much of the literature that offers a critique of international development and global governance tends to draw on a conception of power as domination (Abrahamsen, 2004). The classic formulation of this view is expressed by Robert Dahl, who defined power as "the ability of A to get B to do what B would not do otherwise" (Dahl, as cited in Abrahamsen, 2004, p. 1457). Power, in this definition, is coercive and intentional. Abrahamsen (2004), drawing on descriptions of power articulated by Bachrach and Baratz and Lukes, describes two other forms of power: Power that operates by non-decision, wherein the ability to prevent issues from entering public debate is a way of exercising power, and power that focuses on the ability to "form the very interests and values that determine action in the first place" (ibid, p.1459).

For critical thinkers such as Arturo Escobar, James Ferguson and Wolfgang Sachs, power is unilinear - it is enacted by the powerful nations of the global north on the powerless nations of the south. This dynamic is epitomized in Gupta's definition of development as "orientalism transformed into a science for action" (Gupta, cited in Watts, 2003 p.12). This perspective translates into an account of development projects that serve capitalist interests at the expense of poor populations through the adoption of neo-liberal policies and practices of good governance. Running across this body of work is the notion of development as an essentially western doctrine whose normalizing assumptions - "the myth of the global (and) the myth of human rights" (Watts, 2003) - must be rejected. While not dismissing this corpus of literature and its critique of development initiatives as ultimately serving the interests of western capitalists, a Foucauldian understanding of governmentality expands such a static conceptualization of power. Research 
that utilizes the framework of governmentality as an analytical tool is able to highlight the complex, and often invisible, power relationships at work in international development schemes.

\section{Critiques of International Development}

Before discussing the benefit of using the theoretical construction of "governmentality" in accounts of participatory radio development initiatives in Nepal, it is first necessary to discuss the context of international development and highlight the reasons it has generated such widescale critique among scholars, activists and developing country partners. The contemporary vision of international development, with its focus on poverty alleviation, human rights, empowerment and participation became salient alongside discourses of modernization after 1945. This vision "with its associated machinery of Western lending, technical expertise and universalist discourses of education and technology transfer" (Appadurai, 2001, p. 23) was born through experiments such as the Bretton Woods system which created the World Bank Group and the International Monetary Fund (IMF). This vision of modernization and development has been subjected to intense criticism, not the least of which is the fact that "today, over half a century after the Bretton Woods accords, more than half of the world's population lives in severe poverty" (ibid.).

In the contemporary era, challenges to development programs are often framed in the language of unkept promises or, as Tania Li (2007) suggests, "in the language of rights, increasingly codified in national and international laws" (p.3). Moreover, many, if not most, carefully designed programs of intervention fall short of accomplishing their goals for change those who are impoverished remain impoverished, and inequity, discrimination and marginalization continue. In many cases, it is primarily those who have access to power and 
resources who feel the benefits produced by development programs. As a result, interventions often serve to entrench already-existing hierarchies. In her ethnography of "the village" in Nepal, Pigg (1992) suggests that the tangible advantages of development, with its influx of money brought in by foreign aid, and subsequent burgeoning of office jobs and positions of authority in the bureaucracy, "lie less in receiving the benefits of its programs (though no one minds if an agency decides to bring them piped water, build a clinic, or install electricity) than in becoming one of the salaried workers who implements bikas" (p. 507).

In this context, a variety of other visions of emancipation and equity now circulate globally, many of them propounded and disseminated by the emergence of a global civil society made up of internationally operating non-governmental organizations dedicated to upholding universal human rights and facilitating democratic progress. Emphasis is placed on movements that are mobilized at the grassroots and "partnership" has become the sine qua non of development programs (Abrahamsen, 2004). This is not to say that the outcomes of such schemes, designed to improve the livelihoods of people living in poverty, are always bad; programs often bring changes that people want - better access to education and health services, better roads, clean drinking water, fewer diseases and less corruption. The position of this project echoes Tania Li (1999), whose purpose is "not to condemn" (p.3). It seeks to understand the rationale of participatory radio projects - what they strive to change and the calculations they apply to realize such change - and the resultant epistemological effects on grassroots media movements as they seek legitimization in the communities they aim to empower. To do so, analysis is grounded on the assumption that "development establishes an ideological encounter in which Universalist notions of progress and modernity meet locally grounded social visions"

\footnotetext{
4 "bikas" is the Nepali equivalent for the English word "development"
} 
(Pigg, 1994, p.492).

\section{Governmentality and Development}

As outlined earlier, studies that theorize grassroots media according to a radical democracy perspective are formulated in response to a body of literature that, for the most part, contains "uncritical, laudatory biographies that decontextualize and thus overstate the autonomy of practice" (Hamilton, 2004, p.46), and focus on the conditions of practice in order to probe their determinative effects. Such studies of community or radical radio conceptualize participatory media as both a response to and an attempt to change existing conditions (Atton, 2002; Downing, 2001; Howley, 1999, 2001; Jankowski \& Prehn, 2002; Rodriguez, 2001). However, what is largely missing in a great deal of this formative literature is a consideration of broader contexts of practice. Hamilton (2004) points to the role of "rationalization" as a context of practice that has yet to receive attention in the literature on alternative, participatory and radical media. A rationalized process "envelops itself within a cocoon of self-referential requirements and strictures, which permit participation while at the same time monitoring compliance" (p.47). In a similar vein, Ngare (2008) theorizes changes in East African communication sectors by drawing on a Foucauldian global governmentality perspective to reconceptualize issues surrounding global media governance.

Employing a theoretical framework of governmentality to examine the influence of donor-led models of community radio development in Nepal enables such an exploration of wider contexts of practice (Hamilton, 2004). In his essay on governmentality, Foucault (1979) argued that a certain mentality or rationality of government had become the common ground of all modern forms of political thought and action. He defined governmentality as an "ensemble 
formed by the institutions, procedures, analyses and reflections, the calculations and tactics, that allow the exercise of this very specific albeit complex form of power" (Foucault 1979, p. 20). He sees government not in terms of the monopoly of the state, but in terms of a plurality of practices that are conducted within and across countless social sites - practices that are often contradictory and only ever partially coordinated (ibid.)

Governmental rationality, according to Foucault, is based upon practices of "problematization", which identifies deficiencies that need to rectified, and "rendering technical", which conceptualizes the domain to be governed as an intelligible field with specific limits and particular characteristics ( $\mathrm{Li}, 2007)$. This perspective views such power as always operating in terms of specific rationalizations and directed toward certain ends that arise within them (Rose, 1999). International development programs represent a form of "governmentality" in that they are implemented through calculative practices, uphold a distinct power relationship, and draw from a particular knowledge form. According to Foucault (1979), " there is no power relation without the correlative constitution of a field of knowledge, nor any knowledge that does not presuppose and constitute at the same time power relations" (p.27).

\section{Community Radio Development as Governmentality}

By utilizing a definition of governmentality as that which "works neither through the extension of bureaucratic or military control" (Ferguson, 1994, p. 270), nor through the logic of repression and control implied within a western project of development (Escobar, 1995; Sachs, 1992), but instead through a form of "positive power that wins legitimacy and empowers action" (Watts, 2003, p. 12), this thesis will explore way power is exercised in community radio development projects that rely on INGO funding mechanisms. Examining such initiatives in 
Nepal according to an analytic of governmentality brings to the fore two aspects of the exercise of power: the technical means of government and its mentalities or rationalities. The latter are not ideologies that stand in opposition to truth, nor are they carriers of neutral information. Rather, they are discursive formations, intimately linked to structures of power that produce effects of truth with regard to specific fields of governance (Merlingen, 2004). Analysis will focus primarily on these two aspects - the discursive element and the technical element - to confront issues relating to the influence of donor-led and partnership-based participatory media initiatives on the growth of community-based broadcasting in Nepal.

\section{Discourses of Development in Community Radio Initiatives}

Discourses of development that manifest in community radio schemes make frequent reference to universal human rights, community, progress, inclusion and participation. Together these form the basis for the moral valuations ascribed to community radio projects that explicitly aim to overcome poverty and inequity. The technical element of international development projects comprises the "calculations" and "problematizations" that make a space, and the subjects within it, thinkable and governable. In participatory media development, technical elements include the establishment of partnerships, the reliance on experts, and the conceptual tools of standardization, evaluation, impact assessment and performance benchmarking.

In employing a theoretical framework of governmentality, it is important to explore the ways in which meanings and outcomes are negotiated, albeit within an uneven field of power. In her discussion of development projects in Indonesia, $\mathrm{Li}$ (2007) argues that development encounters are "neither plans unilaterally imposed nor discourses hermetically sealed" (p.301). In her view, compliance among a target population is an accomplishment, not a given. The 
articulation of power as productive rather than repressive, as coming from below as well as above, as heterogeneous, diffuse, immanent and unstable, informs understanding of the practices and negotiations around development orders. Within this perspective, people constitute their aspirations and interests "in terms of the norms through which they are governed as 'free' social agents" (Lewis \& Mosse, 2006, p.4). Following suit with Lewis and Mosse (2006), a focus on the discursive elements that form the basis for development programs proposes that the order of development can be defined primarily as "an interpretive order, socially sustained through “interpretive communities" and necessarily separated through actual events and practices" (p.6). Similarly, Watt (2003) argues that studies of development need to understand the subjectivity of individuals in terms of "enunciative modalities - the statuses, sites, and positions - of their existence as political subjects" (p.7) in order to explore the ways discursive practice are attached to populations and spaces. In analyzing discourse in studies of governmentality, Foucault (1991) is concerned with "the limits and forms of the sayable" (p.59). This includes an examination of the constituted domain of discourse, the resilience or disappearance of utterances, the valuation and adoption of foreign discursive formations and the limits and forms of appropriation (ibid.). It is important to note that Foucault is not referring to a process of unearthing hidden meanings or covert intentions in analyzing discourses (which is the focus of ideology critique). Rather, he is concerned with "the fact and conditions of their manifest appearance; not about the contents which they may conceal, but about the transformations which they have effected" (Foucault, 1991, p.103).

Drawing on Foucault's conception of governmental rationality allows for an analysis of the discursive structures that are inscribed in funding models and the ways they manifest in articulations of grassroots development programs that are formulated according to liberal 
definitions of human rights, modernization and empowerment. For constitutively, a place and a history manifests in a time and space that is interpreted-by a whole series of internalized notions like 'village', 'community', 'nation', 'modern', 'backward', and so on (DeChaine, 2005). Within this general framework, development encounters are explored in terms of the negotiated, contingent, fluid and fragile terrains of meaning within which "discoursing subjects form part of the discursive field" (Foucault, 1991, p.58). In this way, analyzing "discursive regimes" (Foucault, 1972) places emphasis on the ways that power relationships are worked out through compromise and negotiation rather than the familiar dichotomy of accommodation and resistance. This theoretical shift enables an understanding of hegemony not as "the project of a singular and coherent state, but as a terrain of struggle and, more prosaically, as the routine and intimate compromises through which relations of domination and subordination are lived" ( $\mathrm{Li}$, 1999, p. 316).

To promote a particular conception of the world, international development organizations have engaged in constructing programs of governance based upon western conceptualizations of individual freedom and human rights. Founded on a fundamental affirmation of the inalienable and universal human dignity of every individual, the notion of human rights propounded by the Universal Declaration of Human Rights has been held up as an ideal and an archetype for the machinery of the international community since its inception (DeChaine, 2005). As a result, a human rights discourse has refigured the contours of the mediascape in Nepal through the proliferation of grassroots media organizations committed to upholding internationally mandated principles of democracy, rights and equality. Programs founded according to conceptions of international standards of human rights function at the crossroads where a discourse on globalization intertwines with a discourse on morality and is one that is, according to DeChaine 
(2005), "profoundly power-laden". He asks:

How do we reconcile a conception of human rights with the traditional values, customs, and laws of national cultures? What happens when we disagree about what rights are and which ones matter? And who is the we of which we speak? ...What kind of tensions exist as a result of the incursion of global identities? What kinds of identities circulate amongst humanitarian NGOs and how are these identities negotiated? (p.15).

In exploring the ways that a discourse of universal human rights frames development encounters, the following questions will guide the analysis: What kinds of moral discourses do humanitarian INGOs articulate? What effects do INGO actions have on local perceptions of morality, rights, freedom and justice in the communities within which programs are implemented? Are these discourses accepted unilaterally or are they negotiated?

The processes of participation and inclusion are other discursive structures, central to INGO-mandated programs of improvement, which are not as transparent as they may seem. In her discussion of the role of the "development expert", Kothari (2005) suggests that the very act of inclusion, of being drawn in as a participant can perform the exercise of power over an individual. Using a case study of a participatory natural resource development project in western India, Mosse (1994) also demonstrates how the formulation of programs based upon inclusion and participation tend to emphasize consensus building that, given unequal social relations, commonly mean that the interests of the most powerful sections in a community are likely to dominate. The process of participation and inclusion does not always benefit of those groups who have been previously excluded. Cohen (1985) explains that programs which serve to enhance inclusion among marginalized groups of people often result in forms of control that are difficult to challenge because they appear to be benign. Although participatory approaches to development often aim to uncover and overturn social and local manifestations of dominance 
and exclusion, "the process of incorporation also performs a selective function to exclude certain people and particular forms of knowledge which cannot be absorbed" (Abrahamsen, 2004, p.441). In community radio development initiatives, articulations of participation and incorporation are expressed in terms of programs that strive to "give voice to the voiceless" (UNESCO, 2001, p.4). Programs are implemented with the explicit aim of enabling participation among rural populations or among groups of people who are excluded and underrepresented in national and urban-based commercial broadcasting systems as a result of ethno-cultural discrimination or gender and class-based inequity (ibid.).

In development schemes, laudatory notions of participation and inclusion are formulated in accordance with a discourse of "community". The most salient form of "community" relies on its normative interpretation: community is based on commonality and communion and is thus intrinsically good. A study of community media development must attend to the material relations of power that shape, define, and inform community. A governmentality framework enables an exploration of the relationship between community and power and the way power relations articulate individual and social identity in a particular place at a particular time.

A notion of "community" operates on a number of different levels in development rhetoric. On one level, the operations of development INGOs are based upon conceptions of a "global community" and the universalizing moral values and standards that members of it strive to uphold. In this way, the "conduct of conduct" of nations is determined by their level of compliance with the norms and values of the international community at large. To be inducted into an international community, nations must consent to the forms of conduct mandated by the regulations, standards and valuations of international organizations. Conduct, in turn, is measured, recorded and rewarded. By complying with INGO prescriptions and proscriptions, 
governments, local NGOs and advocacy groups gain the legitimacy that comes with acting in accordance with international standards of proper behaviour. A high degree of international legitimacy, in turn, carries advantages such as improved access to other international organizations, resources and funds. Consent, however, is not conceived of as merely a strategic exercise to garner funds from donor agencies. It is a process of socialization. This perspective analyzes power in terms of the "socialization effects" (Merlingen, 2004) that programs have on target states rather than conceiving of it in terms of material or ideological forces. In his analysis of international governance, Merlingen (2004) suggests that "socializees choose to act in accordance with the expectations of the socializer in order to gain certain material and nonmaterial benefits" (p.354).

Clearly there is a power differential at work in development programs; INGOs possess material and normative power in relation to the states they are working to "improve". Traditional critiques of development rely on the perspective that international organizations enact power when they manipulate material resources to alter the policies of target states. However, this analysis draws on a wider conception of power than many other strands of development research. In contrast to the typical conception of power as unilinear, and of development as domination, a governmentality perspective views power "as ubiquitous in presence, microphysical and diffuse in nature, circulating in movement and producing countries, civil societies and individuals in its effects" (Melingen, 2004, p.368). According to a Foucauldian perspective, at the core of normative power is the question of consent. An INGO derives its normative power from the identification of target states with the collective identity of the global or local community (Merlingen, 2004). Given that new members or non-members admire, and aspire to join, the dominant in-group, they grant the community organization the authority to shape the norms upon 
which their polities and policies rest. Hence, "the normative power of (INGOs) rests on the attractiveness of the ideas that they embody" (ibid., p.365). This approach conceives of programs related to international development according to a complex of relays that assembles organizations, transnational corporations, states and other actors. Such a conceptualization, in turn, directs attention to how shared vocabularies and alignments are forged, or fail to be forged, between actors implicated in subjecting countries to international influence and control.

Paradoxically, another way that the discourse of community is articulated in development programs that aim to mobilize action at the grassroots is in its assertion of the local, and its insistence on programs that serve to engender communities based on a geographical determinant or a shared history. In development rhetoric, there is a virtual consensus that community media is good, important and necessary for communities to overcome marginalization. Radio Jagaran, which is the radio station that informs this project's case study, is located in Butwal, Nepal, at the precise junction where the Himalayan hills fade into the plains of the Terai. Radio Jagaran is one of the projects of Jagaran Media Centre (JMC) - a Kathmandu-based grassroots media development NGO. The assumptions about the value of local, participatory media are at the heart of the activities of JMC, which was established by journalists from Nepal's lowest caste, called Dalits, who carry the legacy of untouchability. ${ }^{5}$ Radio Jagaran's mandate of empowering Dalits to speak for themselves invokes a normative interpretation of "community". In conceiving of an apriori given that articulates an essential commonality, Radio Jagaran's vision is formulated according to assumptions about community media's ability to foment a shared history of

\footnotetext{
${ }^{5}$ Nepal has a rigidly stratified Hindu-based social structure. The highest caste is considered to be Brahmin, then Chetri, Janajati and Dalit in descending order. The Dalit caste was originally an occupation-based designation. Members of this caste were thus born into their occupation and often performed work that rendered them "untouchable" (such as skinning dead animals or burying human waste) by higher castes. Untouchability customs prevent Dalits from sharing food, water and public spaces with people from higher castes.
} 
oppression and vision of empowerment. Dalits do not necessarily live in geographical proximity to one another, nor is their allegiance to such a community necessarily voluntary or desired. Even within the Dalit community itself, there are other communities and different levels of selfidentification. A Dalit subjectivity looks much different from one village to another where it intersects with other dynamics such as poverty, migration, and access to resources. A Dalit woman in the far west in Nepal, where rigid gender customs force women into confined isolation while they are menstruating and where extreme poverty requires them to give birth without stopping work in the fields for a single day of rest, has a very different relationship with being Dalit than a relatively affluent Dalit journalist working in Kathmandu.

Although a community is often defined in terms of who is in it, a sense of community is often created out of explicit or implicit recognition of how members of the community are different from non-members. These boundaries, however symbolic or arbitrary, are not innocent; they have material effects and instill power hierarchies that are naturalized and legitimized. It is reductionist and essentialist to ascribe a group identity to individuals and assume that they are therefore members of a community defined by that ascribed identity. Mandelbaum (2000) proposes that, in many circumstances, "there is no community there, only a set of persons on whom we have imputed a common fate, opportunity, identity, or interest" (p. 7). However, in development encounters, the articulation of a "community", and the assumption of commonality, is necessary to identify a target group with a deficiency to be rectified. Inherent to this identification is a boundary between the knower and the object of knowledge: "Knowledge of another's deficiencies depends on, as it constructs, a boundary between the knower and the object of knowledge " (Li, 1999, p.301). As Pigg (1992) has observed in Nepal, the condition of being a backward villager, rather than simply a poor or relatively powerless one, is visible only from afar 
- to know one, you cannot be one. At the root of the assertion of the local, and of the positioning of community as the locus of development encounters, is the politics of difference. At the same time that development projects reaffirm the site of marginalization through a focus on the local and the grassroots, they encourage the formation of an imagined national community in which differences of language, religion, caste and ethnicity create a common terrain or social territory: "the condition of underdevelopment at which development interventions are aimed" (Pigg, 1992, p. 499). Different regions and villages throughout Nepal are conceptualized according to their level of development, a categorization which, according to Pigg, reifies "the village" as the site of underdevelopment:

Bikas comes to local areas from elsewhere; it is not produced locally...much bikas is administered from Kathmandu and staffed at the higher levels by people posted to local projects from other places. From these associations grows the popular notion that bikas is concentrated, to varying degrees, in other places and that villages are places of relatively little bikas (ibid.)

The social ideology of modernization espouses a binary logic, opposing rural people, with their outdated cultural practices and lack of resources, to international development workers or Nepali elites who understand the problems of Nepal and possess the technical knowledge to overcome them. However, a governmentality approach enables an articulation that rejects the notion that the social categories of development are simply imposed from the outside on rural people, and instead explores the ways such categories are assimilated into local cultures and national imaginaries.

An analysis of the discursive terrain, or the "political rationalities", of international development programs is concerned to identify how particular forms of knowledge are embodied in particular actors such that intervention appears not as an external imposition, but as the natural expression of everyday interactions between people and groups (Li, 1999). As Merlingen (2004) 
elucidates, the purpose of examining rationalities is to uncover how the power of INGOs is "programmed and legitimized" (p.372) and to highlight the network of contingencies from which any given rationality emerges. A closely related purpose is to draw attention to how INGOs objectify reality into a terrain to be governed and how they discursively constitute phenomena as problems whose solution requires international interventions (ibid.). This level of analysis is concerned to draw attention to two levels of government articulated by Dean (1999): the episteme of government and the forms of identification (Dean, as quoted in Watts, 2003, p.14, emphasis in original). The episteme of government refers to the forms of thought and knowledge that are employed in governing, whereas forms of identification refers to the forming of subjects, selves, agents and actors in the production of governable subjects (ibid.)

However, political rationalities and programs of governance do not in and of themselves constitute governance; calculative practices, or technologies of governance, transform political rationalities and programs of governance into specific practices (Walters \& Haar, 2005; Rose \& Miller, 1990; Ngare, 2008; Li,1999, 2007). Governmentality interrogates the ways in which practices of governing pose certain problems of rule and asks who is to govern, who needs to be governed and how? (Walters \& Haar, 2005).

\section{Technologies of Government and the Problematization of Social Life in Community Radio}

\section{Projects}

A second aspect of international development programs that an analytic of governmentality highlights is what Foucault calls "calculations" or "political technologies". To distinguish and promote a particular conception of the world based on global liberalism, international civil society and human rights, international development organizations have 
engaged in constructing programs of governance for target nations. As Ngare (2008) argues in his study of East African mediascapes, a governmentality epistemology holds that liberal programs of governance "emerge from the problematization of social life" (p.114). This framework seeks to investigate how programs of governance pose an issue as a social problem and offer a solution based on a particular conception of the social world or political rationality (Rose, 1999). To use the Foucauldian approach of exploring the problematization of social life, the research focus gravitates around investigating "how the different solutions to a problem have been constructed" (Foucault, 1984, p.389). To improve populations requires the exercise of what Foucault identified as a distinct, governmental rationality - "a way of thinking about government as "the right way of disposing things" in pursuit of not one dogmatic goal but a "whole series of specific finalities"'" $(\mathrm{Li}, 1999, \mathrm{p} .306)$. Calculation is central because government requires that the right manner be defined, distinct finalities prioritized and tactics finely tuned to achieve the optimal result. In this process, aspects of social life that are to be governed must be characterized in technical terms; only then can specific interventions be devised.

In community radio projects in Nepal, technologies of governance comprise the identification of target communities, defined by a geographical determinant or a shared history of oppression, who would benefit from the establishment of a station. Furthermore, in order to develop programming that specifically addresses the needs of recipient communities, the deficiencies that need to be rectified - lack of literacy, human rights abuses, conflict, poverty, and so on - must be determined. Solutions are not unilaterally imposed from outside; they are negotiated through partnerships, facilitators and external advisors. Through these mechanisms, communities are empowered to identify and pose solutions to overcoming the difficulties that plague them. Success is measured by the introduction of assessment tools, community mapping 
and surveys. By enlisting communities at the local level and states at the national level, partnerships between INGOs and local governmental and non-governmental organizations invoke specific technologies of governance which help produce modern, self-disciplined citizens, communities and states that can be trusted to govern themselves according to liberal democratic norms (Abrahamsen, 2004). This thesis project aims to demonstrate how the political technologies that frame development encounters at one and the same time are influenced by and create discursive regimes in the communities they target.

This chapter focused on the need to expand conceptual analysis in the field of community media development. The trend in development away from large-scale, capital-intensive infrastructural projects towards small, community-based projects that stress the mobilization of grassroots efforts to improve livelihoods, has led to a dramatic rise in projects aimed at using community radio to promote development goals. The mandates of community radio "to assist social change and the expression and preservation of cultural identity, especially for marginalized sections of the community" (Jankowski, 2002, p.57) embody the discourses of contemporary development encounters, which focus on human rights, participation, inclusion and community. The idea of governmentality is useful as a way of understanding development as an international order (of "global governance") involving forms of power that do not require a state, bureaucratic or territorial framework. It sensitizes researchers to the possibility of resistance, which resides in the precarious linkages between the aspirations of the governors and the goals of those who are to be governed. As $\operatorname{Li}(2007)$ points out, claims to order are always fragile, contested, built on compromise; hegemony is not imposed but has to be worked out. By implication, there is a challenge here to "the deconstructive analysis of development discourse and its presumption of “order"' ( $\mathrm{Li}, 2007$, p.27), hegemony, and unified western agencies acting 
upon other societies through aid. Finally, a governmentality perspective appreciates the mutually constitutive relationship of language and practice, the complex interweaving of representation and intervention. It encourages researchers to explore international governance as a discursive project and a set of material practices: "The former concerns the invention and deployment of vocabularies to make governance thinkable, the latter concerns the use of techniques to make vocabularies practicable" (Merlingen, 2004, p.369) Thus, this approach brings to the fore the ways that the development of grassroots radio projects form part of the terrain within which discourses are appropriated and translated into action by local communities. In doing so, it serves to highlight the international organization and exercise of power as well as the technical means through which INGOs orchestrate and coordinate the conduct of communities.

The next chapter discusses the engaged research model that was utilized for data collection in the field. It explores the common epistemological commitments shared by community radio and participatory research. The following methodology section also works to link the assumptions that underlie engaged research models to the analytical perspective offered by governmentality's focus on the creation and dissemination of knowledge forms. 


\section{Chapter III - Realism or Idealism? \\ Community Engaged Research and Grassroots Radio}

The previous chapter examined the value of using a Foucauldian governmentality approach as the analytical framework for this study. An epistemic orientation enables an interpretation of community radio development projects that serves to redress static conceptions of power that typically define the field of inquiry. Community radio projects, when conceived of as development interventions, represent a form of "governmentality" in that they are implemented through calculative practices, prioritize specific "truths" that are arguably ideological in nature, and draw from a particular knowledge form. This chapter centers on the participatory research methodology used during the course of fieldwork. Given its focus on the power-knowledge relationships that emerge in participatory radio development programs, this project suggests that community engaged research is an effective methodology to employ in studies of community media for social change.

Participatory research designs are attractive for the study of grassroots media organizations. Engaged scholarship involves a common commitment to social and political change on the part of the researcher (Burgess, 2006), and is a valuable approach for community media research, both theoretically and epistemologically. The critiques of traditional ethnographic methods that underpin the move towards participatory research models are viable in studies addressing grassroots social movements. Theoretically, participatory media and engaged research seek to counteract sites of knowledge production that reinforce hierarchical power structures. Epistemologically, such perspectives view interactions in the world not as separate processes, but instead, as "relationships, which we co-author" (Reason, 1988, p.7). As Reason (1998) and Burgess (2006) suggest, epistemology is inextricably linked to participation - 
a claim that is at the heart of both community media and community engaged research. By putting the generation of the research questions, the design of data collection methods and the analysis of results in the hands of the researched, participatory research designs stem from a critique of methods that are potentially exploitative and damaging to the community within which the research takes place (Jankowski, 2002). A core value that is shared by engaged researchers and alternative or community media advocates and producers is "a biding respect for people's knowledge and for their ability to understand the issues confronting them" (BrydonMiller et al., 2003, p. 13).

The nature of grassroots media and community-based social movements demonstrate a need for research designs that take into account the patterns of social relations and the relationships between messages, senders and receivers (Putnam, 2001). Community engaged research is an effective model in this regard because participatory designs do not attempt to answer pre-determined questions; they aim to collaborate with community partners, in short the people who are most able to comprehend the complex and interconnected relations of politics and history as they manifest in a particular site of struggle, in the formulation and analysis of these questions.

A participatory research design was integral to the conduct of this thesis as it allows for exploration of questions regarding the use of community radio as a tool of empowerment and development for people who are marginalized along lines of caste, class, gender and ethnicity. Participatory research models, however, are not commonly used by graduate students, and not without good reason - the rapport and trust-building is more timely and precarious than more conventional methods, and, in a development context, there are often social, cultural and linguistic barriers to overcome. Furthermore, many grassroots organizations are founded upon 
participatory, non-profit principles and are engaged in continual struggles for survival. As such, they often do not have the time or resources to act as truly collaborative partners in research, and operate on different project and completion schedules from academics.

At the start of my MA candidature, I was concerned with community media's participatory and alternative ideologies as they manifested in regions struggling to overcome poverty and conflict. In particular, I was interested to explore the central place that community radio has come to occupy in international development schemes and the claims made for its ability to invigorate grassroots social movements, enhance democratization and facilitate the progression of the Millennium Development Goals. In my early research, I looked to the formative literature on participatory media and CR for development and drew on the work of Horchheimer (2001), Rodriguez (1999), Huesca (1994), Girard (1992), Atton (2002), Jankowski (2002), Tacchi (2005), Downing (2001) and Howley (2005). Given the inherent criticism and rejection of the hierarchical structures of knowledge production, the values underwriting participatory research are aligned with community media's emphasis on inclusion, participation and democratization.

During the early stages of my research, I was offered a fellowship to intern for 14 weeks at a community radio station in southern Nepal. The fellowship organization, The Advocacy Project, partners graduate students with local NGOs in developing countries. Interns are required to work with local organizations to design and implement programs to enhance the ability of organizations to use ICTs for social justice advocacy. I was placed with Radio Jagaran, Jagaran Media Centre's (JMC) community radio initiative. Given that I was working as an intern at the radio station, a participatory research design was useful to circumvent the objectivity demands required by traditional ethnographic approaches. Moreover, in terms of the theoretical analytic of 
governmentality that I am employing, it opened a space for me to explore the ways that journalists and decision makers at JMC and Radio Jagaran frame issues, concerns, visions and mandates. A great deal of this insight was gained through the ongoing collaboration and relationship-building that was necessary to fulfill my role as an intern.

This chapter discusses the questions that this project sought to address and the assumptions upon which the methodological approach was based. It describes the events that unfolded during the 4 weeks of research spent at JMC in Kathmandu and the 8 weeks spent at Radio Jagaran in Butwal, Nepal. Most importantly, it describes the methodological challenges and setbacks encountered in the field. First, it examines the potential that setbacks hold to highlight tensions inherent to participatory research that is carried out in a development context. Second, it discusses the potential engaged scholarship nonetheless holds for community media studies that are linked to development.

\section{Participatory Research}

There are two primary approaches that are utilized in community media research models - participatory research (also called Participatory Action Research or Community Engaged Research) and ethnography (both field ethnography and audience ethnography). Chapter two briefly touched upon the fact that the participatory democratic approach to studies of alternative media advocated by Rodriguez (2001) and Huesca (1995) endorses engaged research designs. This chapter intends to argue this point further by examining other community media scholars who have used variations of participatory models in their research. First, however, it is valuable to explicate the mandates of participatory research and the reasons it has become an important methodological contribution across scholarly disciplines. 
Reason and Bradbury's (2001) working definition for action research is "a participatory, democratic process concerned with practical knowing in the pursuit of worthwhile human purposes" (p. 1). It seeks to bring together action and reflection, theory and practice in participation with others (Brydon-Miller et al., 2003). Credit for the progression of this philosophy is first given to Kurt Lewin who coined the term "action research" in the 1940s to describe a process that "linked the cycles of theory, practice, and problem-solving" (Reason \& Bradbury, 2001, p.4) ${ }^{6}$. Tandon (1988) noted the rhetoric of community as 'involvement with risk of co-option', and compared this to 'authentic participation', where communities control the research process. McTaggart (1997) used the full-term 'participatory action research' to emphasize both authentic participation and relevancy of actions. Still other variations exist, such as emancipatory action research, participatory development communication, feminist participatory research, and community-based participatory research. Competing and oft contested views about participatory research have made it difficult to categorize in any neat or discrete way. However there are a number of shared characteristics and epistemological commitments that unite disparate viewpoints. Reason and Bradbury (2001) identify the following characteristics of participatory scholarship: it works toward practical outcomes to address the issues or concerns faced by individuals and groups in their everyday lives; it produces knowledge that contributes to the well-being of individuals and communities; it is based upon cycles of reflection and action which produce new knowledge forms; it is participatory and, as such, enables individuals to create knowledge for future development (Grosenick, 2008). These characteristics inform the epistemological commitments that distinguish action-based research

\footnotetext{
6 Lewin began constructing social experiments outside the laboratory with community members during WW II (Grosenick, 2008). This work had a specific social change focus and departed from the dominant objectivist, positivist approach to social science research. Later work on group cohesion and organizational management promoted the identification of problems and the cogeneration of possible solutions by groups learning from each other (ibid.).
} 
from traditional models: knowledge is created through action; knowledge is rooted in and must address real-world concerns; knowledge does not reflect a final, absolute reality, but is in a constant process of evolution and, as such, leads to deeper inquiry into more questions and ways of knowing. In this way, participatory research models trouble the common understandings of knowledge, expertise and research as they manifest within the realm of scholarly theoretical inquiry.

One stream of action research that is particularly valuable for my own study, and is typically drawn upon in studies of grassroots media that advocate for engaged research models, evolved within the field of development studies. This form of action research, epitomized in the development work of Freire (1979/1982) and Fals-Borda, (1991), highlights the need for engaged research designs that enable marginalized social groups to participate in their own liberation. Freire called for research that moves away from the models that replicate oppression (intentionally or otherwise) in the name of scientific objectivity. Similarly, Fals-Borda explicated the necessity for development researchers (many of whom were from privileged countries) to depart from the objectivist, scientific stance of the expert and assume the role of the advocate. The emancipatory action research approach advocated by Freire and Fals-Borda was readily adopted by development and post-development researchers in the 1980s and 1990s who saw its potential to redress growing concerns related to the paternalistic nature of developmental research practices and assistance programs in the post-colonial period (Park, 1992).

The model of action research, first developed by Lewin and later articulated in radical development studies, has been appropriated by a number of scholars of community radio. Horchheimer (2002) develops a variant of an action investigative perspective in his description of Participatory Development Communication, which he describes as a "dynamic process of 
goal-oriented structural and cultural changes facilitated by pro-active indigenous communication transactions amongst local peoples within a specific cultural context" (p.318). In terms of community radio development, participatory development communication is an action agenda that engages community members in the decision-making process about the types of content and programming and the means of transmission that they feel suit their needs and the social context within which they find themselves. Horchheimer expresses the importance of participatory projects in terms of their attempts to address the issues that studies on community-based media continually grapple with: How do we enlist people's participation? Who and when do we enlist and to what degree? What factors maximize the utility of grassroots communication? Who are the leading voices and whom do they represent? How is outreach into the community established and organized? These questions are critical for researchers to ask as they develop methodological frameworks within which to study the viability of community media projects. Horchheimer (2002) expresses the pitfalls of applying traditional ethnographic research methods to a community media study:

Many scholars who have studied and researched the processes and effects of communication have tried hard to be the instigators of social change, or the experts in how such change is instigated. This has been an arrogant position, one that aligns communication scholars and practitioners with institutionalized power in society, and it is a strategy that has yielded a lot of pain, most especially for those upon whom we have sought to deliver the fruits of our expertise (p.318)

Van Vuuren (2006) also advocates a participatory action research design for community radio research. In her study, a participatory methodological approach was necessary to answer the questions that formed the basis for her research on community radio. Van Vuuren's study articulates the need for research designs that takes into account an entire community and its pattern of social relations. The participatory research design that she employs rests on Freire's 
(1972) concept of "conscientisation", which she defines as "the empowerment of people through the process of constructing and using their own knowledge" (Van Vuuren, 2006, p.3).

In terms of the unique qualities which characterize community radio and the theoretical visions outlined by the leading scholars in community and alternative media research, this chapter will briefly outline a number of the strengths and weaknesses of a community engaged research design for a study focused on the potential for community radio to engender communities, give a voice to marginalized communities, and enhance development goals. The very nature of community media itself - mobilized according to bottom-up, do-it-yourself principles and organized and run by actors within communities and social movements mandates research projects that are formulated according to participation and involvement in the social context within which the media are produced, and its content disseminated and interpreted. The role of the researcher in this model is not one that imposes solutions from the outside, which may or may not be relevant or sustainable to the insiders of a community; rather, the experienced outsider acts as a facilitator (using Horchheimer's terminology) to assist community members in finding news ways to speak to each other and to help themselves (White, 1999). A participatory action approach is not engaged in merely analyzing the interpretation of media messages within a given social context; it seeks to become actively involved in the formulation, negotiation, and renegotiation of the messages and, as such, of the social context itself (ibid.)

Although participatory action research has proved a viable framework for studying community-based media (Rodriguez, 2001; Huesca, 1995; Janowski, 2002; Horchheimer, 2002, Van Vuuren, 2006) there are many possible difficulties and drawbacks in this approach. Without the formulation of a specific research design upon entering the field, the study may be subject to the self-interested motives of community members, which may not be immediately known by the 
researcher. Furthermore, participatory projects may take a long time to unfold if the participating community is in conflict, or if the community or organization has little capacity to carry out specific tasks due to low interest in the project, limited resources, or a fluctuating and transient volunteer base (Van Vuuren, 2006). These studies run the risk of becoming fundamentally anecdotal in nature, snapshots of a particular organization at a particular point of time in a particular social context, without developing the capacity to truly contribute to the social development of the community or the theoretical development of the discipline. Within critical research studies in the field of communication, anecdotes of this sort confront the methodological importance of generalizability in case study research (Horchheimer, 2002). It is important to note, however, that this is likely to be a potential drawback in any study of alternative media given its inherent heterogeneous and fluctuating nature.

My own experiences volunteering at community radio stations attest to these difficulties. These organizations are almost always under-funded and staffed by volunteers who have myriad other commitments and may not be able to regularly contribute to the project. However, these experiences inspired my interest to engage in a community radio study developed according to participatory research principles. Although I was aware of the limitations imposed by my relatively short period of engagement, I nonetheless held to a belief in Harcup's (2001) claim that even a small study has the potential to offer insight when it breaks away from the usual routine of freezing and dissecting communicative reality, seeking instead to follow and document "media-practices-in-motion" (Rodriguez, 2001, p.21).

\section{Methodological 'Failures' and Setbacks}

During the period of research, a participatory design was useful to developing questions 
regarding the use of community radio as a tool of empowerment for people who are marginalized along lines of caste, class, gender and ethnicity. Answering the call issued by Freire and FalsBorda, I opted to "reject the notion of an objective, value-free approach to knowledge generation in favour of an explicitly political, socially engaged, and democratic practice" (Brydon-Miller et al., 2003, p.13). Given that I was conducting research with groups that have faced severe social marginalization and discrimination, the principles of engaged research spoke to my desire to utilize a methodology committed to progressive social change.

I had little indication of what my work would entail once I arrived in Nepal. For this reason, I rejected planning my study in advance so that I could remain open to previously unforeseen avenues of inquiry. This lack of determinacy, however, does not only create considerable anxiety and uncertainty, but it also often leads to pitfalls in the initial stages of project development and speaks to one of the tensions at the heart of participatory research models. As Burgess (2006) discusses in her account of a doctoral Participatory Action Research project, graduate program protocol often limits the potential to carry out truly participatory research. Graduate students are required to take control of the research process in order to begin demonstrating their 'expertise' - yet, this standpoint is often contrary to participatory action principles. Limited time and resources, lengthy ethics approval regulations, and standardized expectations with regard to research competency can compromise the defining characteristics of community engaged research. For my thesis project, time restrictions coupled with the rigours of undertaking research in a developing country limited my ability to effectively implement a methodology according to participatory research principles.

One of the most confounding challenges I faced became apparent soon after my arrival and remained throughout the duration of my placement: the partner organization was not certain 
what it wanted from my participation. I had intended to reside in Kathmandu for the first week of my placement to work with JMC to establish my work plan, then to spend the remaining 12 weeks in Butwal at Radio Jagaran. However, I arrived in Nepal during a period of intense political upheaval: the 200-year old monarchy was recently overthrown and the country was in the early throes of drafting a new Constitution. As a result, social, cultural and ethnic groups that were socially excluded under the monarch lobbied for representation under the new federal republic. For the first month of my stay in Nepal, there were continual strikes and, as a result, all travel in and out of the capital halted as protesters attacked any public vehicle that intended to pass through a strike zone. Given that it had not been anticipated that I would spend 4 weeks at JMC, there was little for me to do there. Yet, this proved to be a valuable period for building trust among the staff at JMC and for meeting radio advocates working in Kathmandu. At the same time, it significantly delayed the advent of my formal research. Furthermore, relationshipbuilding is a slow but crucial aspect of collaboration in Nepali society. When I did finally arrive in Butwal, I was required to being this process again with my new colleagues at Radio Jagaran. Another challenge that quickly became apparent had to do with trying to juggle the expectations of the Fellowship organization, The Advocacy Project, alongside those of the local partner (JMC). I often had to sacrifice what I considered to be my research goals to manage my responsibilities as an intern. Given that Radio Jagaran was newly established, The Advocacy Project did not have a clearly defined internship project developed with the station, though they had sent interns to JMC in previous years. As a result, the substantive aspects of my role as an intern were ambiguously defined from the outset. During the time I spent at JMC in Kathmandu, internship duties often included activities that I did not feel contributed to the co-generation of knowledge, such as writing and editing English language grant proposals and news articles. One 
of the challenges that quickly emerged speaks to the difficulty of utilizing an engaged research model in a foreign context: navigating unfamiliar cultural codes of conduct often confused and mystified interactions with my Nepali colleagues. Nepalis are unabashedly agreeable people. As a result, participants would often answer my queries by telling me what they thought I wanted to hear. It was frequently difficult to discern whether a response was a true representation of what the research participant/subject thought of an issue or whether it was the manifestation of a cultural code of respect and deference, and indicative of a desire on their part to be nonconfrontational.

The lack of definition with regards to my internship, however, proved valuable once I arrived at Radio Jagaran, as management staff were happy to let me decide what to do with my time. Although this enabled me to engage in activities that I believed were beneficial for my research, such as visiting other radio stations in the area, accompanying journalists on field visits, and conducting interviews with radio station staff and community members, I felt it ultimately did not measure up to the ideals of participatory research as a truly 'collaborative' undertaking. I often consulted on training practices and led workshops focused on radio documentary techniques, but felt that I did not have enough experience or knowledge about the community to adequately contribute in this way. I believed that assisting senior staff at the radio station to develop and implement their own training sessions was more in line with the values that underwrite participatory research. However, there was an overwhelming perception that I possessed expertise in radio production that surpassed the skill sets and expertise of station staff. Holding to a belief that "a true communication professional does not express anything...(S)he helps people to express themselves" (White, 1999, p.317), this at times felt contrary to the perception I held of what engaged research entails. I felt that these workshops did not adequately 
contribute to knowledge generation, primarily because the need for translation, the perception that my expertise was greater than that of local actors, and my inability to teach without relying on academic jargon, resulted in awkward interactions with the study participants. Early on, I recognized that the freedom to define my project was limited by difficulties with transportation, linguistic barriers and a lack of adequate planning, which impeded well-intentioned plans to integrate with the daily activities of the radio journalists and led to fluctuating "iterations of insider-outside positionality" (Burgess, 2006, p.419).

Upon arriving at Radio Jagaran, I envisioned that my study would investigate the following questions raised by Horchheimer (2002): Who participates in community media and which groups in a community are more likely to participate than others? How do individuals and groups from the community participate? How do community media work to advocate for marginalized communities? What is the nature of the connections between the community broadcaster and its host community? I intended to meet my research aims by working with station staff to collectively develop strategies to assess and enhance their advocacy goals. Adhering to the normative stance that community engaged research is a process of "choosing and framing an issue" (Reason \& Bradbury, 2001, p.12), I anticipated that observing the ways participants framed their objectives from their particular points of view would form the basis of an evaluation that could inform my own research objectives. However, as illustrated by the methodological setbacks described above, these goals became little more than lofty aspirations. A lack of understanding on the part of the partner organization with regard to my goals, combined with communication difficulties, time constraints, and the assumption of expertise that accompanies the subject-position of "development worker", undermined the potential for my research project to live up to the principles of participation and action mandated by engaged 
research philosophies.

\section{The Contribution of Engaged Research to Community Media Development Studies}

Although there are clearly demonstrated difficulties, contradictions and tensions that arise when carrying out participatory projects, the principles of engaged research nonetheless hold a great deal of potential for scholarship on community media in development. Given the focus on non-hierarchical forms of knowledge production and the enduring respect for people's ability to understand the issues that confront them, engaged research models have a great deal of potential to broaden the scope for graduate research with grassroots media organizations. There are three primary reasons that engaged research was a fruitful approach for this study, despite challenges encountered in the field. First, engaged research challenges the notion of a positivistic view of knowledge, which posits that in order to be credible, research must remain objective and valuefree (Brydon-Miller et al., 2003). This is an important challenge in both development and community media fields of inquiry and practice. An action-based engaged research design explicitly works to contest the reliance on western development experts that continue to form the basis for many projects in Nepal. The central features that define community radio as such rest on analogous principles - participatory media eschew professionalism and promote respect for people's ability to tell their own stories in their own terms. The ability for engaged research to reject positivistic models of knowledge generation enables projects to call into question normative understandings of expertise in development, media and research arenas.

A second contribution has to do with the focus on voice in participatory research. With their shared emphasis on participation, both community radio and engaged scholarship focus on the connection between voice and knowledge. Researchers and advocates of participatory media 
posit that voice and, in turn, voicelessness, is inherently linked to empowerment and disempowerment. According to this perspective, voice is inextricably linked to sites of power and knowledge. Similarly, Putnam (2001) connects the goals of participatory research to the notion of voice: “(voice) embodies who can speak, when, and in what ways...this perspective (participatory research) highlights the ways voices become distorted through power relationships and embedded in ideology and domination and ways to gain access to and create opportunities for participation" (p.41). Participatory research designs, then, carry similar values and mandates as those promoted by participatory media. However, where alternative media research has been endemically rooted in false dichotomies of global versus local, powerful versus powerless, topdown versus grassroots, engaged research seeks to embrace the tensions that arise from difference and probe the paradoxes and contradictions between them (Putnam, 2001). In this way, community engaged action research is useful for the field of community radio because it holds the potential to move empirical studies away from the dualisms that have historically plagued inquiry into alternative media.

A third aspect of engaged research that allowed it to be a useful methodological tool to employ for this study on community radio in Nepal contests the often levied criticism that participatory models do not lead to theoretical advancement of the field. The focus on voice and participation in accounts of community radio and development, and the subsequent use of voice as a metaphor for the field in community engaged research, implicates governmentality as a useful theoretical frame to interpret the epistemological underpinnings of grassroots media projects that aim to empower disenfranchised populations. The uncertainty of my project, the unexpected contingencies I faced in the field and the epistemological commitments of participatory research subsequently led to the theoretical framework that grounds my analysis. 
Governmentality allows for new ways to reconceptualize cycles of action, reflection and participation in terms of the way they articulate shifting terrains of power, consent and subjectivity in development encounters. As outlined earlier, within the field of development studies, participatory research draws on Paulo Freire's concept of "conscientisation" (Van Vuuren, 2006). Similarly, a Foucauldian perspective on epistemology opens a space to interrogate the assumptions of participation and empowerment that lie at the heart of participatory research, oppositional media and development.

This chapter focused on some of the challenges and pitfalls of participatory research that I experienced in the field and attempted to reconcile such difficulties in light of the potential that engaged models hold for community media research. Given that I was conducting research in the middle of a grassroots social movement that was struggling for equality in a rigidly stratified Hindu society, the principles of action research spoke to my desire as an activist to contribute meaningfully to progressive social change. However, from the perspective of being a graduate student and scholar, there are tensions and challenges to be reconciled. In engaged research, the field of inquiry often becomes obscured as student researchers struggle to navigate complex role hierarchies, to mitigate tensions that arise from competing expectations and to engage in the reflexive self inquiry required to overcome what oftentimes appears as a lack of demonstrable outcomes.

With respect to the short duration of field research undertaken for this project, validity rests on its outcomes as "first-person" engaged research, summarized as: "living in the inquiry, practicing new behaviors, reflecting-in-action, conceptualizing new learning about one's identity, staying present to a range of emotional responses, and cultivating a quality of critical humility" (Marshall \& Mead, 2005, p. 241). While I was not able to explore the transformative potential of 
second- and third-person research ${ }^{7}$, the research contributes to a theoretical reformulation of the ways empowerment and participation manifest in development communications. This theoretical development was possible given the shared epistemological commitments and interpretations of power shared by community media, engaged research and governmentality, which all reject positivist understandings of suffering and oppression in favour of an appreciation of the fact that "science is socially constructed (and therefore) subject to reinterpretation, revision and enrichment" (Fals-Borda, 2001, p. 28). The following case study emerged out of the cycles of reflexivity and action that characterized my daily interactions with community radio practitioners and advocates in Nepal.

\footnotetext{
${ }^{7}$ Reason and Bradbury (2001) describe second-person research as a means for contextualizing a relationship with a community of research and third-person research as work for people in the wider context, where researcher and community become both the data and data collectors in a combined reflexive journey
} 


\section{Chapter IV - Grassroots Media as Development Encounter:}

\section{A Case Study of Dalit Community Radio in Nepal}

At a recent conference on the state of community radio in Kathmandu, Raghu Mainali, a well-known Nepali advocate, expressed discontent over the current field of inquiry into radio projects: "The feedback we (practitioners and advocates) get is that everything is good...but we are at a crossroads (in community radio development). There are four ways we can move: one is politicization, there is commercialization, the third is project-oriented NGO-ization, and the fourth is true community radio." 8 There is a wide body of literature that critically explores the history of development intervention in Nepal, yet much of the research that focuses on community radio development contains, for the most part, "uncritical, laudatory biographies" (Hamilton, 2004). This is paradoxical given that there is a similar rhetoric of empowering people at the grassroots in contemporary development projects whether they aim to produce radio, develop information and communication technologies (ICT for Development initiatives), facilitate micro-enterprise projects or enhance agricultural productivity.

For instance, the United Nations Development Program (UNDP) in collaboration with the Australian agency for international development (AusAID) provide funding to " support the development of forest-based enterprises amongst the Community Forestry User Groups and the vulnerable groups from Sindhupalchowk and Kavrepalanchowk (central region) districts, where the concept of community forestry was pioneered through over 40 years of Australian assistance" (UNDP website). The project explicitly claims to develop individuals from marginalized groups, including women, youth and Dalits, into "microentrepreneurs" and to facilitate greater financial sustainability in poor villages (ibid.). Swiss Development Cooperation

\footnotetext{
${ }^{8}$ AMARC Social Impact of Community Radio, Kathmandu, July 18, 2008. Raghu Mainali's presentation was translated by an interpreter
} 
(SDC) in Nepal emphasizes rural development "with projects and programs in rural infrastructure, agriculture, forestry, skills development, and social services" (SDC website). It similarly focuses on "democratic development and participation" (ibid) in the implementation of development projects. Although such projects are based upon analogous discourses of community participation and grassroots mobilization that form the cornerstone of community radio and ICT for development programs, where communications-centered projects are celebrated for enhancing development goals, there is wide-scale criticism aimed at more traditional initiatives. ${ }^{9}$

Adikhari (2000) adequately summarizes the criticisms of development projects in Nepal when he argues: "how our country (Nepal) is experiencing its so-called magic of development, decentralization, economic upliftment, and local self governance all amount to just bureaucratic jargons. They are adornments employed by ghost speechwriters for ministries. They are jargons that turn people at the grassroots into parrots for they do not know what these actually mean" (p.92). Perhaps the lack of critical inquiry into donor-led participatory radio projects along similar lines is due, in part, to the fact that the corpus of literature is fairly small, and that a great deal of the research conducted has been done so in affiliation with agencies that act as donors or bilateral partners in community radio initiatives (i.e. UNESCO, PANOS, Equal Access among others), whose own interests, ideologies and worldviews cannot be bracketed from analysis. It is also likely attributable to the field of participatory media more generally which, as outlined in Chapter I, posits community radio as a herculean force of resistance, empowerment and social transformation. In an attempt to refocus inquiry into Nepal's independent FM radio sector in a way that gives due weight to the complex interconnections of power and knowledge as they

\footnotetext{
${ }^{9}$ In Nepal, development (bikas) was initially conceived of primarily in terms of creating infrastructure - it connoted things. Development was equated with schools, agricultural technology, roads, water pipes, and health facilities (Pigg, 1992). It is only relatively recent that diffuse notions of empowerment and participation have become the basis for development projects.
} 
manifest in development projects, I follow Pigg's (1992) argument that analysis of the role of development should not be limited to asking the same questions that institutions themselves ask. Development organizations often formulate research projects surrounding issues like "social inclusion, capacity development (and) exit strategy for projects" (UNDP, 2008, p.3). Questions focus on matters of community capacity, modes of participation, availability of funds, social impact and financial sustainability (Tacchi \& Kiran, 2008). Yet, left out in discussions of development within the framework of development discourse "is analysis of the ways the activities of development activities themselves shape Nepalese society as a whole" (Pigg, 1992, p.45, emphasis in original).

Chapter II pointed to the role of rationalization as one context of practice that has yet to receive attention in the literature on alternative, participatory media. Hamilton (2004) defines rationalization as:

the denial of individual human creative practice by coercive limits and pressures that make any given practice efficient, precisely calculable, predictable, and thus controllable (p.47).

According to Hamilton, a focus on rationalization avoids the idealism of uncritical celebrations of practice and the essentialism of taking the determinant context as static and inviolable.

Drawing upon a governmentality framework, this case study broadens inquiry into participatory radio in Nepal by examining the rationales upon which radio development projects are based and the epistemological implications they have in the communities they aim to empower. This theoretical positioning enables an interpretation that interrogates accounts of participatory media development that laud its ability to facilitate democratization and empowerment among marginalized social groups while, at the same time, problematizes critiques of development that conceive of power as domination.

This chapter examines the set of relations framed through the discourse and practice of 
development as they manifest in donor-led community radio initiatives in Nepal. It argues that a Foucauldian understanding of governmentality as the attempt to constitute governable subjects is an accurate guide to development as a project of rule, but that the actual accomplishment of rule owes as much to the understandings and practices worked out in the contingent and compromised space of cultural intimacy as it does to the imposition of development schemes and related relations of power $(\mathrm{Li}, 1999)$. In this sense, "development", conceived of as an assemblage of relations between grassroots organizations, NGOs, state and international actors, is explored in terms of the way it operates as an attempt at community self-fashioning and rule within a particular territorialized space. As such, power and rule are considered always as fragile and contingent accomplishments. Ferguson argues that development discourse has the effect of "depoliticizing everything it touches" (1994, p.xv). Yet, a question remains: whom does the discourse affect in this way? Categories that manifestly do not fit, plans that fail, and compliance withheld or withdrawn expose the fragile nature not only of the government agencies promoting a development program but of the very idea of "the state" as knower, arbiter, and provider for "the people."

Taking as a given that power is a resource that produces knowledge forms (Ngare, 2008), the following case study will examine the community radio sector in Nepal both in terms of how INGO expectations with regards to funding are influencing decisions relating to media programming and the frameworks that are adopted to evaluate impact. This will comprise analysis of the observations and interviews that were conducted during the fieldwork component of this project. Interviews with radio journalists and advocates and observations collected at Radio Jagaran will be compared with the mandates and visions of international partners (INGOs and IDAs) that provide support for local organizations. Support typically consists of financial contributions, technical support and training, but also includes the legitimacy that comes from 
inclusion into Nepal's national project of development and the international human rights community. The development agencies focused on here will be the Embassy of Finland, Action Aid Nepal, and SDC Nepal because they have ongoing partnerships with JMC and helped to facilitate the start-up of Radio Jagaran. ${ }^{10}$ This analysis will attempt to explore the often invisible, complex and fluid power relationships at work in INGO and IDA-led community radio development projects. The following analytical questions will guide the analysis: What is the relationship between the donor community's definitions of successful community radio programming and the definitions of community activists? Are definitions of success, failure and impact promoted by international agencies adopted by practitioners and activists? Or are they negotiated and reformulated? At the level of implementation, to what extent do assumptions within the discourse of international development and the rhetoric of human rights underwrite the staffing, programming and content selection of stations at the local level?

As outlined in the second chapter these questions will be explored by focusing on two aspects of a theory of governmentality - the discursive and the technical - in terms of the ways they manifest in radio development initiatives. This analysis does not attempt to critique radio development programs in terms of the subjugation or domination of local populations but, rather, to highlight the epistemological tensions that are always present and continually negotiated in development programs. Discursive elements include conceptions of universal human rights, community, progress, inclusion and participation which form the basis for the moral valuations

\footnotetext{
${ }^{10}$ SDC has been involved in development cooperation in Nepal for more than 50 years. The current SDC strategy supports "inclusive democratic state-building" and promotes "human security and socio-economic development". SDC has two primary intervention priorities: "contributing to the consolidation of the peace and state-building process" and "contributing to inclusive, connected local government" (SDC website). ActionAid Nepal is an international anti-poverty agency that has been working in Nepal since 1982. AAN changed its approach from direct service delivery to partnership with local NGOs in 1996. Thematic priorities are "women's rights", "education", "food security", "HIV/AIDS", and "peace building" (ActionAid Nepal website). The Finnish Embassy has a long-standing bilateral aid relationship with Nepal. Water, sanitation, education and environment are the main sectors for development cooperation (Finnish Embassy website).
} 
ascribed to community radio projects that aim to overcome marginalization. The technical element of international development projects comprises the "calculations" and "problematizations" that make a space, and the subjects within it, thinkable and governable. In participatory media development, technical elements include the definitions of problems that require intervention, the establishment of partnerships, the reliance on experts, and the conceptual tools of standardization, evaluation, impact assessment and performance benchmarking. The aim of this paper is not to evaluate community radio projects in Nepal in terms of whether they achieve their stated objectives. Rather, it is to use a particular case study of a radio initiative as context for conceptual analysis. Even though there is evidence that a considerable amount of participatory communication is taking place in Nepal through community radio, this case study neither attempts to justify the program nor present data toward this end. Rather, it aims to initiate a theoretical approach capable of elaborating the nature and scope of participatory radio and to locate the role of international and local development agencies in the establishment of community media projects. Before moving to the reporting and analysis of findings, it is useful to articulate the context within which community radio in Nepal has been embraced within the discourse of development.

\section{Current State of Community Radio in Nepal: Issues and Challenges}

Community radio in Nepal is lauded among international development agencies for its role in ending a decade long civil war, for resisting a period of direct rule that resulted in total media censorship, and for promoting humanitarian and development aims in rural areas. Mainali (2007) defines four types of community radio in Nepal, differentiated in terms of ownership: 
NGO, Cooperative, local government and educational. ${ }^{11}$ The prefix "community" when applied to a description of FM stations in Nepal is ambiguous, and many advocates criticize the sector for not living up to the mandates of participatory radio:

Despite large numbers of stations that use the label 'community radio', many of these stations would score low or fail if a well thought out set of criteria - including those principles espoused by Nepal's own community radio groups - were applied to their operations. This inconsistency is exacerbated by the absence of definitions, standards and criteria as well as the means to enforce them (Pringle \& Shuba, 2007, p.23).

There is confusion over what exactly community radio is and whether current practices reflect internationally accepted standards. One of the most crucial concerns levied has to do with community representation and claims of empowerment. There is consistent concern that radio stations are primarily run by elite ethnic and caste groups in all forms of ownership (ibid.). Domination by elite groups raises the question of whether community radio reinforces inequality and serves to empower the already empowered or whether it truly serves to catalyze social change at the grassroots. There is significant tension between the universally expressed claim that stations are working to enable marginalized social groups and to "give a voice to the voiceless" (UNESCO, 2002) and the fact that the extent to which traditionally underrepresented groups participate in senior level decision-making capacities is extremely limited (Pringle \& Shuba, 2007). As Pringle and Shuba argue, "Most community radio stations do not have any clear vision - beyond a sense of "mission journalism for social transformation"” (p.17). Few stations have any kind of institutionalized or written procedures or policies that reflect 'participation' of communities and ensure the representation of local peoples at decision-making levels (ibid.). Steve Buckley, president of AMARC, similarly questions the degree to which

\footnotetext{
${ }^{11}$ See appendix $3.68 \%$ of stations are owned by NGOs (many of which are "special interest stations"), $25 \%$ are cooperative (where community members are shareholders), $4 \%$ are affiliated with journalism and mass communications colleges and $3 \%$ are owned by local governments (elected village level committees). (Mainali, 2007, Pringle \& Shuba, 2007).
} 
principles of representation and inclusion are actually adhered to in practice:

It (the community radio sector) claims to really give voice to the poor and marginalized, but this is not so well represented in practice by continuing absence of people from lower castes and from other disadvantaged groups in both production and management (personal communication, July $15^{\text {th }}, 2008$ ).

There is also significant criticism of community radio stations in terms of content. Along with community ownership and local representation, the ability to provide content that is produced by community members and truly reflects the needs of a given community is a central feature of participatory radio. However, at the level of content, inclusiveness and representation is also an issue at most FM stations in Nepal. Given that content is inextricably linked to decisions about programming, imbalances in ownership and management influence what types of content are prioritized and from what perspective (Pringle \& Shuba, 2007). One concern that is frequently raised is the reliance on syndicated programs that are created by Kathmandu-based production houses and development agencies and aired by a large number of FM stations throughout the country. Although most advocates feel that syndicated programs can be valuable in terms of informing local communities about national news and as means to generate revenue (Pringle \&Shuba, 2007, Rijal, 2008) many stations are becoming overly reliant on centrally produced, shared content. ${ }^{12}$

\section{The Role of External Donors in Community Radio Projects}

Few would deny that the intentions of development programs are often benevolent. Many do not appear to be driven by ideological or colonialist ambition, but as the natural expression of people and groups to improve the circumstances of themselves and others. This does not,

\footnotetext{
${ }^{12}$ Syndicated programs are typically "social issue" programs that are produced by production houses (usually affiliated with international development organizations) in Kathmandu. Production houses pay FM stations to broadcast the content. Some organizations, like Equal Access are working to partner with stations and build the capacity to develop content at a local level rather than enforcing content from Kathmandu (Rijal, personal communication, July $23^{\text {rd }}, 2008$ ).
} 
however, negate the power dynamics operative in development initiatives. The claim to expertise in optimizing the lives of others, for example, is an expression of power that merits careful scrutiny (Li, 1999). Through planned objectives, standardized missions, progress reports, and impact assessments, donor-led community radio projects structure a field of action - "they modify processes...they make certain courses of action easier or more difficult" (ibid.,p.17).

Virtually all non-profit, FM stations in Nepal have received international assistance in some form or another (Pringle, personal communication, April $9^{\text {th }}, 2009$ ). Local forces have generally driven community radio development in Nepal with international agencies and donors in a supporting role, typically in providing capital investment and helping to develop both local and national capacities. In many cases, assistance takes the form of start-up funds or grants to cover operating costs, however support also often extends to covering the costs of equipment, providing technical assistance or hiring experts to fill advisory and consultancy roles (ibid). In radio development initiatives, external donors typically enact the position of "trustee" (Li, 1999). Li (1999) suggests that the role of trustee "is to enhance capacity for action, and to direct it" (p.4). This role is evident when looking at the Finnish Embassy's evaluation of its development projects in Nepal. In defining the relationship between the embassy and its local NGO partners, the report specifies that "it is efficient to use core funding combined with program funding for NGOs that have potential and can be closely monitored to build the capacity of the organization and the staff" (p.19, emphasis added). The report further explains that "more monitoring of projects is needed - NGOs require mentoring and feedback to develop the organization and the capacity" (p.31). The Swiss Agency for Development and Cooperation (SDC) in Nepal has analogous project mandates. SDC aims to "strengthen the capacity of rural people to maintain and improve their livelihood" (2006, p. 23). Similarly Action Aid Nepal (AAN) focuses its development activities on "organizing and building capacity of rights holder groups to enable 
them to claim their rights and build proper access to and control over productive resources and decision-making processes that have a bearing on their life" (Country Strategy, 2005, p.13). ${ }^{13}$

In contemporary development practice in Nepal, the position of trustee is one that is negotiated, though often in an uneven terrain of power, through a reliance on 'partnership' (Abrahamsen, 2004). Partnership, and the related discourse of 'participation', is a theme that has become the sine qua non of development rhetoric since the late 1990s. Throughout the developing world, aid relationships have been recast as partnerships between donor and recipient countries, with donors attesting that they no longer seek to impose their vision of development on poor countries but instead wish to be partners in strategies determined and 'owned' by recipients themselves (ibid.). However, even commentators supportive of the general thrust of partnerships frequently draw attention to the difficulties in achieving 'genuine' partnership based on equality and mutual respect in a context where "one party is in possession of the purse and the other the begging bowl" (Abrahamsen, 2004, p.1454); other voices maintain a colonialist critique by arguing that partnerships are simply a disguise for continued donor dominance of developing countries. Understanding of the ways partnerships enact transformations in local contexts requires a novel analysis of power relations. Most assessments of partnerships tend to analyze the capacity of certain actors to control the actions of others and thereby construe power as domination. A broader conceptualization of power takes into account techniques of cooperation and inclusion and explores how strategies of partnership can act as forms of power through "the production of specific forms of legitimate agency" (Abrahamsen, 2004, p.1456).

The government of Nepal endorses participatory development and partnership with international agencies in order to move away from earlier top-down strategies (Stone, 1989).

\footnotetext{
${ }^{13}$ The Finnish Embassy, AAN and SDC have established partnerships with JMC and were the primary donors that provided funding and equipment for the start-up of Radio Jagaran
} 
Partnership operates on a number of levels in the community radio sector- there are partnerships established between international organizations and the local NGOs or cooperatives that run radio stations, between the $\mathrm{NGO}$ or cooperative and the radio station, and between the radio station and community representatives or special interest organizations. There are many dilemmas and contradictions that become apparent when examining the notion of partnership as it manifests in community radio development projects. These tensions are highlighted by Stone's (1989) analysis of development intervention in Nepal, when she asks: "How is this style of selfreliant, egalitarian, participatory development to work in a region like Nepal, where principles of social hierarchy and human interdependence are so culturally pervasive?" (p. 208).

One of the tensions that manifests in partnerships between international development agencies, NGOs and FM stations has to do with the fact that "radio stations end up being run and invariably accountable to another organization" (Pringle \& Shuba, 2007, p.30). This creates a proxy ownership where the parent organization provides financial and other types of resources and, as a result, the radio stations themselves are not truly independent, nor directly accountable to the community (ibid). This echoes one of the criticisms of development interventions levied by Shebdi (2004) who suggests that, "[ $t]$ he attitude of foreign aid is greatly affected by the Nepali sense of paternal dependency. When this passive paternal dependency is applied to foreign aid, the only active agent of development becomes the foreign party, who then must supply the resources, the administration, the imagination to plan, and the motivation to make it all work" (p.241). Although it is problematic and highly paternalistic to claim that Nepalis are only ever passive recipients of aid without agency to imagine or be self-motivated, a passive relationship to development interventions amongst target communities has been identified. Stone (1989) and Pigg (1992) suggest that this is due in part to the contrast between bikas, as villagers perceive it, and the ideals of development promoted by national or international organizations. In 
considering how to achieve modernization or "development", villagers are often not thinking in terms of changing attitudes or behaviours but are concerned with the rather more material needs of bringing electricity and basic education, transportation and medical facilities to their villages (Pigg, 1992; Stone, 1989). When speaking with community members about their local radio stations, many felt that radio was important, but few would express it in terms of participation or empowerment in any kind of cultural or political sense. People did report an enjoyment in getting local news, local language programming and listening to educational programs-but they also reported being motivated to listen to the radio for entertainment. During interviews conducted with participants at a radio workshop for Dalit youth, many expressed that their favourite radio program was Saathi Sanga Manka Kura ('Chatting with My Best Friend'), a syndicated program produced by Equal Access Nepal that aims to "empower youth with the knowledge and life skills to deal with the difficult issues they face in their daily lives, with the specific objectives of preventing HIV infection and intravenous drug use" (Equal Access Nepal website). Given that the show is produced at a production house based in Kathmandu, within a normative understanding of community radio, it arguably has little connection to the communities in which it is broadcast.

While it is undeniable that partnership happens in Nepal's development projects, it does not entirely manifest in straightforward egalitarian, non-hierarchical forms. Although known for its cultural diversity, many regions of the country can be characterized by the predominance of hierarchical principles, which underlie local caste and kinship systems and permeate all interpersonal relationships. In the context of rural Nepalese village life, an important feature of hierarchy is that it entails and expresses interdependence between persons and groups (Sharma, 1978). This interdependence is expressed not only in a number of ideological and ritual ways (Stone 1983), but also in economic terms. Caste and kinship hierarchies, for example, prescribe 
patterns for the distribution and exchange of many goods and services. In several contexts, including those outside the realms of caste and kinship, one's access to desired goods and services very much depends on one's ability to establish, maintain, or manipulate one's position within a larger social hierarchy. As villagers perceive that access to resources within their rural communities has traditionally depended on personal relationships and positions within social hierarchies, so they perceive that "development" is going to work this way too (ibid). Thus development, which comes from outside, "happens" when the community contains high status members who have important social links with the external world of resources. As Stone (1989) illustrates, villagers are quite eager to "link up" with persons and institutions in the outside world in an effort to better their lives.

In my own research, I discovered similar motivation and eagerness to engage in development projects on the part of local villagers. Local communities warmly received me when I would visit them to discuss what they thought about the role of radio in their villages. I assisted in the implementation of a workshop to train village women to recognize and diagnose the symptoms of Uterine Prolapse, a post-partum disorder that affects a great number of women in poor villages. The women at this workshop were eager to partner with organizations to receive preventative and treatment-based health training. Other development workers in Nepal express similar experiences in their interactions with local communities. In their account of an appropriate technology project that aimed to build a washing machine as part of a bicycle development initiative, Mario Bruzzone and Aaron Whieler of Wrench Nepal (2009) claim:

It was clear to us that the project was a source of pride for the students who were sanding parts, reaming holes to larger diameters, and fitting pieces together...Yet another indicator of the project's appropriateness to the community was desire for imitation. A local resident who had seen our process asked the welder in town if he could make her a washing machine of her own; the welder asked us to leave the machine with him so he could study it (p.6). 
Although there are clear indications that local communities are eager to participate in development programs, the problem is that, especially for poorer and uneducated villagers, their experience has led them to believe that they lack the social status to command the respect of the outside world, or the ability to pursue meaningful interaction with it (Stone, 1989). In this way, there are indications that development is often not able to circumvent local hierarchical structures, which enable or disable active participation.

For the reasons expressed above, partnership in community radio projects often manifests in ways that contradict the normative notion of "partnership" as it appears in development rhetoric. This tension has led to a criticism of community radio in Nepal among local and international community radio organizations in terms of the continual partisan affiliations that historically characterized the media sector. Steve Buckley, president of AMARC, suggests that partisan broadcasting remains a significant concern:

The emergence of partisan broadcasting is one particular problem and there's a danger that the setting up of some partisan radio stations is going to encourage others so that every political party is going to think of getting their hands on a radio station (personal communication, July $14^{\text {th }}, 2008$ ).

For these reasons, many stations are criticized for not being truly rooted in nor accountable to the communities they are meant to serve. These contradictions are, in part, due to the manifestation of an international mandate of development as it is conceived of and negotiated in a local context. As Buckley suggests, There are deep-rooted divisions, hierarchies, forms of discrimination and other forms of social injustice in Nepali society and it would be misleading to say that those don't also appear to some extent, greater or lesser, in various forms of community radio (ibid).

Partnership, while lauded and often established in principle, is much more complex in the actual practice of radio development in Nepal. While it is undeniable that international development 
agencies possess economic and normative power in partnerships with local organizations, partnership only truly works when it coincides with already established social orders in the target community. Within this general framework, "rule and its compromises are enabled and constrained by the sedimented histories, contemporary social forces, and international resource flows configuring a particular national arena" (Li, 1999, p. 12).

As outlined above, the role of donor agencies in the history of development in Nepal is a contentious issue. However a cursory review of the literature specifically focused on community radio development that has been published over the past ten years provides scant evidence of critical analysis into the role of trustee that development agencies have adopted in project design and implementation initiatives. ${ }^{14}$ There appears to be little indication that there are people or organizations that question the validity of radio projects that are led by, and answerable to, national or international non-governmental organizations and agencies. Critiques typically focus on issues of sustainability or concerns that support for stations that claim to be inclusive, but are not representative of local marginalized groups in practice, reinforces traditional lines of social dominance (Pringle \& Shuba, 2007). However, in speaking with community radio advocates and practitioners, it becomes evident that many of them believe that the social missions of some stations appear to be little more than lofty declarations to appease donor agencies and civil society organizations operating within the region. During an interview, Nirmal Rijal, Country Director of Equal Access Nepal, expressed one of the major problems with a community radio sector that is reliant on donor-supported initiatives:

Sadly the aim is (often) not to serve the community; it's to start something. That has been the trend because we've seen people just get attracted because there is funding. I won't name the organizations but there is funding from organizations to get started,

\footnotetext{
${ }^{14}$ One exception is Pratyoush Onta of The Martin Chautari Foundation who has published a number of reports that critically address the role of NGOs in community radio projects. Criticism focuses primarily on issues of financial sustainability and editorial independence. It is conceivable that other researchers are doing similar work, but publications are often difficult to access. Onta's Papers can be accessed from http://martinchautari.org.np
} 
for equipment support and for some running costs, so that has been the attraction for a lot of them (Rijal, personal communication, July $23^{\text {rd }}, 2008$ ).

Suman Basnet, Regional Coordinator for AMARC Asia Pacific, expressed a similar view with regard to the implications of overabundant donor funding for the community radio sector in Nepal:

Why does a particular radio station feel compelled to write a proposal in tune of the liking of a particular donor? You've set up your community radio stations in such a way that you cannot do without a donor's money. Had you set up your community radio stations independent of the external donors then you wouldn't have to stoop that low (Suman Basnet, August 29 ${ }^{\text {th }}, 2008$, personal communication).

There is clearly a gap between the way participatory radio in Nepal is represented via the status reports of international organizations which focus on consensus and partnership and present the sector as coherent, unified and homogenous, and the reality of practice, where there is significant conflict over issues of ownership, management, visions and principles.

\section{Jagaran Media Centre and Radio Jagaran}

Radio Jagaran was established by Jagaran Media Centre (JMC) - a Kathmandu-based NGO that uses media to combat ongoing caste-based discrimination and human rights violations against the Dalits, traditionally considered Nepal's lowest caste and "untouchable" according to caste-based decorum. Before discussing the establishment of Radio Jagaran, the organization that forms the basis of this case study, it is useful to briefly outline JMC's mandates in terms of the social marginalization of Dalits.

\section{Dalit Discrimination in Nepal}

JMC president, Suvash Darnal (2005), defines the "existing caste system, caste discrimination and the traditional caste structure" as the "root causes" of poverty and conflict in 
Nepal, and explains that "true development, strengthening of the process of democratization and poverty eradication are almost impossible in the face of such problems and systems of inequality and discrimination" (p.3). The English word "caste" is derived from the Portuguese "casta" meaning birth or difference. Caste generally encompasses all of the activities of life - duties, rights, occupations, and social positions - which are fixed on the basis of heredity. The most prominent and enduring outcome of the history of caste-based social structure is the legacy of untouchability. Within the caste system of both India and Nepal, the lowest castes - the untouchables - are called Dalit. The word Dalit comes from the Sanskrit 'dal' meaning to break into pieces, to shatter (ibid.). The history of caste-based social order in Nepal is complicated and confusing. Suffice it to say that untouchability customs have prevented Dalits from entering temples and hotels, marrying outside of caste, sitting in or near the home of someone from an upper caste, sharing food and water, and attending public spaces including educational and medical facilities. Historically, transgressions of these cultural conventions brought severe consequences that were legally and politically sanctioned, including banishment, imprisonment and death for the Dalit. Punishment was also severe for an upper caste person who willingly broke rules of untouchability and often resulted in a loss of caste and demotion to Dalit. Traditionally, the only way to overcome Dalit social status was to live a life that observed all caste-based regulations with the hope that karmic forces would enable rebirth into a higher caste. Most areas outside of major cities are still highly segregated according to caste. Although castebased discrimination was legally outlawed as a violation of human rights in Nepal in 1962, untouchability is still common and Dalits are forbidden from entering temples, holding positions in public offices, collecting water from communal taps, and entering the residences of nonDalits. Breaking taboos of caste hierarchy still carries severe consequences including rape, beating, and lynching of Dalits (Mohara, personal communication, July $4^{\text {th }}, 2008$ ). 
JMC was established in 2000 by a group of ten young Dalit journalists with the aim of using media to advocate for groups of people (Dalits in particular) who suffer ethno-cultural discrimination according to traditions defined by caste hierarchy. It mandates to combat caste-based discrimination by generating local and global awareness of Dalit issues and empowering talented Dalit journalists, writers, artists, and professionals....in an effort to continue placing pressure on the government (and Nepali society) to end the severe social exclusion brought upon by the archaic and oppressive caste hierarchy (Jagaran Media Center website).

The center's vision is evidently based on the normative assumptions of community media's ability to reflect and forge a shared history of oppression and vision of empowerment.

Radio Jagaran broadcasts at FM 93.6 MHz from Butwal, Nepal, located in the Rupandehi district of the Terai region. JMC established Radio Jagaran in December 2007 with the aim of empowering Dalits and other excluded groups (Janajati, women, Madhesi and minority Muslim communities) "through local dialogues and educational programs respecting the cultural and linguistic diversity of the program area" (Final Report for Radio Jagaran, p.1). ${ }^{15}$ According to Radio Jagaran's final report, JMC has selected Dalits to fill roles in "all functioning mechanisms of Radio Jagaran" (ibid.). Radio Jagaran's perspective of community media's ability to empower communities by "reforming who gets to speak and in what capacity" (Horchheimer, 2002, p.318) reflects a transformation in the goals of radio development in Nepal away from its ability to act as "the fourth estate" to a perspective that emphasizes the role it plays in engendering, validating and empowering communities- whether geographically defined or defined according to a common history or shared background.

According to the typology of community radio in Nepal outlined above, Radio Jagaran is

\footnotetext{
${ }^{15}$ Given its proximity to the border of India and the history of migration, the Terai region - where Radio Jagaran is located - is one of the most diverse areas of Nepal ethnically, linguistically and culturally. Janajatis represent a caste category that identifies indigenous groups of people and Madhesis are one of Nepal's most agitated ethnic groups.
} 
an NGO-model. ${ }^{16}$ More specifically, it falls under what Pringle and Shuba (2007) label as special interest radio. A phenomenon that is attributed to the current phase of indiscriminate licensing procedures, special interest stations "are highly focused and specialized, mostly along identity lines" (Pringle \& Shuba, 2007, p.21). Radio Jagaran is the only radio station currently broadcasting that is managed by a Dalit and that specifically focuses on Dalit issues (Gayak, personal communication, August 30, 2008). Radio Jagaran broadcasts for 18 hours per day and 6 hours are dedicated to education or social issue programming. The station has local language music and news reading programs, as people who reside in many of the poorest villages in Nepal do not speak the national language (Nepali). Issue-based shows include a Dalit human rights program, a women's program, a labour rights program and a program for peace-building that uses a talk-show format to bring members of conflicting groups together to seek resolution.

During the establishment of Radio Jagaran, emphasis was placed on the representation of excluded groups: in hiring staff, "women and the members of excluded groups were given first priority during the selection process" (Radio Jagaran, 2008, p.3). A steering committee was formed to guide the overall activities of the station, and primarily comprises Dalit representatives. ${ }^{17}$ From the progress reports of Radio Jagaran and interviews with station management, it is unclear what the operational role of the steering committee is, but Radio Jagaran's progress report (2008) explicates that it serves to "guide the overall activities of the station" and to "monitor and evaluate progress" (ibid.). According to the Finnish Embassy, JMC and Radio Jagaran operate in a way that is unusual for a media centre:

\footnotetext{
${ }^{16}$ The minimum requirement to set up an NGO in Nepal is that 13 people must be a part of the administrative structure. Typically, an NGO is based in Kathmandu and its radio station is established in another region. JMC is based in Kathmandu, but also has recently established a regional office adjacent to Radio Jagaran in Butwal.
}

${ }^{17}$ The committee consists of 5 Dalit men, 1 Dalit woman, 1 non-Dalit woman, 1 Madhesi and 1 Janajati. 
It (the media centre) combines information with action, having potential to function as a Dalit rights "watch dog" organization. It provides an example of a Dalit-run organization boosting the self-esteem of the group and creating in the same time an example of multi caste working environment (non-exclusiveness policy) (Finnish Embassy report, p.20).

In discussing a plan to create listener clubs in target communities, Radio Jagaran's station manager articulates this vision:

We want to establish listener clubs but make them not just listener clubs but social mobilizers...they will conduct social welfare programs in their community. It is not only for taking feedback like many stations do. We want to develop them as activists. They are not only representative of their community, they also work for their social movements. By listening to our radio they transfer the idea into their existence...they work for the community and raise the ideas in the community from our radio (Shivaji Gayak, personal communication, August $30^{\text {th }}, 2008$ ).

Radio Jagaran's mandate to catalyze social movements is also reflected in its strategic plan where it outlines a summary of activities that will serve as a "model for social mobilization". The plan comprises the following activities: "Select social mobilizers and provide orientation on the social mobilization model; form Jagaran Groups; assist Jagaran Groups to prepare need-based local level rights oriented activism plans" (p.3-4).

\section{Discourses and Techniques of Development in Community Radio Projects - A Case Study}

\section{of Radio Jagaran}

In Radio Jagaran's strategic plan (2007), it is immediately apparent that the mandates of inclusion, participation, human rights and community that form the basis of development discourse were utilized in the early planning stages and continue to form the core tenets of its mission. The objectives and expected outcomes that were defined during the initial stage of planning Radio Jagaran (see appendix 2) echo the visions of development propounded by international development agencies and likewise laud community radio's ability to overcome the 
"current burning issues of Nepal" defined as "poverty eradication, conflict management and restoration of peace" (Darnal, 2005, p.4). This thesis explores the way community radio as a development encounter creates particular "interpretive communities" (Lewis \& Mosse, 2005) the ways discursive practices are attached to populations and spaces - and attempts to highlight "the transformations they have effected" (Foucault, 1991, p.103). By utilizing a focus on discourse, data collected for the case study explores the epistemological implications of this particular radio development project on the society it is supposed to 'improve' $(\mathrm{Li}, 1999)$ in an attempt to redress the absence of critical inquiry into community radio projects. It draws on academic studies of development that have utilized a discourse-oriented approach. Such studies, inspired by Foucault, put a focus on the processes by which the dominating discourse on development also orders and creates the object it pertains to address. Through this mechanism, a set of procedures that decides what constitutes valid statements, in this case about development, is produced, thereby displacing alternative ways of seeing the world (Alsvik, 2002). This analytical framework draws on the field of development inquiry represented by Ferguson (1994) who argues, in line with Foucault, that discourse is a practice, that it is structured and that it has real effects (Ferguson 1994) ${ }^{18}$ Ferguson's argument is that planned interventions may produce unintended outcomes that occur in the encounters between representatives of development agencies and local communities. Hence, Ferguson's stance is that instead of only focusing on development as the simple projection of the interest of a "subject" (i.e. the World Bank, Imperialism, Capital, etc), one should pay attention to the unintended outcomes of the planned intervention. These interventions can end up coming together into powerful constellations of

\footnotetext{
${ }^{18}$ Ferguson argues that planned interventions may produce unintended outcomes which end up as "[I]ncorporated into anonymous constellations of control- authorless "strategies"... the most important political effects of a planned intervention may occur unconsciously, behind the backs or against the wills of the "planners" who may seem to be running the show" (Ferguson 1994: 20)5.
} 
control that were never intended and in some cases never even recognized, but are all the more effective for being "subjectless" (Ferguson, 1994,p.19).

\section{Underdevelopment in the Nepali social imaginary}

Most people in Nepal are painfully aware of the "underdevelopment" of their country even if their actual experiences of it vary. The "development encounters" (Escobar, 1995) experienced in the field suggest that perceptions of place and, ultimately, of identity among colleagues and interview subjects were defined in relation to the quantifiable value of "development" that I embodied as a representation of the West. Pigg (1992), and Liechty (1995) describe similar experiences during their research on development projects in Nepal. Liechty suggests that

As an ideology bikas creates a national identity for Nepal based on an external referent. From infancy Nepalis have etched into their minds the notion that Nepal is a, if not the, "Least Developed Country" (LDC). The ideology of bikas asks Nepalis to imagine themselves as a nation vis-à-vis other nations in contrast with which Nepal ranks as possessing the "least" of some quantifiable new value known as "development"” (p.168).

Development, and the "commodities of modernity" (ibid) are external, distant in time and space, from where Nepalis conceive their lives to be situated. This ideology of bikas represents what Liechty calls a "self-peripheralizing mentality" in which development is seen as a foreign commodity (ibid).

Some of these feelings may have been stronger in Liechty's and Pigg's studies than they were in this one, given that most of this project's informants were young journalists living in Butwal, one of Nepal's largest cities. Nevertheless, their way of conceptualizing the Nepali state, and ultimately their own situation, within the international community are profoundly similar. This exemplifies that people living under quite different conditions verbalize, at least to a certain 
extent, their ideas of development within the same discursive field. Many of the journalists expressed that they had once had views similar to those held by members of the villages they lived in before moving to the city. In many ways, they described how prior to working as journalists for Radio Jagaran, they did not understand what internationally (and arguably western) mandated notions of development, human rights and empowerment meant. This changed for them once they attended training sessions on community radio and human rights hosted by national and international radio advocacy organizations and largely funded by development agencies. While the expatriates working in development programs in Nepal, schooled in cultural relativism, tend to speak in somewhat neutral terms about what villagers "believe," educated Nepalese elites both in and out of development institutions waste no breath in speaking of villagers as fettered by custom and superstition (Pigg, 1992). For instance, one of Radio Jagaran's guiding principles is "the promotion of scientific knowledge" whereby it aims to:

introduce scientific concepts, technologies, approaches, knowledge and skills which can serve local population to improve their scientific knowledge, and discourage superstitious traditions and practices (Radio Jagaran, 2008, p.2).

Whether the "ignorance" of villagers is spoken of with pity, compassion, or derision, what is perpetuated is the idea that villagers are, in Appadurai's words, "incarcerated" in a way of thinking by virtue of being "natives" of a kind of culture-territory. Place and person fuse in the reification of cultural essence (as cited in Pigg, 1992, p.301).

Dinesh Harijan, a journalist at Radio Jagaran who produces an issue-based program on Dalit human rights, expressed his view of the value of a Dalit-focused community radio station in the following way:

First of all I didn't know what it was, our human rights. Then I attended a training session for young Dalits held by JMC about Dalit human rights. Now in my human rights program I am changing my society for the new generation so there will not be caste discrimination...so upper caste people will not hate lower caste. Then all 
people can know that Dalits have the same human rights as higher caste people. My father did not know what human rights were. But now he listens to my program and he knows. When the people in our target community (Dalit community) know what human rights are, then my program is successful. When they don't know, we are not satisfied... because Dalit people have no money. They are uneducated people. They are very poor people. This is the main target of my program (Dinesh Harijan, personal communication August $3^{\text {rd }}, 2008$ ).

As expressed in the above interview with Dinesh, there is a very specific type of power that comes with knowledge about human rights - empowerment is attained when one comes to understand an internationally mandated conception of human rights. By virtue of producing a Dalit human rights program, Dinesh has appropriated both the role of watchdog for human rights violations against Dalits and the role of educator to teach people to understand their own rights. Ramu C.K., a journalist who produces a program to promote better educational opportunities for Dalits expresses that he views his role as a journalist in a similar capacity:

Dalit people always feel dominated by higher castes. Why are we always less? We have to do something for our village and community. First it is very important to work for education for Dalit community. Most Dalits cannot get a good education. I should be something good for my community and work to educate people, so I started working in the media sector (Ramu C.K., personal communication, August $4^{\text {th }}$, 2008).

Where villagers may see discrimination in terms of heredity or fate, Dinesh and Ramu see radio as a force to alter this subjectivity by reformulating discriminatory actions as human rights violations. However, in the villages and among community members, the value of radio is often not perceived in these terms. While few would deny that having access to radio is a good thing, it is primarily those working at community stations or radio advocates that would define its value in terms of human rights and empowerment. This epistemological gap between villagers and the emergent semi-professional class of journalists suggests that progress and "development" are framed in terms of knowledge. Lacking knowledge of human rights is both an attribute and a condition of being a "backward villager" (Pigg, 1992) that would benefit from a development 
intervention that reforms knowledge. The framing of a "development" intervention is a delicate cultural operation, which, as $\mathrm{Li}$ (1999) argues, requires the identification of a target group with a deficiency to be rectified. Knowledge of another's deficiencies both depends on and reproduces a boundary between the knower and the object of knowledge (ibid).

Similarly, Binod Pariyar, another issue-based journalist who produces a weekly issue-based program about worker's rights explains that

In Nepal, labour workers make very little money... also there are very poor government regulations. In factories, the people do very hard work but do not earn enough money... when I take the voice of farmers and workers, we can broadcast the voices to the related NGO sector. When I go to the factories, I take the voice of the workers. I broadcast their voices on the radio and people will listen... and people will feel how hard the work is for the worker... in my village I saw so many people who would do this hard work (labour jobs) and they struggle to live. So, I asked, why can I not do something for their rights? (Binod Pariyar, personal communication, August $\left.15^{\text {th }}, 2008\right)$.

Binod has a similar social positioning as Dinesh and Ramu- by virtue of his knowledge of human rights and empowerment through his involvement with Radio Jagaran and its partner organizations, he has been "uplifted" from his community where he is able to assume the role of advocate to help raise the voices of people who are unable to raise their own voices. This experience suggests that the notion that an awareness of human rights that comes through interactions between development organizations, community radio stations and local communities reflects what Pigg (1992) has observed in Nepal: the condition of being a backward villager, rather than simply a poor or relatively powerless one, is visible only from a distance-- to know one, you cannot be one.

Radio station staff members, however, do not universally hold such views. Staff members who are not representative of marginalized groups typically did not express such visions of empowerment in terms of promoting social justice. Hemant Giri, program coordinator of Radio Jagaran, expresses his interest in working in community radio as a professional aspiration: 
...from childhood, I would listen to the radio, but I did not know how it worked, how people speak in radio, but when I grew up my interest turned into my profession (Hemant Giri, personal communication, July $28^{\text {th }}, 2008$ ). He was chosen as a member of the management team because of his extensive experience in commercial radio, though as non-Dalit, he arguably does not represent the disadvantaged groups that Radio Jagaran aims to empower. As a program coordinator his primary responsibilities include researching potential stories in the coverage area and advising journalists about the selection of story content; his experience in radio along with a general understanding of its value for the development of Nepal, particularly for underdeveloped regions (ibid.), enabled him to assume the role of expert.

The articulations of empowerment expressed by human rights journalists at Radio Jagaran are not the result of cultural and economic domination by an international development agency nor do they reflect a strategic attempt on the part of the radio station to merely define itself in a way that attracts donors (though it is arguable that its strategic plan and mission statement reflect this). It was oftentimes difficult to discern what was actually meant by respondents during interviews and whether interviews with journalists and community members formed an accurate reflection of what journalists and community members think about community radio projects. This is in large part due to difficulties with translation alongside the tendency many Nepalis have to respond to questions by saying what they think foreign development workers want to hear, a habit that is likely attributable to cultural codes of conduct reflective of a highly stratified society coupled with the history of development in Nepal. Nonetheless, there appeared to be an overwhelming sense that a very specific type of knowledge will lead to "social and economic upliftment" (Radio Jagaran, 2008, p.2). This experience echoes Li's (2007) claim that it is less important that plans and discourses prevail than that they engage, providing room for maneuver and opportunities for compromise. To frame encounters in 
development terms, some level of compliance with the terms must be achieved. As an agreement between two parties, a compromise, assumes that agency is distributed, if unevenly. Agency, in terms of empowering members of marginalized communities to transform themselves and, in the process work to transform others, is negotiated and articulated through the discursive frames of participation, inclusion and human rights. However, this discursive frame is not unilaterally imposed, nor do all members of the radio station define their relationship to the community in these terms.

As discussed earlier, the Nepali government has created strategies for development in accordance with the dominating tendencies in the international aid community, to be able to get the economic support upon which they are so reliant (Alsvik, 2002). The development strategy of the Nepali government is concentrated around issues such as community development, decentralization and good governance. I have suggested that these government strategies of "decentralization" and "participatory development" have to be seen in relation to discourses of development and to Li (1999) and Ferguson's (1994) claim that designed or planned social order is schematic in form. To be able to intervene, the state or aid organizations have to create a social reality within which intervention is possible. Analyses and projects are constructed in relation to certain variables, namely those that are conceived of as possible to manipulate. To improve populations requires the exercise of what Foucault identified as a distinct, governmental rationality - a way of thinking about government as "the right way of disposing things" in pursuit of not one goal but a "whole series of specific finalities" (Foucault as cited in Li, 1999, p.6). Calculation is central because government requires that the right manner be defined, distinct finalities prioritized and tactics finely tuned to achieve optimal results. Calculation requires that the processes to be governed be characterized in technical terms to enable organizations to devise specific interventions. 
Community radio development in Nepal can be viewed as a form of governmental rationality in terms of the discursive structures that create particular political subjectivities as outlined above, but it can also be seen in relation to practices of "problematization", which identify deficiencies that need to rectified, and "rendering technical", which conceptualizes the domain to be governed as an intelligible field with specific limits and particular characteristics (Li, 2007). In community radio development projects in Nepal, technologies of governance comprise the identification of target communities, defined by a geographical determinant or a shared history of oppression, who would benefit from the establishment of a station. Radio Jagaran's mandate of empowering Dalits to speak for themselves does not rely on the same geographical determinant as other stations in establishing a vision of community, yet it invokes an analogous normative interpretation of it. Although Radio Jagaran's target population comprises people living within the three districts of its coverage area, it relies more on a definition of community based on a shared history of oppression (whether by Dalits, women, Janajatis, Madhesis or Muslims) than a sense of shared geographical space. In this regard, Radio Jagaran's vision is formulated according to the unquestioned optimism embedded in the conception of community upon which most community radio projects are based. Under the veil of such optimism, community media are evaluated on their ability to bind together people with a shared environment, history and ethnicity. However, this often obscures the multidimensional and highly varied reality of people's relations to the places in which they live. Real communities are made up of differing individuals, in different positions, with different backgrounds, possessing different resources, and facing different circumstances and situations. Dalits do not necessarily live in geographical proximity to one another, nor is allegiance to their community necessarily voluntary or desired. Even within the broader Dalit community, there are different communities and different levels of self-identification. A Dalit social position looks much 
different from one village to another where it intersects with other dynamics such as poverty, migration, and access to resources.

During a community interaction session at Radio Jagaran, this tension became evident as community groups discussed the strengths and weaknesses of Farakilo Daharti (Wider Earth), an issue-based program sponsored by Search for a Common Ground. ${ }^{19}$ One respondent argued that the talk show program is not inclusive because it focuses primarily on Dalit issues:

Dalit people want an equal society, but they create differences by being exclusive. Exclusive programs contribute to caste discrimination. Inclusive radio should not be in the name of the Dalit community because this creates stratification and discrimination.

Another participant expressed a similar concern:

The program should focus on class and economic problems. The objective of the program - to talk about marginalized and oppressed people and to focus on the peace-making process - is good, but all groups should be addressed... it should not be limited to a focus on Dalit issues.

Although the principles that underwrite the creation of community radio stations emphasize their ability to bring about communities, in reality the communities they aim to help construct and represent are negotiated and contested terrains of meaning and subjectivity.

In addition to identifying and defining communities and the subjectivities within them, community radio stations must determine the deficiencies to be rectified in order to develop programming that specifically addresses the needs of recipient communities. At the AMARC conference in Kathmandu, Dixit stated that social problems are on the rise in Nepal. There are strikes, trafficking, untouchability, illiteracy, and ethnic conflict. He asked: What is the role of community radio in this? Has radio sent the message that individual freedoms should not impinge on the rights of others? (July $15^{\text {th }}, 2008$ ). Deficiencies in target communities are often

\footnotetext{
19 "Farakilo Daharti is a franchised talk show on the peace process, produced by 2 regional partners and 9 FM stations in conflict-affected areas of Nepal. While the 11 editions of the programs share intended outcomes and objectives, each producer selects topics and content based on his or her area" (Search for a Common Ground, Nepal Update, 2009)
} 
defined in relation to the Millenium Development Goals. In speaking of the current state of community radio in Nepal, Ragu Mainali asked:

What have we been doing on behalf of the backward communities? How have their voices and interests been looked after by us? What kind of role can we play in realizing the Millenium Development Goals? And social transformation? And personal identity? What kind of role can we play in this? What kind of roles have we played in issues of peace and gender equity? (AMARC, July $15^{\text {th }}, 2008$ ).

Radio Jagaran identifies similar problems in its strategic plan: it will work to "end gender-based discrimination", “discourage superstitious traditions and practices", "advocate against the negative effects of the open economy and globalization" and "mitigate racial, religious, structural and gender-based violence" (p.2). In addition to overcoming discriminatory practices against minority groups, Radio Jagaran defines voicelessness as the primary deficiency among its target population. When asked why JMC decided to start a radio station, JB Bisowkarma of JMC explained: Many radios are started, but the voice of voiceless people like Dalits, Janajati has not been priority. They should be raising the voices, problems, interests, matters through their radio stations, but they didn't do that (personal communication, April 22, 2009). Similarly, Prakash Mohara of JMC identified the motivation for starting Radio Jagaran in relation to a deficit of voice:

Cases of Dalits went neglected in many instances, so in order to cover the issues, $J M C$ was established and radio is one of the components of achieving our purpose. This is a community radio because not a single radio has been established for the Dalit community, to act and be the voice for the voiceless (personal communication, April 14, 2009).

In community radio development projects, solutions are not unilaterally imposed from above; they are negotiated through partnerships, facilitators and external advisors. Through these mechanisms, communities are empowered to identify and pose solutions to overcoming the difficulties that plague them. Success is measured by the introduction of assessment tools, community mapping and surveys. 
International donor organizations and national community radio advocacy groups stress adequate impact assessment mechanisms as one of the sector's most pressing issues. Radio Jagaran's station manager expressed this as one of the station's primary concerns:

People do not have knowledge about monitoring and evaluation and how to make programs that impact the public. We don't have the knowledge ... Community radio impacts a lot in our community, in our Nepal, but we have not any specific method to measure the impact. In our radio we conduct programs related to women, marginalized people, youth, disabled people, education and it creates knowledge about these people. By listening to our program, they empower themselves and the quality of education is increasing. But as a whole, all of media impacts slowly (Gayak, personal communication, August 30, 2008).

Success is measured by utilizing methods of evaluation that have been introduced and often required by international development organizations that provide support. In order to secure funding, respondents expressed that donor organizations require ongoing evaluation of community impact. When asked about evaluation of Radio Jagaran, Mohara stated: $J M C$ submitted 3 evaluation reports to donor agencies to date. Most of the time, they want to see listener surveys, budgets, and community involvement in Radio Jagaran in terms of clubs, groups and others (personal communication, April 14, 2009). Similarly, Rijal claims that community radio stations are often funded by donors (and) donors want clear evidence that activities are producing social impact results. This often affects the way an impact assessment is carried out (presentation, AMARC, July $15^{\text {th }}, 2008$ ).

Although it has not yet implemented specific strategies to measure impact, Radio Jagaran is planning to establish research groups and develop interaction programs to collect feedback and suggestions about programs. Success is currently evaluated according to the station's ability to facilitate decreased caste-based discrimination and increased access to cultural and symbolic resources for Dalits. Gayak explained that in the absence of specific tools that can produce measurements of success (e.g., community surveys and listener groups), there are other indications that the radio station has contributed to social transformation: 
One issue related to Dalit discrimination has to do with a local Dalit who was nominated as a president on a school board, but upper caste people disqualified him even though he won the election for the position... Our radio raised the issue and he was re-established as the chairperson. Also there was an issue of sex workers at a hotel in our coverage/target area and we raised this issue as well. The owners of the hotel were forced to compensate the women because of our programs after police officers arrested the owner of the hotel (Gayak, personal communication, August $30^{\text {th }}, 2008$ ).

In their evaluation of the programs they support in Nepal, the Finnish Embassy also draws on these events as indicators of the success of Radio Jagaran's mission and also as justification of its continuing support:

The relevance (of Radio Jagaran) is increased through the combination of the radio as a powerful tool and the follow-up action, e.g. the case of two Dalit women that were used as sex slaves in a hotel was raised with the police. Consequently the women were freed and the hotel owner jailed, while the two women received a compensation of 20000 NRs. Similarly a Dalit man was selected as a chair of the school management committee but the local authorities did not approve - after raising the case in the radio the man is now the chair of the school committee (p.20).

Radio stations typically utilize project proposals, performance benchmarking and social impact assessment tools to predict and demonstrate social transformation. For instance, Radio Jagaran's strategic plan details the outcomes it will achieve over a 5-year period in terms of specific results that can be measured according to "Objectively verifiable indicators (OVIs)" and outlines the "Means of verification indicators (MVIs)" (See appendix 2.1, p.2). According to the plan, Radio Jagaran will work to redress social issues related to "representation of Dalit, Women, Janajati, Madhesi, and Muslim communities in all levels of Government, non-government organizations and political parties", "exclusion", "issues related to women and children" and "discrimination" by ensuring that it "is established and operational as a rights-oriented station" (p.4). Its ability to act as a "rights-oriented station" is determined according to very specific criteria including percentage of programs related to human rights, capability to produce educational/awareness, news and entertainment programs in local languages, and financial self- 
reliance (ibid.) In the progress report prepared for its international partners, JMC iterates its commitment to "make Radio Jagaran a true voice of the marginalized community people, especially of excluded groups" (Radio Jagaran, 2008, p.6). To ensure this:

JMC is proactively working for establishing a radio station that is planned, managed, organized and developed by marginalized group. At present, JMC is playing key role in setting up the station, running the program and building the capacity of local excluded groups. Once, the local excluded communities get technically and financially empowered, JMC plans to handover the Radio Jagaran to the community and JMC will limit its role to technical support only. By doing so JMC believes that this radio will be able to raise issues of Dalits in true sense (ibid).

Frequently described as a "new managerialism" (Abrahamsen, 2004, p.1459), development schemes implemented and supported by national and international NGOs represent "an increasing decentralization and localization of power and decision-making centers, away from the state" (ibid). The move toward decentralization is accompanied by a vast array of new mechanisms and techniques of auditing, accounting, monitoring and evaluation, which link grassroots development projects to political strategies at the state level. The "calculative practices" or "technologies of governance" (Walters \& Haar, 2005) that manifest in community radio development projects through the establishment of partnerships, the reliance on experts, and the conceptual tools of standardization, evaluation and benchmarking, creates spaces that are thinkable and governable. This process is, according to Merlingen (2004), disciplinary in nature insofar as it helps constitute "a physics of relational and multiple power" focused on individuals (Foucault, 1991, p. 208). It works by rendering individuals visible, recording their attributes and performance, measuring deviation from established norms and comparing individuals to each other (Merlingen, 2004). By enlisting communities at the local level and states at the national level, partnerships between international non-governmental and development organizations and local governmental and non-governmental organizations invoke specific technologies of governance which help produce modern, self-disciplined citizens and states that can be trusted to 
govern themselves according to liberal democratic norms (Abrahamsen, 2004).

The technologies of governance in this case study are operative on two levels. First, techniques of monitoring and evaluation compare radio stations to one another according to specific normalizations related to international mandates of human rights and the national project of development. AMARC (2007) describes the worldwide growth of community radio as: a story of people and communities striving to speak out and to be heard. Community radio has provided a means of empowerment and of self-reliance. It has enabled people to engage in dialogue about their conditions and their livelihoods. And it has contributed to the defense of cultural and linguistic diversity. It is a story in which the pursuit of social and development goals has been deeply entwined with the struggle for human and political rights and particularly the right to freedom of expression (p.22).

AMARC's report, which details the outcomes of a long-range participatory action research project launched in 2006, rests on an evaluation process that highlights the fact that communities seek to use community radio as a medium to express their own issues, concerns, cultures and languages. According to AMARC, "community ownership of the media and participation in programming have led to communication processes that can empower local actors to achieve poverty reduction, forward development objectives, and encourage inclusiveness, participation, peace-building, good governance, and accountability" (ibid.). AMARC found that the lack of proper enabling legislation is the single most important barrier to increased effectiveness of the social impact that community radio can have. Working around this barrier involves encouraging exchanges of experiences amongst practitioners (e.g., its network of more than 3,000 members from 110 countries) in order to strategize about how to better highlight the potential of community-based radio to have social impact. In addition, the evaluation emphasizes the need for appropriate tools and indicators to evaluate social impact that goes beyond information dissemination indicators or small project impact on individuals.

In the community radio sector in Nepal, indicators of success, as well as challenges to 
achieving it, are largely formulated according to the terms outlined in AMARC's report. While many practitioners and advocates have indicated that measurements of positive social impact are necessary in ensuring continued support from donor agencies, there was also an overwhelming sense that stations evaluate themselves according to such criteria. During a workshop on advocacy journalism and radio documentary formats that I conducted with journalists at Radio Jagaran, the question of impact was continually raised. Journalists wanted to know how the effect of radio campaigns could be evaluated in terms of social justice. They asked, if the radio broadcasts a particular campaign and no discernible change occurs in the community, does that mean that the program failed to achieve its mission? The general notion among the staff at Radio Jagaran appears to be that failures to achieve demonstrable effects (i.e. a measurable decrease in caste-based discrimination) are the result of poor quality journalism and radio production. In this way, it is not only the conduct of radio stations that is monitored in terms of their ability to improve the lives of people who are marginalized along gender, ethnic and caste-based lines; communities themselves are qualified and classified through the normalization of standards of human rights and inclusion. Monitoring and evaluation, the techniques of which are taught by development agencies, combines the procedures of both hierarchical observation and normalizing judgment to effect a 'normalizing gaze' through which the truth about communities, and the individuals within them, is established (Merlingen, 2004).

Monitoring and evaluation techniques not only serve to measure individuals and communities in terms of liberal conceptions of empowerment and self-reliance, they also obscure the political foundations of discrimination and poverty by emphasizing knowledge of human rights and participation as the central forces for overcoming discriminatory practices and inequality. In these ways, grassroots social movements "strive to convert a sense of 'passive belonging' to the lived world into a sense of 'governmental belonging"' (DeChaine, 2005, p.15) 
by encouraging individuals to take control of their lives and participate in concerted action, initially at the level of the local community, and eventually in the higher sphere of the nation (ibid).

Foucault saw individuals as self-determining agents, able to challenge and resist the structures of domination in modern society. For him, practices of freedom enable individuals and societies to define " admissible and acceptable forms of existence or political society" (Foucault, 1997, p.298). As discussed at length in Chapter II, Foucault's later work observes the nature of liberal governmentality as a type of rule not imposed by a top-down formulation of power but by "a calculated leaving alone.... which allowed subjects to conduct their own surveillance and control through apparently "natural processes"' (Paras, as cited in Hearn, 2008, p.22). This case study of Dalit community radio in Nepal has sought to demonstrate the ways that donor-led and partnership-based community radio projects in Nepal operate as techniques of governmentality. It explored how community radio initiatives, as development interventions, work to prioritize certain truths and construct knowledge forms that naturalize the predominantly western, liberal discourses of improvement in the communities they aim to empower.

Although there are clear indications that local practitioners and activists have adopted many of the discourses of development promoted by international agencies that offer financial and resource-based support as well as training in social issues and technical production, there is also ample evidence to claim that such discourses are not adopted uncritically. Significant contestation over the terms of community radio, including financial structures, modes of operation, programming and management demonstrates the ways the diffuse and vaguely defined discursive structures of empowerment and participation mandated by international organizations are negotiated in local contexts. These contestations trouble static conceptions of power and domination offered by critiques of development as a fundamentally ideological encounter that 
solidifies western dominance over poor nations. It also questions the overly simplistic notions of community and subjectivity that are relied on in laudatory biographies of community radio, which often manifests according to a politics of resistance thought of exclusively in terms of subversive action. Throughout this chapter Foucault's work on epistemes was drawn on and enabled for an interpretation of community radio development projects that does not deny that there are power relations at work, but that defines them as fluid and contingent. Power, according to this perspective, is an accomplishment ( $\mathrm{Li}, 2007)$.

The way governmentality appreciates the mutually constitutive nature of language and practice, of representation and intervention (Merlingen, 2004, p.368) is highlighted in this case study. Community radio projects in Nepal demonstrate the complex interweaving of discourse (mentalities of governance) and calculation (technologies of governance) in community radio projects through progress reports, vision statements, and measurements of successes and failures. Grassroots media development projects also highlight the mutually constitutive nature of representation and intervention, as intervention depends upon as it constructs boundaries between social subjectivities. As such, they draw attention to the fact that "the sense and object of governmental acts do not fall from the sky or emerge ready formed by social practice. They are things which have to be invented" (Burchell et al., 1991, p.1). When we focus our gaze into the communities that produce participatory media, we see the constitution and reconstitution of power relations and social subjectivities as people move through the landscape of ordinary life (Howley, 2005). 


\section{Conclusion}

I traveled to Nepal with a solid foundation in the literature of participatory radio for development and thought that I had a good idea of what I would find in the nascent community radio sector there. As detailed in Chapter $\mathrm{I}$, which interrogated the assumptions upon which the establishment and evaluation of community radio stations are typically based, I had a normative understanding of alternative media according to discourses of opposition, resistance and empowerment. I set out to explore how marginalized social groups use radio (as opposed to other media) as a tool to facilitate social transformation and reform structures of oppression and domination by reforming who gets to speak, to whom, and in what capacity (Horchheimer, 2002). Upon arriving in Nepal, I was continually confronted with circumstances that affected the research process and baffled my understanding of community radio rooted in laudatory notions of participation and inclusion.

I often felt the overwhelming presence of a notion of bikas during my stay in Nepal. It manifested in terms of national, community and individual identity and representation. Often whenever I met people for the first time, either in urban or rural areas, they would ask me how I liked Nepal. I would say that I liked it very much, a response that was positively received but typically followed with a comment about how poorly developed Nepal is. I was often asked to compare Nepal to Canada in terms of a very particular conception of development - Are people poor in Canada? Do they have electricity? Is there caste discrimination in Canada? This echoes Alsvik's (2000) observation that "the categories of developed and not developed, rich and poor seemed to be a standard way through which they (Nepalis) conceptualized the world and their position within it" (p.43).

One of the first things that struck me was the proliferation of "development" in Nepal and the overwhelming perception of it as one of the least, if not the least, developed country, 
both on the part of foreign development workers and Nepalis. Due to the large influx of foreign aid that has flooded the country over the past 50 years, there are literally thousands of NGOs operating in Nepal. International organizations and foreign governments provide so much foreign aid that starting a grassroots organization (that may or may not do really great things) committed to social change can be a lucrative undertaking. Another aspect of development that became immediately apparent is the gap between the city (and "the west") as the site of modernization and the village as the place of backwardness and the expressions of individual identities formulated in relation to this scale of development in the Nepalese social imagination. In these ways, I quickly perceived that the cultural effects of development interventions are related to the ways social identities are recast and the discursive structures that mark social differences. Development interventions alter conceptions of place, identity and history by placing them within liberal discursive frames, thereby reifying conditions of oppression and locating social subjects on one or other side of a power hierarchy. The effect of this dichotomy is that historical subjects are conceived of as possessing innate characteristics in relation to development goals; being powerful or powerless, modern or backward, become inherent characteristics. It is well documented in development literature that many carefully designed development programs fall short of accomplishing their goals for change. Ironically, the diffuse, international development vision nonetheless succeeds in producing a profound ideological shift in target communities.

My observations and experiences with community radio projects invoked similar feelings and raised analogous questions. Nepal's community radio sector has flourished since it liberalized the airwaves for the first time in 1997. Drawing on an already established tradition in other areas of the developing world, Nepal embraced community radio for its potential to overcome propagandistic and elitist national media systems, to bring news and information to 
remote areas, and to educate people about human rights, equality, health, family planning and sustainable agricultural practices. I became intrigued by the sheer proliferation of community radio. Through visiting community radio stations in different regions of Nepal, attending radio workshops, interviewing journalists and members of advocacy organizations, running workshops related to radio production, human rights reporting and advocacy journalism, and observing daily station activities, field reporting and community interactions, I was struck by the similarity of radio programming and the common rhetoric of human rights and empowerment that were expressed by station staff and management who were working to address the needs of radically different communities. This realization echoes Green (2003), who asks "why are development projects so similar in so many places?" (p.1) Similarly, Townsend (1999) highlights this issue when she asks " $[\mathrm{H}]$ ow may we understand a community of ideas which produces such strikingly parallel local talk in such distant and dissimilar locales?' (p.613). In an attempt to address this question, I have suggested that, although ideas about development may be interpreted and articulated in numerous ways, "the contact point at which individuals are driven and know is tied to the way they conduct themselves and know themselves." (Foucault, 1980, p.7; emphasis in original).

Amongst practitioners and advocates, community radio is heralded according to the perspective of participatory media as capable of catalyzing social change and the larger discursive frame of development. Most stations dedicate significant portions of their programming schedule to raising development issues, including gender equality, HIV/AIDS, indigenous representation, and poverty alleviation. However, in practice there is a great deal of contestation over whether or not stations in Nepal are truly living up to established mandates of community media. Questions that are central to theoretical and empirical inquiry into community media practices are continually raised in Nepal's community radio sector: Who 
speaks for whom? Who decides what are legitimate voices to be heard? Which points of views are the most compelling? How are community views solicited and encouraged? Do the community members who are producing the media accurately represent all individuals who define themselves as a part of that community? What happens to a unified community identity when members appropriate a multitude of highly varied and often conflicting cultural identities? However, these questions are often framed in terms of debates over policy ${ }^{20}$, administrative structure or financial sustainability. There is very little debate over the relationship between community radio projects and the larger national and international project of "development" and "modernization" in Nepal.

During the 14 weeks I spent in Nepal, I became intrigued by the ways in which the funding requirements established by the INGO donor community appear to be re-focusing the programming agendas of grassroots media organizations. This has implications for how the 'truths' and 'realities' of poverty, human rights violations and related issues are constructed by community radio stations. A fundamental question about how knowledge and reality are constructed emerged: have the funding models developed by the INGO sector, which underwrites much of this media programming, shifted the episteme (Foucault, 1970) of media development initiatives in Nepal? In my thesis project, I have attempted to interrogate community radio development projects in Nepal by locating them as "development encounters" (Escobar, 1995) and examining them according to the epistemological shifts that occur when universal notions of human rights, inclusion, development and progress meet locally grounded social visions. Focusing on radio projects as development interventions has enabled me to use community media as a lens to examine the dialectical process between the global forces and

\footnotetext{
${ }^{20}$ There is currently not a policy that distinguishes community radio from commercial or state media nor any legislation that allocates frequencies based on this distinction (Pringle \& Shuba, 2007).
} 
conditions that form the basis of international intervention in territorialized spaces and the everyday lived experience of local communities.

Methodologically, I decided to conduct research based on participatory action principles. This was due, in part, to the opportunity I had to work with Radio Jagaran as an intern, but primarily rested on a firm belief that the principles of engaged social research are integral to explore the complex and fluid terrain of power relations as they manifest in grassroots social movements. I felt that a participatory research model was appropriate to my thesis project on both theoretical and epistemological levels.

As discussed in Chapter III, an engaged research stance was an attempt to question and destabilize the power relations inherent in interactions between foreign development workers and local communities. Given that I was intending to explore the basis upon which decisions are made and stories are chosen and the ways stations instill themselves in their communities and encourage and support community involvement, I felt that a traditional ethnography would not be very useful to answering these questions. Moreover, as a community radio practitioner myself, I felt that I had skills to share with local practitioners and was embarking on a project that had the explicit goal of collaboration and knowledge sharing. Traditional ethnographic approaches would have been inappropriate given the active component of my internship, which required me to work directly with the grassroots organization that I was researching and participate in their struggle for social change. On an empirical level, then, participatory research allowed me to circumvent the reliance on objectivity that foregrounds other ethnographic approaches.

An engaged research design was also useful to develop the theoretical position of my thesis, given the epistemological commitments it shares with participatory media. Both stem from a critique of power relations and systems for generating knowledge that uphold existing 
hierarchies and entrench oppression and marginalization. However, one difficulty apparent in a great deal of literature on participatory media and engaged research is a reliance on a binary conception of power - being powerful or powerless becomes an inherent characteristic. I felt that a participatory research design was useful to interrogate static notions of power often relied on in research about oppositional media and grassroots social movements that are rooted in resistance. However, as elucidated in the methodology chapter, this was difficult to do given the relatively short duration of my time in the field and the assumptions that accompanied my position as a foreign development worker in Nepali society. I was often looked upon as an expert even though many local radio practitioners possessed an expertise that far exceeded my own. This was problematic for me in terms of the mandates of participatory research that I struggled to uphold and led to "iterations of insider-outsider positionality" (Burgess, 2006). At the time, I felt that methodological tensions led to significant setbacks in the research process. However, in reflecting upon them, I was able to theorize about the discourses of participation, inclusion and empowerment that form the central tenets of development, community radio and participatory research. The assumptions that underlie these areas of inquiry are inherently oppositional in nature as they all strive to challenge systems of domination, marginalization and oppression. Furthermore, they all rely on a conception of the way power is inextricably linked to systems of meaning-making and knowledge production.

A participatory research design enabled me to experience more than the aggregate of audience interpretation and feedback or the logistics of decision-making and story selection as it related to the principles of community media production. The outcomes of a media ethnography may not have been useful in contributing to the field of alternative media studies given the aforementioned contradictions and tensions that often arise due to Nepal's historical relationship with international development organizations, and the resultant effects this 
relationship has on interactions between foreign researchers and local activists.

While much of the literature on development in Nepal critically examines the role of international donors, the literature on community radio lauds it for its potential to facilitate social transformation. In confronting these two bodies of literature, I began to question the disparity between them, given that FM radio in Nepal is funded, in large part, by international donor organizations. I do not deny that there are valuable insights to be gained from community radio projects that explore claims of empowerment or potential for resistance, or for criticisms of development that stem from the fact that donors hold considerable power over poor countries and that the liberal terms of development projects are largely non-negotiable. Nonetheless, there are significant analytical limitations to both approaches, arising primarily from their conceptualization of power. A collaborative design enabled me to explore the rationalities that form the basis for community radio initiatives and underwrite their place as development interventions in Nepal. The methodological setbacks experienced in the field, then, shifted my thesis toward an exploration of the governmental rationalities that form the basis for community radio projects. This allowed for a re-conceptualization of power in it terms of the way it works through systems of knowledge and discursive practices to provide the meanings, norms, values and identities that not only constrain actors, but also constitute them.

This theoretical repositioning enabled me to conceive of international development agencies, NGOs and grassroots social movements (of which participatory radio is a part) not as monolithic, organizational structures, but rather as shifting flows of people, ideas, resources, and most of all power. An epistemic analysis, grounded in Foucault's notion of governmentality, shifted emphasis from a set of organizations to a fluid web of relationships and rested on an analysis of the place "where technologies of domination of individuals over one another have recourse to processes by which the individual acts upon himself and, 
conversely ... where techniques of the self are integrated into structures of domination" (Foucault, as cited Abrahamsen, 2004, p. 1459). By focusing on the interactive space where organizational structures meet grassroots social movements, I attempted to draw attention to the flows of funding, knowledge, ideas and people that move through the various levels, sites and associations that constitute a community radio project established according to a development agenda. In doing so, I explored community radio as constitutive of target populations who are "both the object of improvement and the subject that does the improving" (Abrahamsen, 2004, p. 1459).

A focus on rationalities, and the way they manifest through "technologies of government" (Gordon, 1991), oriented the analysis of the data collected during my internship to the problems acted upon by international organizations and local NGOs, the arguments that are put forward to justify development interventions, and the strategies for tackling problems as they related to assumptions about community radio's ability to facilitate empowerment, inclusion and representation. The purpose of examining rationalities is to question how the power of development organizations is programmed and legitimized and to highlight the network of contingencies from which any given rationality emerges (Merlingen, 2004). A closely related purpose is to draw attention to how international development organizations and local NGOs objectify reality into a terrain to be governed. In this regard, my analysis focused on the way that community radio in Nepal frames development interventions, given that it is inherently allied with certain kinds of knowledge about the political, social and economic characteristics of a particular community and the people within it.

The case study sought to examine the claims of empowerment that ground community radio projects in Nepal by problematizing notions of human rights, development, inclusion and community as signifiers that are strategically deployed in the establishment and evaluation of 
community radio stations. Upon examination of the various perspectives that actors in the sector hold, it is apparent that such signifiers are vaguely or ambiguously defined by the authors that use them; their meanings are taken as given in the discourse. In radio development initiatives, there is significant disagreement over the best ways to design and implement projects that live up to visions formulated according to such ambiguously defined and oft contested signifiers.

Debate over best practices in establishing and operating community radio stations in Nepal that live up to the standards of inclusion and representation they promote primarily centers on issues related to organizational structure, administration, financial sustainability and impact assessment. NGO-led radio projects, as agenda-driven special interest groups, have been criticized for mirroring the traditional bureaucratic hierarchies that they putatively scorn. Another one of the major criticisms leveled at donor-led community stations concerns their general lack of accountability; another is that they must often sacrifice goals that are long-range and difficult to achieve for more short-term, demonstrable accomplishments. The debates in the FM radio sector, then, focus primarily on the technologies of government while rendering the rationalities largely invisible. The following quotes taken as part of my data set reflect some of the major debates that are focusing the agendas of radio stations and organizations that provide training, advocacy and support for the sector:

For the information, people believe in radio. People believe in it. Whatever you like, in some home you went and visit and ask questions, people say 'it was told on radio, so we must have to do it like this'. So much strong trust between the people about the radio, we have. So people listen to radio, people believe radio. Like people read the paper but they don't believe it. They say 'oh, we have to read 3-4 papers to make a clear remark or clear way. We have to read 3-4 papers because they are some how biased against the one party or other party, one group or other groups...So still we have strong trust between the people about the radio (Mohan Chapagain, July $9^{\text {th }}$, personal communication).

Many community radio stations, unfortunately don't seem to have a plan as to how to start being functionally operational. That itself indicates a very big challenge 
that lots of radio stations in this country are being set up without any proper planning and that itself, you've got the foundation wrong, that's what I feel. That gives rise to many other problems. I think that is one area where the whole idea of why does one want to set up a community radio has to be thought about very carefully (Suman Basnet, August $29^{\text {th }}, 2008$, personal communication).

Well, there is a lot of support and there is a lot of unregulated support and that is what I would say is spoiling the sector. A lot of the donors give money for establishment but without taking into account how they would sustain beyond establishment (Nirmal Rijal, July $23^{\text {rd }}, 2008$, personal communication).

Significant contestation over the terms of community radio development indicates that stations and advocates do not depend on international organizations to determine the best way to conduct and implement projects or to reach out to target communities. Nonetheless, the realm of possible action is discursively constrained within the rhetoric of development and modernization and the power of normalization enacted through incentives for grassroots organizations and local communities to participate voluntarily in various programs to improve, educate and help themselves. Abrahamsen suggests that "the reconceptualization of recipient countries as partners in their own development is not simply a trick of deception, or a rhetorical devise, but has very real productive power" (p.1463). In partnerships technologies of governing others are inseparable from technologies of self-government. Understood as a form of 'conduct of conduct', partnerships and funding mechanisms invest recipient countries and local communities with a set of goals and self-understanding about the techniques of improvement. The subject of development interventions is linked to what Dean (1999) termed "technologies of agency". Target populations are engaged as active and free subjects, as informed and responsible actors, capable of taking control of their own lives and futures. Paradoxically, while it promotes self-reliance and self-conduct, the practice of rendering technical also confirms expertise and constitutes the boundary between those who are positioned as trustees with the capacity to diagnose deficiencies in others and those who are subject to expert direction. One of 
the effects of technical interventions that problematize aspects of social life thereby defining the space to be governed was an intelligible field with specific deficiencies to rectify, is that questions are rendered non-political in the process. This echoes Ferguson's (1994) argument that development discourse has the effect of "depoliticizing everything it touches" (p.xv) by insistently "reposing political questions of land, resources, jobs or wages as technical 'problems' responsive to the technical 'development' intervention" (ibid., p.270).

In general, an analysis grounded in Foucault's theoretical positioning of governmentality opens a window on community radio development that reveals the ways that international organizations, in cooperation with local actors, conduct the conduct of countries their governments, civil societies, communities and individuals. To look at development communications, and community radio development in particular, from a governmentality perspective is to mark out for investigation the undramatic ways in which power is implicated in the routinized activities and good intentions of international development agencies and to highlight the discursive structures through which modalities of power are made possible. This enables a new interpretation of power, which "no longer appears as the visible apex of a figure which the powerless must ascend or flatten to secure their interests" (DeChaine, 2005, p. 68), but rather explores the ways it becomes actively embedded in the rules and norms of the lived world. Power often makes its presence felt through a variety of modes playing across one another: "the erosion of choice, the closure of possibilities, the manipulation of outcomes, the threat of force, the assent of authority or the inviting gestures of a seductive presence" ( $\mathrm{Li}$, 1999, p.7).

As evidenced by the vision statements and project reports fashioned in the language of development rhetoric and by interviews with journalists and community members, Radio Jagaran, as a case study of community radio in Nepal, is a testament to the fact that knowledge, 
welfare and power are indissociable, a lesson commonly learnt in development encounters. Foucault understood subjects to be formed by practices of which they might be unaware, and to which their consent is neither given nor withheld. Some practices render power visible; they trigger conscious reactions adequately described in terms such as resistance, accommodation or consent; other modes of power are more diffuse, as are peoples' responses to them (Li, 1999). This tension is expressed by radio journalists and activists who hold strong to a belief in participatory media's ability to empower marginalized groups thereby facilitating social change, yet who continually struggle to see the tangible effects of transformation in target communities and in the nation as a whole.

Analyzing the ideological dimension of colonial encounters, a number of writers have argued that the colonized appropriate and internalize the colonial vision, even while resisting it. If we extend this understanding of colonial relationships to contemporary international development, then Nepal's national project of development poses questions as to how, precisely, an ideology of modernization becomes assimilated into local culture. Community radio is a lens to examine the dialectical process between the governmental practices that emerge through international development interventions and the everyday lived experience of local communities. Communities are dynamic, evolving, and contested social constructions articulated within and through a constellation of social agents, practices and institutions. Locally oriented, participatory media reflect and embody this process of articulation. 


\section{References}

Abrahamsen, R. (2004). The power of partnerships in global governance. Third world quarterly, 25 (8), 1453-1467.

Acker, J. B. (1983). Objectivity and truth: Problems in doing feminist research. Women's studies international forum , 6, 423-435.

ActionAid Nepal. (2005). Nepal - Country strategy paper 2005-2010. Kathmandu: ActionAid.

AMARC. (2004-2005). Country assessment paper: Nepal. Kathmandu: AMARC.

AMARC. (2007). Community radio social impact assessment: Removing barriers, increasing effectiveness. Montreal: AMARC.

Alsvik, K. (2002). Meanings of locality and notions of development in a Nepali village. Dissertation, University of Oslo Centre for development and the Environment, Department of Social Anthropology, Oslo.

Andersen, B. (1983, 1991). Imagined communities. London: Verso.

Ansu-Kyeremeh, K. (2007). Implications of globalization for community radio broadcasting in Ghana. In L. Fuller, Community media: International perspectives. New York: Palgrave macmillan.

Appadurai, A. (2001). Deep democracy: Urban governmentality and the horizon of politics. Environment and urbanization, 13 (2), 23-43.

Atton, C. (2002). Alternative Media. London: Sage.

Aw, E. (1992). Lessons from a little known experience. In B. Girard (Ed.), A Passion for radio. Montreal: Black Rose Books.

Banjade, A. (2007).Community radio in Nepal: A case study of Community Radio MadanPokhara. Dissertation, Scripps College of Communication, Ohio University, Columbus.

Barry, A., Osborne, T. \& Rose, N. (1996). Foucault and political reason. London: UCL Press.

Beck, U. (1996). The cosmopolitan perspective: sociology of the second age of modernity. British journal of socioloy, 13, 1-32.

Berrigan, F. (1979). Community Communications: The role of community media in development. Paris: UNESCO.

Bruzzone, M. and Wieler, A. (2009). Whose washing machine? A socio-technical guide to process in a cross-cultual design-build project in the Kathmandu Valley. San Francisco: Wrench Nepal. Retrieved from http://bikecart.pedalpower.org/washing.html 
Brydon-Miller, M., Greenwood, D., \& Macguire, P. (2003). Why Action Research? Action Research, 1 (1), 9-28.

Burchell, G., Gordon, C., Miller, P. \& Foucault, M. (1991). The Foucault effect: Studies in governmentality. Chicago: University of Chicago Press.

Burgess, J. (2006). Participatory action research: First-person perspectives of a graduate student. Action research, 4, 419-428.

Carpentier, N., Lie, R. \& Servaes, J. (2007). Multi-theoretical approaches to community media. In L. Fuller, Community media: International perspectives. New York: Palgrave Macmillan.

Carroll, W.K. \& Hackett, R.A. (2006). Democratic media activism through the lens of social movement theory. Media, culture \& society, 28 (1), 83-104.

Cohen, S. (1985). Visions of social control. Cambridge: Polity Press.

Coyer, K. (2007). What is community radio? A comparative snapshot of community radio. Annual Meeting. San Francisco: International Communication Association.

Dagron, A. (2007). Call me impure - myths and paradigms of participatory communication. In L. Fuller, Community media: International perspectives. New York: Palgrave Macmillan.

Darnal, S. (2005). Dalits of Nepal. Kathmandu: Jagaran Media Centre.

David, M. (1992). Mahaweli Community Radio. In B. Girard (Ed.), A Passion for radio. Montreal: Black Rose Books.

DeChaine, D. (2005). Global Humanitarianism: NGOs and the crafting of community. Lanham: Lexington Books.

Deleuze, G. \&. Guattari, F. (1987). Introduction: Rhizome. In A thousand plateaus: Capitalism and schizophrenia (B. Massumi, Trans.). Minneapolis: University of Minnesota Press.

Dixit, K. (1997). Foreign aid in Nepal: No bang for the buck. Studies in Nepali history and society, 2 (1).

Downing, J. (2001). Radical Media: Rebellious Communication and social movements. Thousand Oaks: Sage.

Escobar, A. (1995). Encountering development: The making and unmaking of the Third World. Princeton: Princeton University Press.

Fals-Borda, O. (1991). Some Basic Ingredients. In O. a. Fals-Borda, Action and Knowledge: Breaking the monopoly with participatory action research (pp. 3-12). New York: Apex Press. 
Ferguson, J. (1994). The anti-politics machine: "development", depoliticization, and bureaucratic power in Lesotho. Minneapolis: University of Minnesota Press.

Foth, M. \& Tacchi, J. (2004). ethnographic action research website. In I. Pringle, Profiles and experiences in ICT innovation for poverty reduction (pp. 27-32). New Delhi: UNESCO.

Foucault, M. \& Gordon, C. (1980). Power/Knowledge:Selected interviews and other writings, 1927-1977. New York/London: Harvester Wheatsheaf.

Foucault, M. (1982). Afterword: The subject and power. In Dreyfus H, \& Rabinow, P. (Eds.), Beyond structuralism and hermeneutics (pp. 208-226). Brighton: Harvester Press.

Foucault, M. (1977/1991b). Discipline and Punish: The birth of the prison. New York: Random House.

Foucault, M. (1991a). Governmentality. In G. Burchell, C. Gordon \& P. Miller (Eds.), The Foucault effect (pp. 87-104). Chicago: University of Chicago Press.

Foucault, M. (2000). Power: Essential works of Foucault, 1954-1984, vol. 3. New York: The New Press.

Foucault, M. (1970). The order of things: an archaeology of the human sciences. New York: Pantheon Books.

Fraser, C. a. (2001). Community radio handbook. Paris: UNESCO.

Freire, P. (1982). Pedagogy of the oppressed. New York: Continuum.

Fuller, L. (2007). Community media: International perspectives. New York: Palgrave Macmillan.

Girard, B. (1992). A passion for radio: Radio waves and community. Montreal: Black Rose Books.

Gramsci, A. (1971). Prison notebooks: Selections from the prison notebooks of Antonio Gramsci [Quaderni del cracere]. (G. S. Q Hoare, Trans.) London: Lawrence \& Wisthart.

Green, M. (2003). Globalizing development: Policy franchising through participatory project management in "non-places". Critiques of anthropology, 23 (1), 1-21.

Grosenick, G. (2007). Expanding communications scholarship throught he incorporation of participatory/action research. Comprehensive Exam, Carleton University, School of Journalism and Communication, Ottawa.

Haas, T. (2004). Alternative media, public journalism, and the pursuit of democratization. Journalism studies , 5 (1), 115-121. 
Hall, S. (1986). On postmodernism and articulation: An interview with Stuart Hall. Journal of communication inquiry, $10(2), 45-60$.

Hamilton, J. (2004). Rationalizing Dissent? Challenging conditions of low-power FM Radio. Critical studies in Media Communication , 21 (1), 44-63.

Harcup, T. (2005). "I'm doing this to change the world"" Journalism in alternative and mainstream media. Journalism Studies , 6 (3), 361-374.

Hearn G. \& Foth, M. (2005). Action Research and the design of new media and ICT systems. In K. (. Kwansah-Aidoo, Topical issues in communications and media research (pp. 7994). New York: Nova Science.

Holland, J. \& Blackburn, J. (1998). Whose Voice? Participatory research and policy change. London: Intermediate Technology.

Hollander, E., Stappers, J. and Jankowski, N. (2002). Community media and community communication. In N. a. Jankowski, Community Media in the Information Age. Cresskill: Hampton Press, Inc.

Horchheimer, J. L. (2002). The Revolutions may not be televised. In Jankowski, N.W. \& O. Prehn (Eds.), Community meida in the information age: Perspectives and prospects.. (pp. 317-333). Cresskill: Hampton Press, Inc.

Horchheimer, J. (1993). Organizing democratic radio: Issues in praxis. Media, Culture \& Society, 15, 473-486.

Horchheimer, J. (1999). Planning community radio as participatory development. In S.White (Ed.), The art of facilitating participation: Releasing the power of grassroots communication. New Delhi: Sage Publications.

Howley, K. (2005). Community media: People, places and communication technologies. Cambridge: Cambridge University Press.

Huesca, R. (1995). A procedural view of participatory communication:lessons from Bolivina Tin Miners' Radio. Media, Culture and Society, 11, 101-119.

Institute of Development Studies. (2005). Voices for change: Tuning into Community Radio. Id21 Insights , 58, 1-8.

Jagaran Media Centre. (2008). Radio Jagaran progress report. Kathmandu: Jagaran Media Centre.

Jagaran Media Centre. (2007). Vision, mission, guiding principles and strategic plan of Radio Jagaran. Kathmandu: Jagaran Media Centre. 
Jallov, B. (2005). Assessing Community Change: development of 'bare foot' impact assessment methodology. The radio journal - International studies in broadcast and audio media, 3 (1), 21-34.

Jankowski, N. \&. Prehn, O. (Eds.) (2002). Community Media in the information age: Perspectives and prospects. Cresskill: Hampton Press, Inc.

Jankowski, N. (2003). Community media research: a quest for theoretically grounded models. Javnost - The Public, 10 (1), 5-14.

Jankowski, N. (2002). The conceptual contours of community media. In N. Jankowski \& O. Prehn (Eds.), Community media in the information age: Perspectives and prospects (pp. 3-19). Cresskill: Hampton Press, Inc.

Kivikuru, U. (2006). Top-down or Bottom-up? Radio $\mathrm{n}$ the service of democracy: Experienes form South Afirca and Namibia. The International communication gazette, 68 (1), 531 .

Kothari, U. (2005). Authority and expertise: The professionalization of international development and the ordering of dissent. Antipode, 37 (3).

Laclau, E. \&. Mouffe, C. (1985). Hegemony and socialist strategy: Towards a radical democratic politics. London: Verso.

Lewis, D. \& Mosse, D. (2006). Encountering order and disjuncture: Contemporary anthropological perspectives on the organization of development. Oxford development studies, 34 (1).

Liechty, M. 1995. Media, markets and modernization. Youth identities and the experience of modernity in Kathmandu, Nepal. Youth cultures, a cross-cultural perspective. Vered Amit- Talai and Helena Wulff (Eds), London and New York: Routledge

Lewis, P. M. \& Booth, J. (2002). Radio Theory and Community radio. In N. \&. Jankowsi, Community media in the information age: Perspectives and prosepcts (pp. 47-62). Cresskill: Hampton Press, Inc.

Lewis, P. M. (1989). The Invisible Medium: Public, commercial and community radio. London: Macmillan.

Li, T. (1999). Compromising power: Development, culture and rule in Indonesia. Cultural anthropology, 14, 295-322.

Li, T. (2007). The will to improve. Durham: Duke University Press.

Mainali, R. (2007, March 6-7). Volunteering and community participation in community radio: Experiences from Nepal. Kathmandu. 
Marshall, J. \&. (2005). Editorial: Self-reflexive practice and first person action research. Action research, 3 (3), 235-244.

Martin-Barbero, J. (2002). Identities: Traditions and new communities. Media, Culture and Society, 24, 621-641.

Maslog, C. (1997). Communication for people power: An introdution to community communication. UNESCO - Project TAMBULI.

McTaggart, R. (1997). Reading the collection \& guiding principles for participatory action research. In R. (. McTaggart, Participatory action research: International contexts and consequences (pp. 1-43). Albany: University of New York Press.

Merlingen, M. (2004). Governmentality: Towards a Foucauldian framework for the study of IGOs. Cooperation and conflict: Journal of the Nordic International Studies Association, 38 (4), 361-384.

Ministry of Foreign Affairs for Finland. (2008). Local cooperation funds: Role in institution building of civil society organizations. Helsinki: Hapakaino Oy. Retrieved on April $6^{\text {th }}$, 2009 from http://formin.finland.fi

Mosse, D. (1994). Authority, gender and knowledge: Theoretical reflections on the parctice of participatory rural appraisal. Development and change , 25, 497-526.

Nairn, K., Munro, J., and Smith, A. (2005). A counter-narrative of a failed interview. Qualitative research, 5 (4), 221-244.

Ngare, J. (2008). Neoliberal Global Governance: A study of how international development organizations transform east African mediascapes. Carleton University, Ottawa.

O'Connor, A. (2006). Voice from the mountains: Radio and antrhopology. Lanham: University Press of America.

Park, P. (1992). The discovery of participatory research as a new scientific paradigm: Personal and intellectual accounts. The American sociologist, 23 (4), 29-42.

Pigg, S. (1992). Inventing social categoried through place: Social representations and development in Nepal. Comparative studies in history and society, 34 (3), 491-513.

Pringle, I. \& Shuba, B. (2007). Ten years on: The state of community radio in Nepal. UNESCO.

Putnam, L. (2001). 2000 ICA Presidential Address: Shifting voices, oppositional discourse, and new visions for communication studies. Journal of Communication Studies , 51 (1), 3851.

Reason, P. \& Bradbury, H. (Eds.) (2001). Handbook of action research. London: Sage Publications. 
Reason, P. \& Marshall, J. (2001). On working with graduate research students. In P. Reason \& H. Bradbury (Eds.), Handbook of action research: Participatory inquiry and practice (pp. 413-419). London: Sage.

Reason, P. \& Torbert, W. (2001). The action turn toward a transformational science. Retrieved March $23^{\text {rd }}, 2009$ from http://www.bath.ac.uk/ mnspwr/Papers/Transformational SocialScience.pdf.

Reason, P. (1988). Human inquiry in action: Developments in new paradigm research. London: Sage.

Reason, P. (1994). Three approaches to paticipatory inquiry. In N. Denzin \& Y. Linkin (Eds.), Handbook of qualitative research. Thousand Oaks: Sage.

Rodriguez, C. (2001). Fissures in the mediascape: An international study of citizens' media. Cresskill: Hampton Press, Inc.

Rose, N., O'Malley, P. \& Valverde, M. (2006). Governmentality. Annual review of law and social science, , 2, 83-104.

Rose, N. (1999). Powers of unfreedom: Reframing political thought. Cambridge: Cambridege University Press.

Rothenbuhler, E. (2001). revising communication research for working on community. In G. Shepherd \& E. Rothenbuhler (Eds.), Communication and community (pp. 159-180). Mahwah: Lawrence Erlbaum Associates.

Sachs, W. (1992). The development dictionary: A guide to knowledge as power. London: Zed Books.

Shepherd, G. (2001). Community as the interpersonal accomplishment of communication. In G.Shepherd \& E. Rothenbuhler (Eds.), Communication and Community (pp. 25-37). Mahwah: Lawrence Erlbaum Associates .

Shepherd, G. \& Rothenbuhler, E. (Eds.) (2001). Communication and community. Mahwah: Lawrence Erlbaum Associates.

Singh, K. (1999). Rural development: Principles, policies and management (Second edition). New Delhi: Vistaar Publications.

Stone, L. (1989). Cultural crossroads of community participation in development: A case from Nepal. Human organization, 48 (3).

Subedi, M. (2001). Development and underdevelopment of modern health services in Nepal. Deva vani , 4 (4), 217-24.

Swiss Development Cooperation (2005). Swiss cooperation strategy for Nepal. 
Tacchi, J. \& Kiran, M. (2008). Finding a voice: Themes and discussions. New Delhi: UNESCO.

Tandon, R. (1988). Social transformation and participatory research. Convergence , 21 (2/3), 514.

Townsend, J. (1999). Are non-governmental organizations working in development a transnational community? Journal of international development , 11, 613-623.

UNESCO. (2002). Hands on community radio in Nepal. UNESCO.

VanVuuren, K. (2006). The trouble with community radio research, or, how methodological setbacks can inform theoretical development. 3C Media , 2, 1-15.

Walters, W. \& Haar, J. (2005). Governmentality and Political Studies. European Political Science , 4, 288-300.

Watts, M. (2003). Development and governmentality. Singapore journal of tropical geography, 24, 6-34.

White, S. (Ed.) (1999). The art of facilitating participation: Releasing the power of grassroots communication. New Delhi: Sage Publications. 


\section{Websites cited}

ActionAid Nepal. http://216.64.143.192/ action/

Equal Access Nepal. http://www.equalaccess.org/country-nepal.php

Embassy of Finland, Kathmandu. http://www.finland.org.np

Jagaran Media Centre. http://www.jagaranmedia.org

Search for a Common Ground. http://www.sfcg.org/programmes/Nepal/programmes_Nepal.html

Swiss Development Cooperation in Nepal.

http://www.sdc.org.np/en/Home/Swiss_Development_Cooperation_in_Nepal

United Nations Development Program (UNDP) Nepal. http://www.undp.org.np/index.php

UDHR. http://www.un.org/en/documents/udhr.

Wrench Nepal. http://www.wrenchnepal.org/ 


\title{
Individuals and Organizations Consulted
}

\author{
Association of Community Radio Broadcasters in Nepal (ACORAB) \\ Mohan Chapagain \\ Pramod Tandakar
}

\section{Equal Access Nepal}

Upendra Aryal (Content Director)

Pawan Prakash (IT In-Charge)

Nirmal Rijal (Country Director)

Jagaran Media Centre (JMC)

JB Bisowkarma (Journalist and Executive Member)

Prakash Mohara (Journalist and Executive Member)

\section{Nepal Federation of Environmental Journalists (NEEFJ)}

Ragu Mainali (President)

\section{Radio Jagaran}

Deepa Bardewa (Journalist, Shift In-Charge)

Chiran Baral (station advisor)

Ramu C.K. (Journalist)

Shivaji Gayak (Station Manager)

Hemant Giri (Program Coordinator) 
Dinesh Harijan (Journalist)

Binod Pariyar (Journalist)

World Association of Community Radio Broadcasters (AMARC)

Suman Basnet (Asia-Pacific Regional Coordinator)

Steve Buckley (President)

Wrench Nepal

Mario Bruzzone

Aaron Wieler

Bijay FM

Community Radio MadanPokhara

Chitwan FM

Muktinath FM

Radio Katwal (JMC)

Radio Lumbini

Radio Sagarmatha 


\section{Appendix 1 - Map of FM Radio in Nepal}

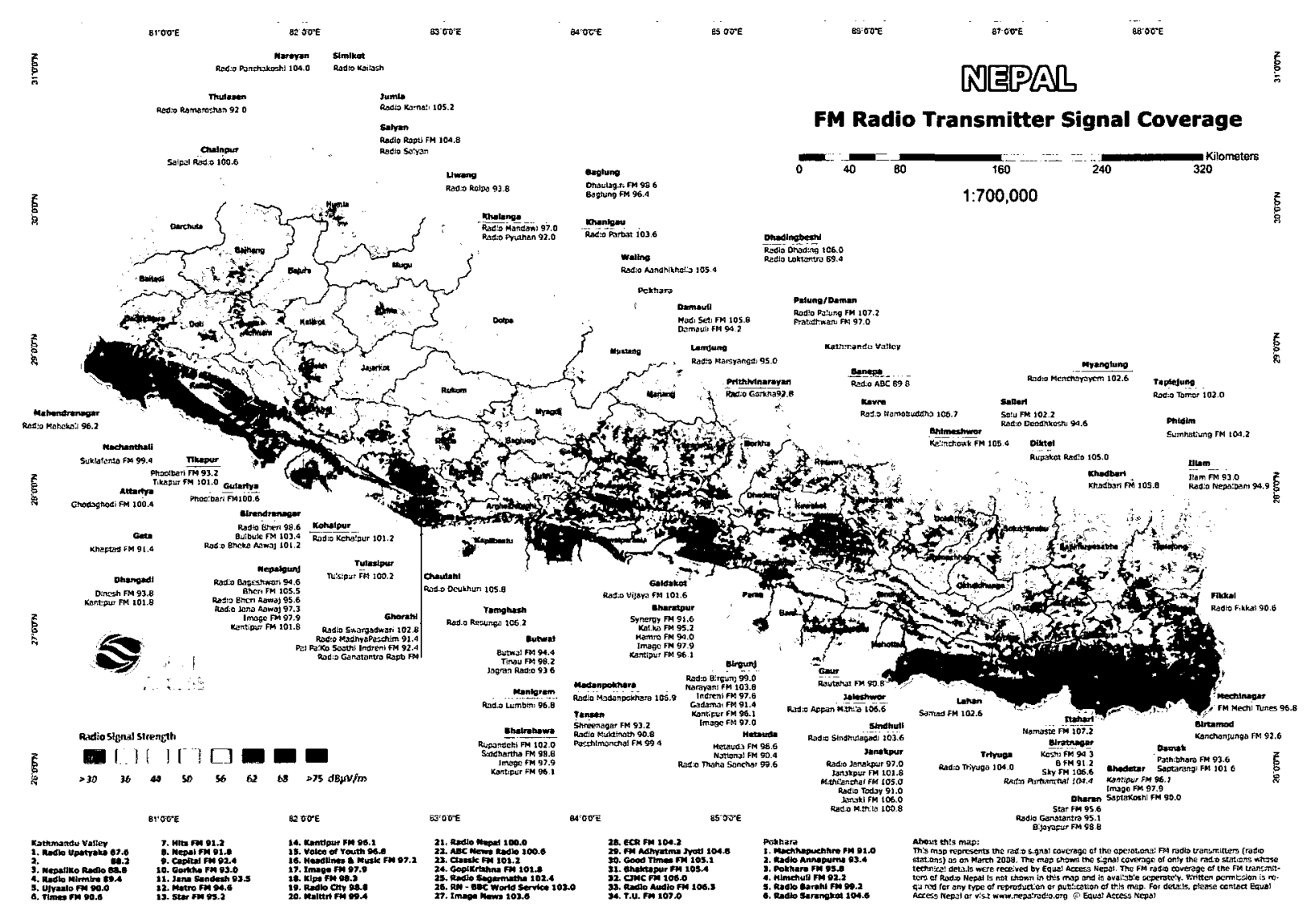

(Equal Access Nepal, 2008) 
Appendix 2.1 - Radio Jagaran Strategic Plan (Produced by Jagaran Media Centre, 2007)

Vision, Mission, Guiding Principles and Strategic Plan of Radio Jagaran/Butwal

\section{Vision}

Creation of equitable society free from all forms of discriminations.

\section{Mission}

Radio Jagaran will be actively engaged in the social movement to abolish existing regional, racial, linguistic, and religious, class, caste, and gender-based discriminations in Rupandehi, Kapilvastu and Nawalparasi districts. 


\section{Guiding principles}

1. Pro-rights based approach: Radio Jagaran will produce and broadcast programs contributing towards social transformation and promoting the rights of Dalit, Janajatis, Madhesis, Women, Muslim and other minorities.

2. Diversity and social harmony: Radio Jagaran is committed to promote social harmony and peace in the society. It respects the cultural and religious differences of communities in Rupandehi, Kapilvastu and Nawalparasi districts. Radio Jagaran will produce and broadcast radio programs in different languages spoken in this region.

3. Gender and social equity: Radio Jagaran will be actively engaged to end the gender-based discriminations and foster equity-based social development among the population.

4. Protection of environment and promotion of rural tourism: Radio Jagaran is committed for environmental protection and creating economic opportunities for the people in this region. To keep this value the Radio Jagaran will design, produce and broadcast radio programs to protect environment, and to promote rural tourism.

5. Skill, art and culture: Radio Jagaran will advocate against the negative effects of open economy and globalization on traditional culture, skills and occupation of Dalit, Janajati, Madhesi, Women, Muslim and other minority communities. However, Radio Jagaran will promote appropriate technological options in modernizing traditional survival skills and occupations of the communities.

6. Promotion of scientific knowledge: Radio Jagaran will introduce scientific concepts, technologies, approaches, knowledge and skills which can serve local population to improve their scientific knowledge, and discourage superstitious traditions and practices.

7. Right to information: Radio Jagaran believes that 'right to information (RTI)' is one of the fundamental rights of people. With this clear stand Radio Jagaran will produce and broadcast informative programs which are important for the population to empower them. 


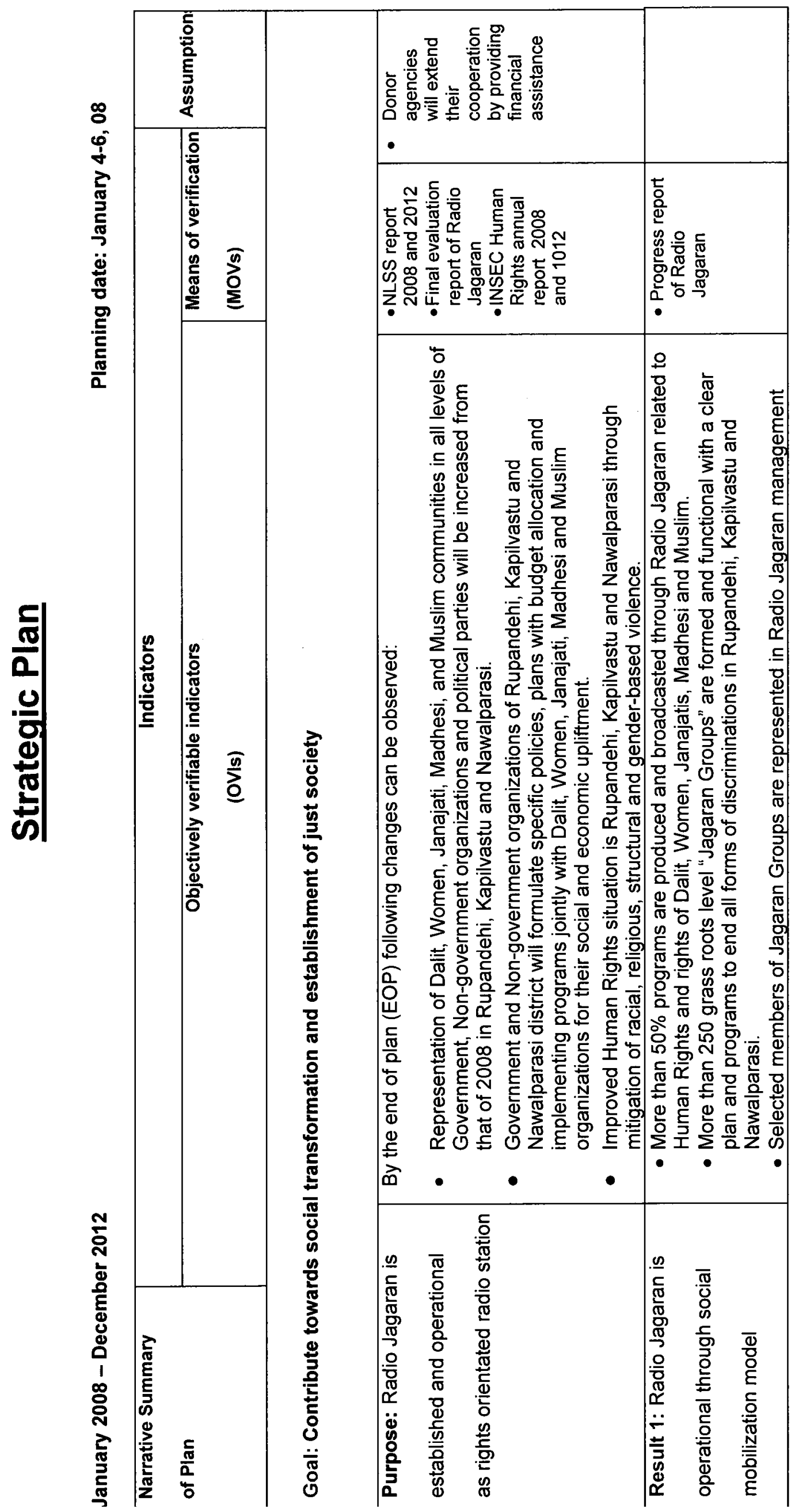

兽 


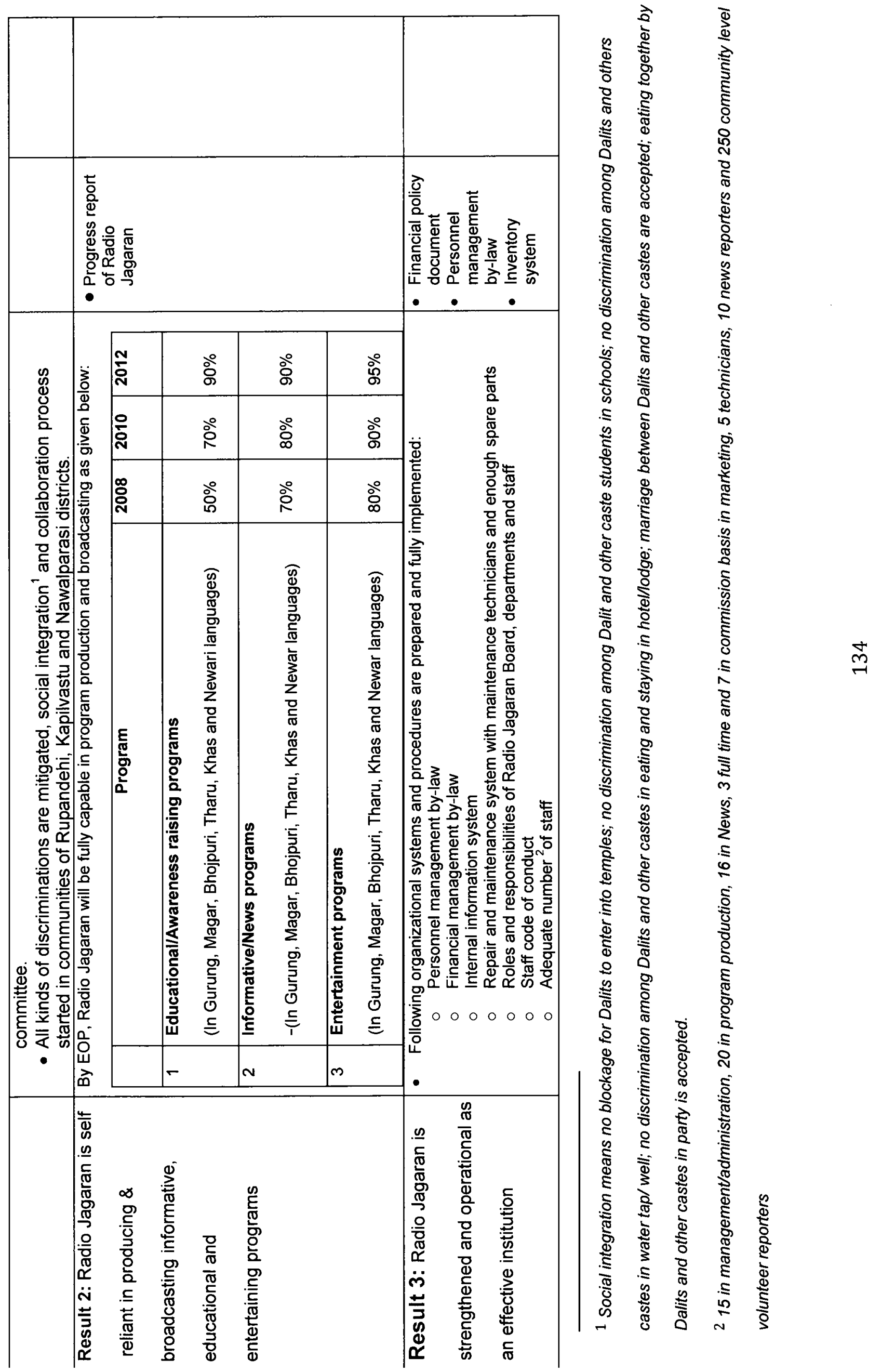




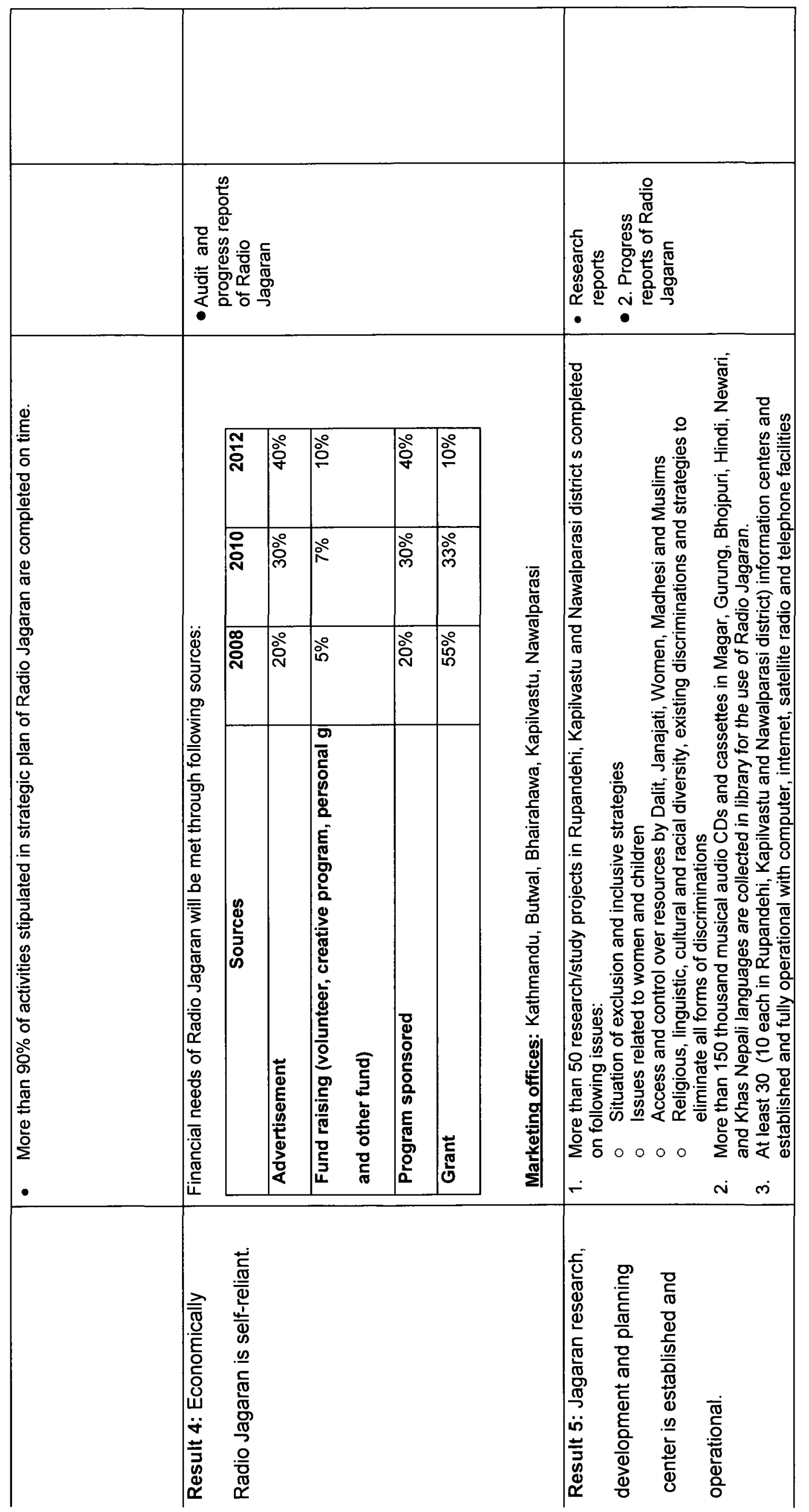




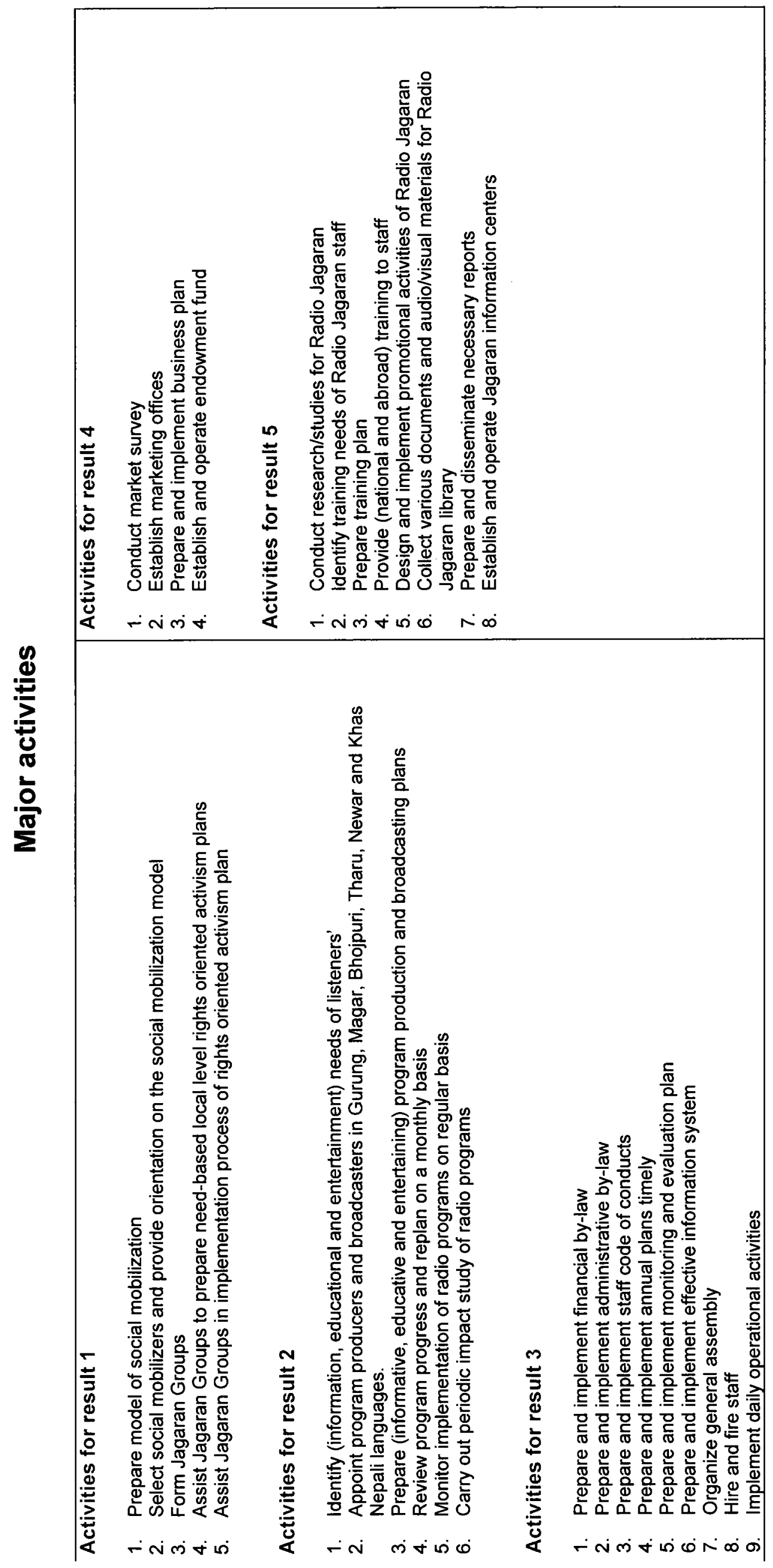




\section{Appendix 2.2 - Radio Jagaran Progress Report (Produced by Jagaran Media Centre, 2008)}

\section{Executive Summary}

Jagaran Media Center (JMC) is an organization established by a group of young Dalit journalists in order to protect and promote the rights of Dalits through the use of mass media. In January 2007, Nepal Government provided JMC a license to run a F.M. radio station at Butwal of Western Development Region. The JMC named F.M. radio station as Radio Jagaran.

In order to establish and operate the Radio Jagaran for initial period of one year, budget of NRs $\mathbf{8 , 8 4 5 , 0 0 0}$ was estimated. Embassy of Finland to Nepal provided financial support for establishing the F.M. station and for providing technical training for its staff. For this purpose, JMC received grant of NRs 2,715,000 out of which NRs 2,501,067 had already been spent. Meanwhile, Action-Aid Nepal has supported NRs 200,000 for institutional development of Radio Jagaran. Besides, DANIDA / HUGOU and Swiss Development Cooperation (SDC) have principally agreed to support other components of the project.

JMC started to set up Radio Jagaran from October 2007. From 6 November 2007, Radio Jagaran broadcasted test programme. With current transmission capacity of the station, the Radio Jagaran can be received in Rupandehi and Kapilbastu districts and in some parts of other neighboring districts.

Radio Jagaran was formally launched on 17 December 2007. Today it broadcasts 18 hours of programme everyday. Respecting language diversity the Radio Jagaran has already started to broadcast news in four local languages namely Magar, Gurung, Bhojpuri and Newari languages. Radio Jagaran is planning to produce and broadcast several other radio programmes in these languages.

$\mathrm{JMC}$ is building local capacity for handling management, financial and technical issues to operate the community radio. Accordingly, training programme on 'Quality radio programme production' was 
provided for the staffs. Besides professional short term consultants are coaching staffs on various issues related to broadcasting. Once the local excluded communities get technically and financially empowered, JMC plans to handover the Radio Jagaran to the community and limit its role for overall guidance and supervision only. By doing so, JMC believes that this F.M. radio will be able to raise issues of Dalits in true sense.

Embassy of Finland to Nepal is the first external development partner that encouraged JMC to pursue this Radio Jagaran project by providing moral as well as financial support. Without this support, it would have taken much longer time to reach at this stage of development. Jagaran Media Center family wishes to thank Embassy of Finland to Nepal for the same during this crucial starting period of Radio Jagaran project. 


\section{Progress Report}

\section{Radio Jagaran - Butwal}

\section{Background:}

Jagaran Media Center (JMC) is an organization established by a group of young Dalit journalists in 2000 . JMC is registered with the Government of Nepal and affiliated with the Social Welfare Council. JMC is working for promotion of the rights of Dalits through extensive use of mass media and through capacity building of Dalit journalists.

As the majorities of Nepalese people are illiterate and are spread thinly in villages, radio is one of the strongest mass media in Nepal. However, before 1990, there was only one government run radio; public or community radios were not permitted. After political changes of 1990 , government began providing license to run community F.M. radios. Today there are some 165 community F.M. radio stations around the country. Nonetheless, these F.M. radio stations are owned and managed by different other groups and therefore, their interests and experiences have not been compatible to address the ground realities of Dalits, the so called 'untouchable' groups.

In this context, JMC conceptualized a F.M. radio station that is managed and run by Dalits ${ }^{3}$. JMC received a license to run a F.M. radio station at Butwal of Western Development Region from the Ministry of Information \& Communications in January 2007. As per the license the capacity of the F.M. is to be 500 watt and the frequency for airing radio wave is to be $93.6 \mathrm{MHz}$.

At the central level, JMC established the Jagaran Radio Support Fund (JRSP) as a basket fund which will

\footnotetext{
$3 \mathrm{JMC}$ has earlier been producing and airing weekly radio programme named 'Katuwal' through radio Nepal and through networks of $16 \mathrm{FM}$ radio stations since 2002 .
} 
be used for the implementation of the station. Individual donors, donor agencies, I/NGOs can contribute to the basket fund. Around NRs $1,500,000$ (fifteen hundred thousand) has already been committed at the basket fund from the local community of Butwal.

Embassy of Finland to Nepal provided financial support of NRs 2,715,000 to purchase various equipments for F.M. radio station and to train staffs. With this support, Radio Jagaran started to operate from 17 December 2007.

Radio Jagaran aims to empower the local Dalit and other excluded groups i.e. Dalit, janajati, women, madheshi and minority Muslim community through local dialogues, and educational programmes respecting cultural and linguistic diversity of the programme area. Accordingly, the Radio Jagaran has already started to broadcast news in four languages namely Magar, Gurung, Bhojpuri and Newari languages and planning to produce and broadcast several other radio programmes in these languages.

JMC is pursuing to make Radio Jagaran a true community radio of Dalit and marginalized groups. Accordingly, JMC has proactively selected Dalits, in all functioning mechanisms of Radio Jagaran. 


\section{Radio Jagaran- Butwal}

\section{Goal}

To contribute towards reforming the state through promotion of dialogue and inclusiveness.

\section{Objectives}

- To establish as a model F.M. radio station of excluded groups.

- To act as a platform to raise the voice for the voiceless.

- To empower the community through creative dialogue for inclusiveness.

\section{Expected Outcomes:}

- A common platform of all the marginalized groups will be formed.

- Voices of marginalized groups will be raised peacefully in the process of forming New Nepal.

- Access of Dalits to resources and opportunities will be increased.

- Marginalized groups and people from working class will unite together in an organized manner.

- Process of critical mass formation for Dalits' upliftment will be supported.

\section{Outlook of radio programmes}

- Educational

- News (in 4 local languages)

- Talk shows, interviews

- Entertainment

- Others
$5: 30$ hours

2:00 hours

2:00 hours

6:00 hours

2:30 hours

(Objectives and outcomes of the project will broadly discuss and finalized through a Strategic Planning Workshop wh scheduled for 3-7 Januarv 2008.) 


\section{Completed Activities}

\subsection{Radio Station established:}

During this reporting period, an office space for management and technical works has been set up at Kalikanagar Butwal. The office has approximately 1,200 square feet space that includes a recording room, fully equipped space for administrative and public relation works. A set of radio transmission equipments installed to run the radio station. (see annex $3 b$ )

\subsection{Hiring and training of Staffs:}

Running a radio station is a complex task that needs a large number of staffs with various skills. Till date, a total of 46 staffs (including 18 full timers, 10 part timers and 18 volunteers) have been recruited to operate the FM station.

Vacancy announcement were published through local newspapers. Staffs were recruited through screening of application package and interview. Positive discrimination was made for women and members of excluded groups during the selection process

\subsection{Training of Staffs:}

After hiring the staffs, a 10 days training on production of quality radio programme was provided to all the relevant staffs.

The proposed trainings on social marketing and project management were slightly changed. Instead of conducting training, JMC decided to hire a professional short term consultant to coach management and technical staffs on these issues. JMC believe that the coaching for three months period will be more effective in building capacity of the local staffs.

\subsection{Collection of Materials:}

To run a radio station, a sound collection of audio materials are needed. In this regards, Radio Jagaran- 
Butwal has started to collect relevant materials. So far the FM has been able to collect 50,000 Nepali songs, 5 signature tunes, 16 peace jingles and over 100 reference books.

\subsection{Starting broadcast:}

After installing the equipment and doing all the preparatory works, Radio Jagaran aired its test programmes from 10 November 2007. The test programmes were of 6 hours a day. During this period professional external technical persons, coached local new staffs on various technical aspects of recording, programme development and broadcasting the programmes.

After resolving initial problems, Radio Jagaran officially launched its programme from December 17, 2007. The Radio Jagaran now airs 18 hours of programme per day.

\subsection{Other preparatory works:}

a. Local discussion: Several rounds of intensive discussion with women, Dalits, civil society networks, janajati, local journalists etc were carried out during preparatory phase. Based on these discussions over all strategic plans, operational model, social marketing strategy, and programme outlines were developed.

b. Steering committee formed: To make policy decisions and to guide overall activities of the radio station, a steering committee consisting 11 members was formed. The members of steering committee were selected based on local discussions with stakeholders. The committee consists of 5 Dalits men, 1 Dalit women, 1 non Dalit women, 1 madheshi Dalit and 1 janajati. (see annex 2).

c. Supervision and monitoring: During this reporting period, regular monthly meeting of the Steering Committee was organized to monitor and evaluate progress of work of the Radio Jagaran. JMC provided all the management, logistic and administrative support in the process. 


\section{Inauguration of Radio Jagaran:}

The Radio Jagaran was formally inaugurated on $17^{\text {th }}$ December 2007 . In the programme, political persons including Prachanda- Chairperson CPN-M, Chabilal Bishowkarma- Minister Agriculture and Cooperatives, Amik Sherchan-Chairperson Janamorcha Nepal, Chitra Bahadur K.C.-Chairperson National Janamorcha Nepal, Surya P. Pradhan-MP Nepali Congress delivered key note speeches. Over 5,000 local stakeholders attended this public inauguration ceremony and the event was widely covered in international media, national and local news papers.

\section{Business/ Sustainability Plan:}

Making money by running a F.M. radio is not an easy task. JMC has developed a strategic plan to raise the money for Jagaran F.M.-Butwal through following ways:

- Providing space to the socially responsible advertisements of the commercial houses and development organizations,

- Bringing the socio-economic programs/packages that directly impacts in the reform of the socioeconomic institutions which are of primal interest of both the donors and the community,

- Providing the internship opportunities for the students of private schools, and getting service charge for the same from the school administration,

JMC recognizes that the greatest strength of any community radio is its community. Radio Jagaran would thus rely upon community in order to serve the needs of the community.

\section{Conclusion}

Jagaran Media Center is committed to make Radio Jagaran a true voice of the marginalized community people, especially of the excluded groups. To ensure this, JMC is proactively working for establishing a radio station that is planned, managed, organized and developed by marginalized group. At present, JMC is playing key role in setting up the station, running the programme and building the capacity of local excluded groups. Once, the local excluded communities get technically and financially empowered, JMC plans to handover the Radio Jagaran to the community and JMC will limit its role to technical support only. By doing so JMC believes that this radio will be able to raise issues of Dalits in true sense. 
*Annex 1: Milestones of Radio Jagaran

$\begin{array}{lll}\text { s.n. } & \text { Event }\end{array}$

1. Applied for License to run Radio Jagaran January 17, 2007

2. License received from government to run Radio Jagaran February 6, 2007

Grant approved from Embassy of Finland to establish Radio

3. station (to equipment and staff training )

August, 2007

4. Recruitment of Staffs

July 07- till date

4. Procurement of radio equipments

September-October 07

7. Set-up Radio Station and office at Butwal

October-November 07

9. Meeting with stakeholders

September onwards

10. Broadcast of test programmes

6 November 07

11. Training of technical staffs/ Coaching

18-27 July 07 /ongoing

11. Steering Committee formation

December 07

Inauguration of Radio station and start of formal

12.

broadcasting

17 December 07

Annex 2: List of Steering committee members

1. Binod Pahadi, Chairperson

2. Dipak Kumar Bishowkarma, Member

3. Dipak Pariyar, Member

4. Prakash Shrestha, Member

5. Man Bahadur Bishowkarma, Member

6. Kopila Rasaili, Member

7. Buddhiram Harijan, Member

8. Saroj Gautam, Member

9. Ganga Khanal, Member

( 5 Dalits men, 1 Dalit women, 1 non Dalit women, 1 madheshi Dalit, 1 janajati. 


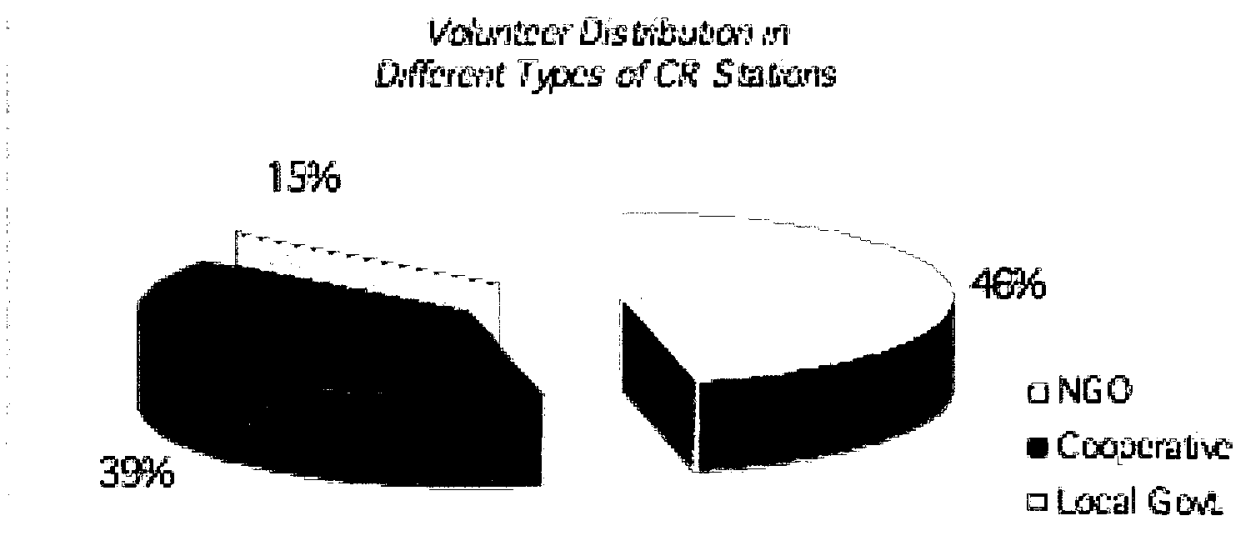

(Mainali, 2007) 